UCRL-50007-83

Distribution Category UC-41

UCRL $-50007-83$

DE85 001434

\title{
Hazards Control Department Annual Technology Review 1983
}

\author{
Scientific Editor: R. V. Griffith
}

Manuscript date: June 15, 1984

\section{DISCLAIMER}

This report wis prepared as an aceount of work sponsored by an agency of the United States Governoment. Neilher the United States Goverament nor any agency thereor, nor any of theit employes, mukes any warraty, express or implied, or assumes any legal biakility or respousi. bility for the accuracy, completeness, or usefutness of any information, appararus, prodoct, or process disclowed, or represents that its use would nol infringe privately otraed rights. Reference herein to wy specific commercial product, process, or service by trade name, thademath, manufacturer, or otherwise does not necessarily constitute or imply its endorscment, recommendation, of favoring by the United States Government or any agency thereof. The views and opinions of authors expressed herein do not necessarily state or reflect those of the United States Government or any agency thercof.

\section{LAWRENCE LIVERMORE NATIONAL LABORATORY University of California - Livermore, California - 94550}




\section{Foreword}

This report, which covers the period from October 1982 to September 1983, is divided into three major sections. The first section, Progress Reports, covers the status of activities undertaken or continuing during the period; additional reports or separate publications will cover the final results of these activities. The second section, Technical Notes, contains reports on interesting activities of a more limited scope on which further reporting is not anticipated. The third section lists recent publications.

Readers who are interested in more detail may contact the authors of the reports. 


\section{Contents}

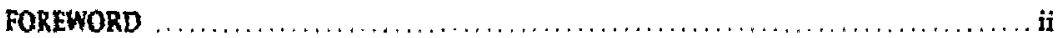

\section{PROGRESS REPORTS}

Industrial Hygiene

Field Testing of Carbon Adsorbt: Beds-II

Protection of Self-Contained Breathing Apparatus During High Work Rates

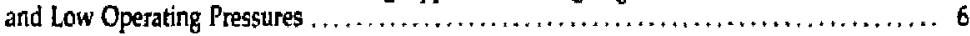

Radiation Protection

Calculating Spectra and Dose Rates in the ${ }^{x} \mathrm{Co}$ Pool .......................... 9

Measuring $\mathrm{Pu}$ in a Glove Box Using Portable Nal and Gemanium Detectors ............ 21

Fitre Safely

Evaluation of Personal Alarm Devices for Firefighters......................... 28

Evaluating Electrical Cables by the LLNL Ease-of-Igrition Apparatus................ 35

Zone-Model Correlations with Experimental Enclosure Fires .......................43

Definition of the Concentration Gradient Above Flammable Liquids .................48

\section{TECHNICAL NOTES}

Industrial Hygiene

Impact and Vibration Testing of Firefighters' Self-Contained Breathing Apparatus ........ 57

Instrument Development

Measurement of Aerosol Concentration as a Function of Size and Charge ..............61

Radiation Protection

Comparison of Calculated Neutron Spectrum and Dose Equivalent from NBS

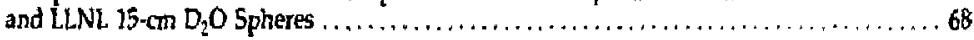

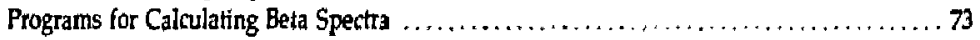

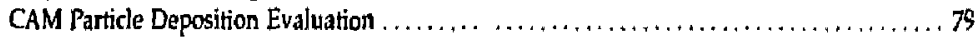

Mercury Scrubber for the Ostlund Tritium Monitor ........................ 83

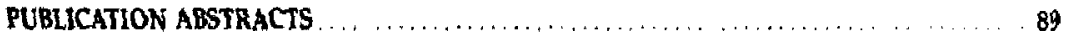




\section{Progress Reports}

$1 / 2$ 


\section{INDUSTRIAL HYGIENE}

\section{Field Testing of Carbon Adsorber Beds-II}

\section{Peter M. Swearengen, James S. Johnson, Charles A. Harder, and Cynthia A. Cadena-Fix}

We studied activated-carbon-adsorber beds used for air-cleaning to measure service life. We used ethane gas in a pulse test to determine the residual adsorption capacity (RAC) of the carbon. Small cartridges were placed in a manifold parallel to the main bed with the air flow closely matching that of the main bed. The cartridges were moved periodically and tested in the laboratory for the RAC.

\section{Introduction}

Activated carbon adsorbers are used at LLNL for air-cleaning of both large and small ventilation systems. We know that carbon adsorber beds lose the capacity for organic vapors auring their lifetimes. At some point during this decline, the carbon should be removed and a fresh batch ir:stalled. The high cost of replacement, however, dictates that such maintenance be done only when necessary. The purpose of our project is to follow the service life of several adsorber beds and to measure the remaining effective adsorption capacity (i.e., residual adsorption capacity or RAC).

Previous work has shown that ethane gas could be used to measure the RAC of a carbon bed.' Subsequent work in our laboratory has corroborated this, and a testing manifold has been fabricated that samples in parallel with a large carbon adsorber bed. This manifold will contain multipje cartridges of activated carbon. Our ratiorale for this particular system is that changes observed in the test cartridge carbon will reflect conditions in the main bed.

\section{Experimental Description}

We calibrated the removable carbon cartridges within the test manifold for their retention time of ethane gas under controlled flow condjtions. At periodic intervals, the cartridges will be removed fro:n the manifold and tested in the laboratory to observe any change in response to the ethane test. A variable uptake of water can occur on crrbon with fluctuating relative humidity in the air passing through the filter. This uptake will be accounted for by an equilibration period for the cartridge using very dry ( $<5 \%$ RH) air. The flow of dry air will remove water adsorbed on the carbon.

A schematic diagram of the carbon test manifold is shown in Fig. 1. We designed the system to be modular, allowing access to one cartridge without affecting the rest of the system. Valves isolate the cartridge of interest from the system flow, and the removal or installation of a single unit is possible in a matter of minutes. Individual cartridges are protected from dust or particulate attrition by HEPA filters installed upstream. The in-line HEPA filters downstream from the cartridges protect the pump from particles that might escape from the carbon lead. The pressure drop across the carbon system can be monitored during operation by the magnehelic gauge. Finally, we installed a control valve on the downstream (exhaust) manifold to allow the total vacuum seen by the pump to be held within manufacturer's specifications. If the vacuum becomes too large, outside air can compensate for the flow.

We also installed a critical orifice in the system downstream from each cartridge to ensure constant and uniform flow. Flow through each orifice was determined using an NBS traceable spirometer. The pressure drop across each orifice was held to a vacuum greater than $38 \mathrm{~cm} \mathrm{Hg}$ during calibration to ensure operation in the critical range.

For our air-cleaning system, residence times across the bed vary depending upon the fumehood sash opening. Values can range from 0.16 to 


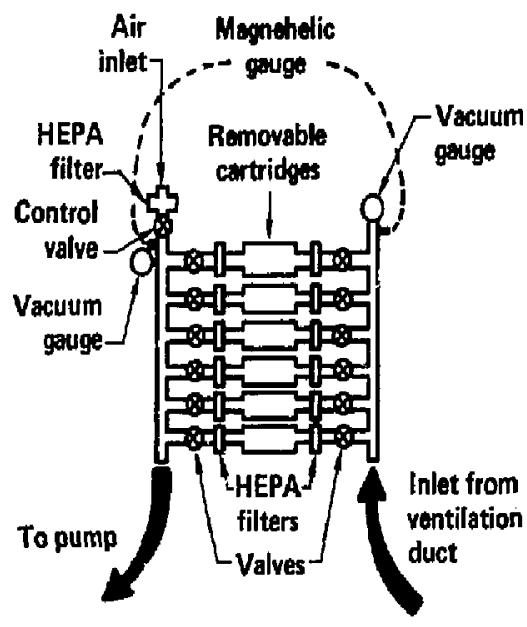

Figure 1. Schematic of carbon test manifold.

0.22 sec. Sinse a long residence time would tend to optimize adsorption (and most rapidly deplete the bed capacityl, the test cartridges should represent only the worst case of the bed condition, and, therefore, we set the flows for the longer residence time.

The charcoal for each test sample was placed in a $5.08-\mathrm{cm}$ diameter cylindrical cartridge $5.08 \mathrm{~cm}$ in height. With a cross sectional area of $20.27 \mathrm{~cm}^{2}$, the linear flow velocity through the bed was $1397 \mathrm{~cm} \cdot \mathrm{min}^{-1}$, assuming a mean flow of $28.3 \mathrm{lpm}$. The residence time in the carbon bed is $0.218 \mathrm{sec}$. This value can be compared with a typical industry standard of $0.1-0.2 \mathrm{sec}$ for aircleaning of organic vapors. ${ }^{2}$ This figure can also be compared to nuclear applications where a minimum residence time of 0.25 sec is required for removal of organic radioiodine compounds. ${ }^{3}$

\section{Results}

Table 1 summarizes the ethane-pulse testing of individual carbon cartridges. Five ml volumes of the gas were injected into a flowing air stream via a gas-tight syringe. The air flow in the cartridge test system was controlled by a Tylan massfow controller. The flow was split downstream from the cartridge, with part of the exhaust going to a tlame ionization detector (FID) in a Varian $1520 \mathrm{~A}$ gas chromatograph. $A$ value was placed below the split to adjust the flow to the detector. All remaining flow was exhausted. A schematic of this test system is shown in Fig. 2.

We measured the time for the ethane to flow to the detector without adsorption effects by filling a test cartridge with a mixture of glass beads $1 \mathrm{~mm}$ and $3 \mathrm{~mm}$ in diameter. The $1-\mathrm{mm}$ beads were added to the larger beads in the cartridge until the pressure drop across the cartridge was equal to that of a typical carbon-filled cartidige

Table 1. Ethane retention times.

\begin{tabular}{ccc}
\hline Cartridge & $\begin{array}{c}\text { Wt carbon } \\
(\mathrm{g})\end{array}$ & $\begin{array}{c}\text { Retention time } \\
\text { (min) }\end{array}$ \\
\hline M1 & 45.92 & $5.86 \pm 0.03$ \\
M2 & 50.49 & $5.93 \pm 0.06$ \\
M3 & 44.42 & $6.27 \pm 0.37$ \\
M4 & 46.56 & $5.51 \pm 0.05$ \\
M5 & 52.84 & $4.17 \pm 0.25$ \\
M6 & 52.03 & $5.56 \pm 0.09$
\end{tabular}

Flow velority: $8.22 \mathrm{~cm} \cdot \mathrm{sec}^{-1}$ based on $10 \mathrm{slpm}$ flow from mass-flow controlles through $\& 2^{\prime \prime}$ diameter carbon cartridge.

Space time: $0.3089 \mathrm{~min}$

'Sutcliffe-Speakman 208C Carbon, 8 X 16 mesh.

byerage of 6 measured values.

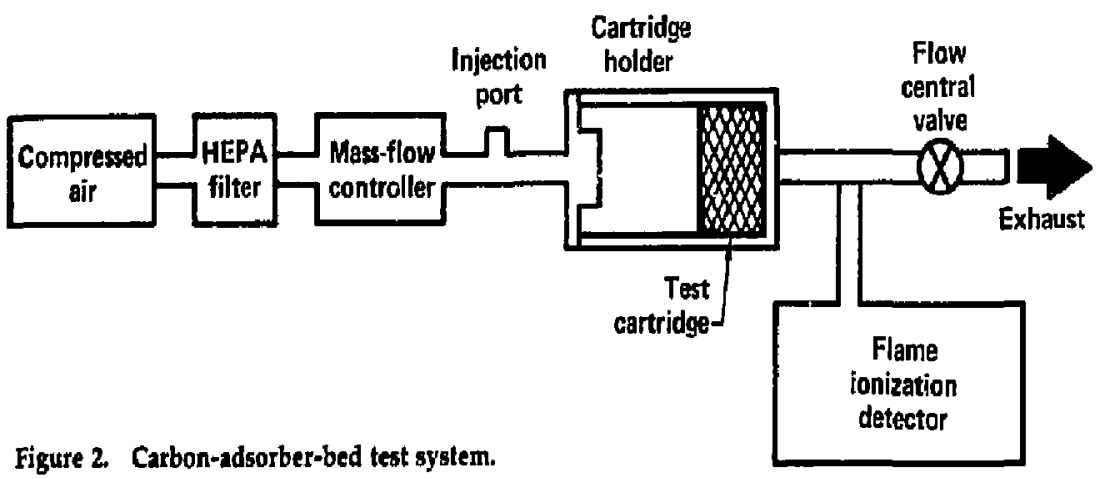


( $\sim 2.20^{n} \mathrm{H}_{2} \mathrm{O}$ on a Dwyer manometer). We injected ethalie actoss the blank cartridge to obtain a base time for ethane travelling to the FID. This retention time is often referred to as "space time." Subtraction of the space time from a measured retention time across a carbon-filled cartridge should give a retention time due only to the adsorption effects from the carbon. We also give a listing of the retention times for six carbon cartridges of Manifold I in Table 1.

\section{Future Work}

Future work will involve several refinements to the current testing scheme and the analysis of the cartridges altready in service. A blank cartridge will be installed in the laboratory where the main air flow is entering the fume hood under study. This cartridge will then be analyzed to measure background contributions from sources other than the chemical vapor fumes contained within the fume hood. Such data will measure the decline of RAC from fume-hood activities compared to the decline due only to other air pollution sources. Finally, a second carbon manilold is under construction to study a different air-cleaning system in a separate facility.

\section{References}

I. P. M. Swearengen, J. S. Johnson, R. A. da Roza, and C. A. Harder, Hazards Control An* nual Techrology Review, Lawsence Livermore National Laboratory, Livermore, CA, UCRL50007-82 (1983).

2. David Ainsworth, Sutcliffe Speakman Inc, privale communication, October, 1981.

3. American Association for Contamination Control (AACC, Tentalive Slandard for HighEfficiency Gas-Phase Adsorter Cells IAACC des* ignation: (S-8T), Amendment 1, Appendix C, Dctober 1973. 


\title{
Protection of Self-Contained Breathing Apparatus Luturing High Work Rates and Low Operating Pressures
}

\author{
Jerry W. Stengel and Roberta A. Rodrigues
}

Our previous investigation of firefighters" self-contained breathing apparatus (SCBA) at high work rates had indicated that only one-third of the SCBA tested could maintain the necessary pressure. SCBA must maintain positive facepiece pressure during high work rates at low cylinder pressures. During firefighting use, the most critical need for SCBA protection may occur at the time the low pressure alarm sounds, and the firefighter exits or conducts a rescue operation. We performed follow-up investigations on available SCBA at high work rates and low operating pressures, showing that current SCBA can mairtain positive facepiece pressure, even though only one SCEA actually did it at the alarm point.

\section{Methods}

The testing equipment and procedures described in our previous report ${ }^{1}$ were used again (Fig. 1). We measured peak and minimum lacepiece pressures at full cylinder pressure, repeated at several decrements, and stopped at the lowpressure alarm point. Measurements were recorded for a minimum of ten successive breaths. The breathing marhine parameters were 100 liters/ minute ventilation rate, $2.06 \mathrm{~L}$ tical volume, and 49 respirations/minute. We estimated this to cause peak flows of between 300 and 400 liters/minute.

A significant question concerns the validity of the typical pressure-monitoring location in the breathing zone, between the upper lip and nose of the head form (Fig. 2). While this is the appropriate place for measuring maximum breathing resis* tance, it does not necessarily represent pressires at the outer sealing surfaces of the facepiece. Pressures at the sealing surfaces ate more directly related to protection against inward leakage of contaminated air.

Theoretically, the breathing-zone pressuse could go negative during inhalation, while pressures at the sealing surfaces remain positive. Breathing-zone moniloring would produce a false indication of loss of protection. This is especially true when the facepieces have nose cups that isolate an area surrounding the breathing zone from the rest of the facepiece. Comparisons of pressures measured at seven locations on two different lacepieces with nose cups showed no noticeable difference in pressure tracings. Monitoring locations appear valid within the limits of sensitivity of the equipment used-estimated to be \pm 0.1 inch $(0.25 \mathrm{~cm})$ of water pressure.

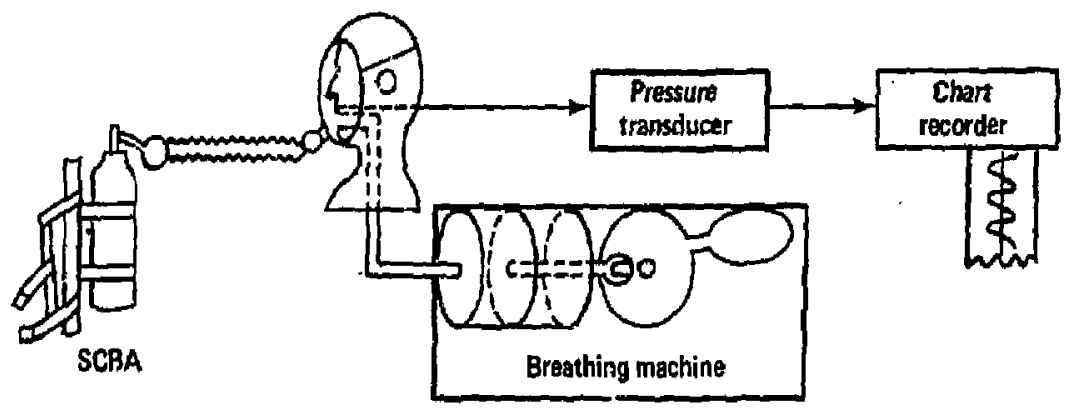

Figure 1. Diagram of SCBA testing apparatus. 


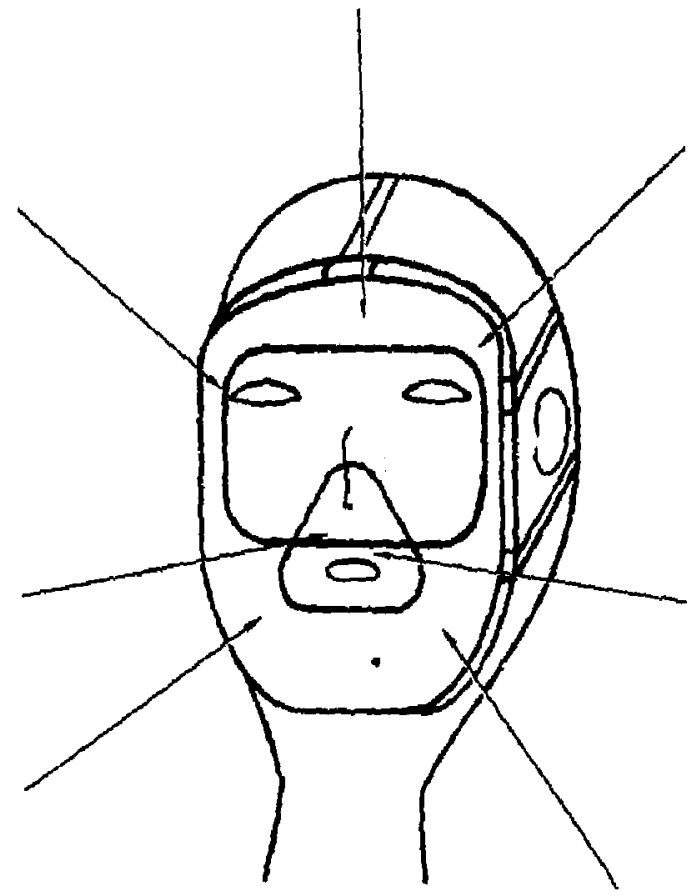

Figure 2. Pressure map of various test locations within facepiece.

\section{Results}

One out of the six SCBA we tested maintained positive facepiece pressure. Although more faceplece pressures fell with decreasing cylinder pressures, some remained relatively constant and one actually increased tasepiece pressure (Figs. 3a and 3 b). As operating pressures decreased, hreathing resistances (maximum facepiece pressure) generally increased. Pressures beyond 4 inches $(10 \mathrm{~cm})$ of water are considered excessive and pressure beyond 9 inches $(22.5 \mathrm{~cm})$ are intolerable to most wearers.

Yarying performance is attributed to different demand-valve-design characterisitics. The shapes of the breath-waveform pressure tracings are also characteristic "signatures" of differing designs. In general, SCBAs with facepiece-mounted demand valves performed well, presumably due to the elimination of frictional losses of rapidly flowing, low-pressure air through a $0.5 \mathrm{~m}$ length of comugated hose from belt-mounted demand valves.

\section{Conclusions}

Adding the criteria that $S C B A$ must maintain positive-facepiece pressure at or below the alam point makes the high-work-rate test severe in that only one SCBA tested did it. Our results imply that firefighters performing strenuous work are losing protection (protection fackors $<10,000$ ) at low operating pressures. However, our results also demonstrate that high perfornance (maintairing positive facepiece pressure al low operating pressures) is achievable with current technology. Therefore, this test is strongly recommended as a baseline lest against which effects of the firefighting 'environment (e.g., temperature, corrosion, etc.) should be evaluated. The National Fire Protection Agency is curently developing such tests,? 


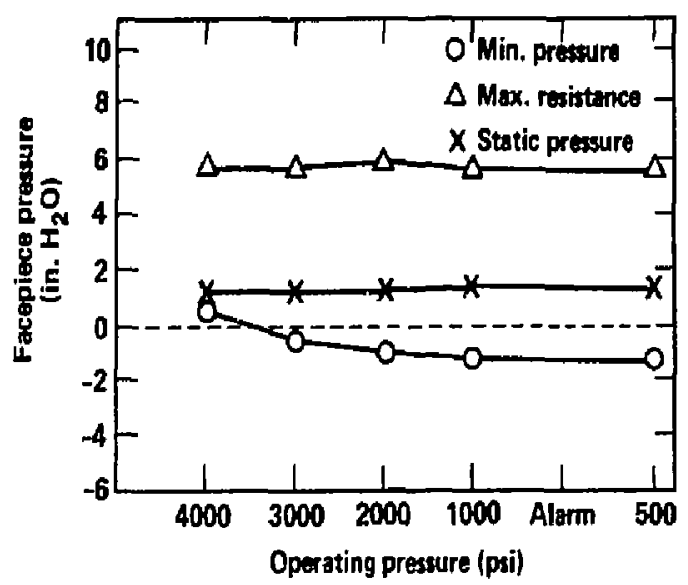

Figure 3a. Positive facepiece pressure as a function of a compressed-air, cylinder-operating pressure (VE $=100$ liters/minute).

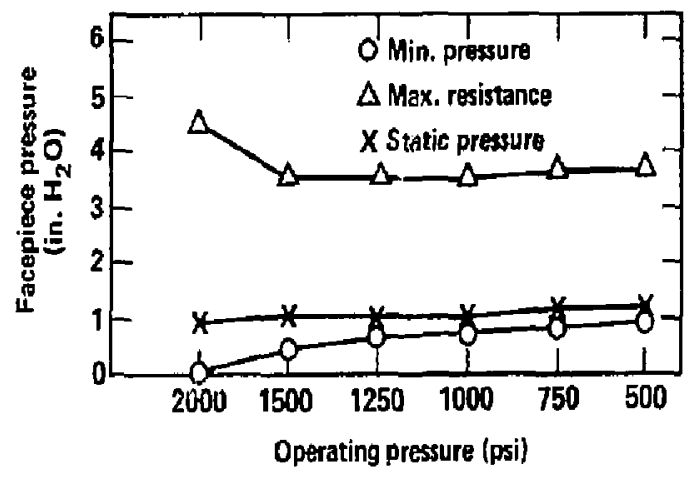

Figure $3 b$. Negative facepiece pressure as a function of a compressed-air, cylinder-operating pressure (VE $=100$ liters/minute).

\section{References}

1. J. W. Stengel, "Self-Contained Breathing Apparatus Protection at High Work Rates," Hazards Control Deparfment Anmual Technology Revieul-1982, UCRL-50007-82 (1983).
2. NFPA Committee for Revision NFPA 1981 Standards on SCBA and NFPA Committee on Protective Equipment for Firefighters, Draft on Standard for Self-Contained Breafhing Apparatus for Firefighters, National Fire Protection Associauion (1981). 


\title{
RADIATION PROTECTION
}

\section{Calculating Spectra and Dose Rates in the ${ }^{60} \mathrm{Co}$ Pool}

\author{
Charles T. Prevo
}

We have calculated the spectra and dose rates at various locations in the Hazards Control ${ }^{60} \mathrm{Co}$ irradiation pool. The calculations were performed usir.g the radiation transport code, MORSE76L.

\section{Introduction}

The Standards and Calibrations Laboratory (Bldg. 255) is part of the Radiation Dosimetry Group of the Hazards Control Department's Radi. ation and Environmental Safety Division. lts purpose is to maintain radiation standards for LLNL; the Standards and Calibrations Lab also offers tadioactive sources that provide gamma, neutron, beta, and $x$ rays for calibrating instruments, irradiating various materials for LLiNL researchers, and performing routine calibrations for the LLNL Personnel Dosimetry Program.

One such facility is the ${ }^{\infty 0} \mathrm{Co}$ iradiation pool that provides a high-intensity gammina field for radial ion-damage studies and dosimetry development orograms. The ${ }^{61} \mathrm{Co}$ irradiation pool is $2 \mathrm{n}$ in diame er and $6 \mathrm{~m}$ deep. The intonse source that lies at the bottom of the pool consists of 72 pencilshaped, encapsulated ${ }^{0} \mathrm{Co}$ rods $(20,000 \mathrm{Cl})$ arranged vertically in a wire-mesh basket so that they form a circle $25 \mathrm{~cm}$ in diameter.

The Waste Package Project has been studying the effects of radiation on corrosion and leaching of materials at the Tuft Repository in Nevada. To support this study, we have characterized the radiation field from these ${ }^{60} \mathrm{Co}$ rods using the radiation transport code, MORSE76L. Gamma-fluence spectra and dose fates were calculated at various positions in the pool.

\section{Results}

We calculated the spectra and dose rates under two sets of conditions. One, the source holder and geometry (Fig. 1) shows the source hold er ar "basket" sitting on a stainless-steel plate $1.905 \mathrm{~cm}$ thick ( $3 / 4$ inch). The top of this plate is $16.510 \mathrm{~cm}$ (6-1/2 inches) off the pool bottom. The plate diameter is $1.54 \mathrm{~m}$. Location $A$ is $12,159 \mathrm{~cm}$ above the top of this plate and on the axis of the holder. Location B, also on the axis, is $21.159 \mathrm{~cm}$ above the plate. Locations $C$ and $D$ are at the same height as $A$, but off-axis 15.2 and $47 \mathrm{~cm}$, respectively.

For the second case, the samples to be irradiated were placed in an assembly depicted in Fig. 2 (also shown in Fig. 2 are the lucations of interest). The composition of the sample is given in Table 1 . Calculations of spectra and dose rates were made at locations, $A, B, C, D, E . F, G$, J, and $K$. The dose rates for all nine positions are given in Table 2 . Measurements of the dose rates have not been completed; however, a preliminary measurement at position $A$ was within 5\% of the calculated value. The spectra are given in Tables 3 through 11 and are shown in Figs. 3 through 11. 


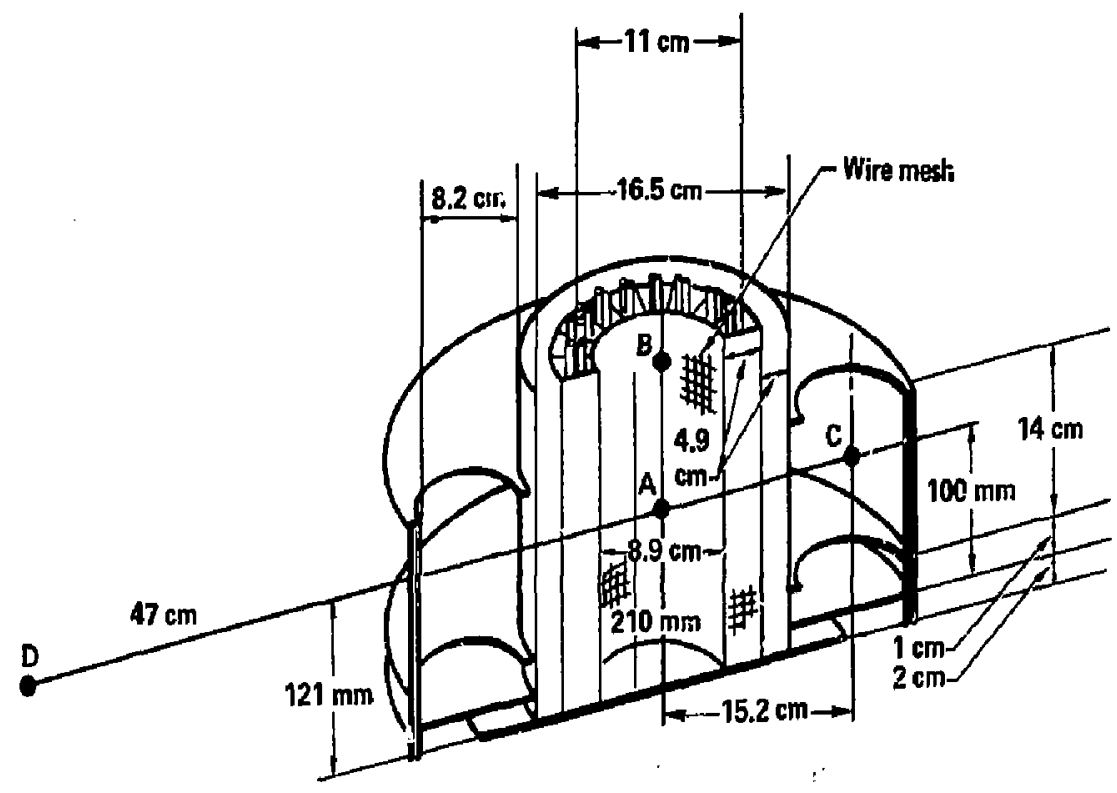

Figure 1. Locations oi positions $A, B, C$, and D relative to the source holder.

Table 1. Isotopic composition of the irradiated sample.

\begin{tabular}{cc} 
Element & $\begin{array}{c}\text { [sotopic composition } \\
\text { (atoms } / \mathrm{cm}^{2}-\text { batri) }\end{array}$ \\
\hline H & 0.0155 \\
O & 0.0401 \\
Al & 0.0029 \\
Si & 0.0128 \\
Fe & 0.0084 \\
\hline
\end{tabular}




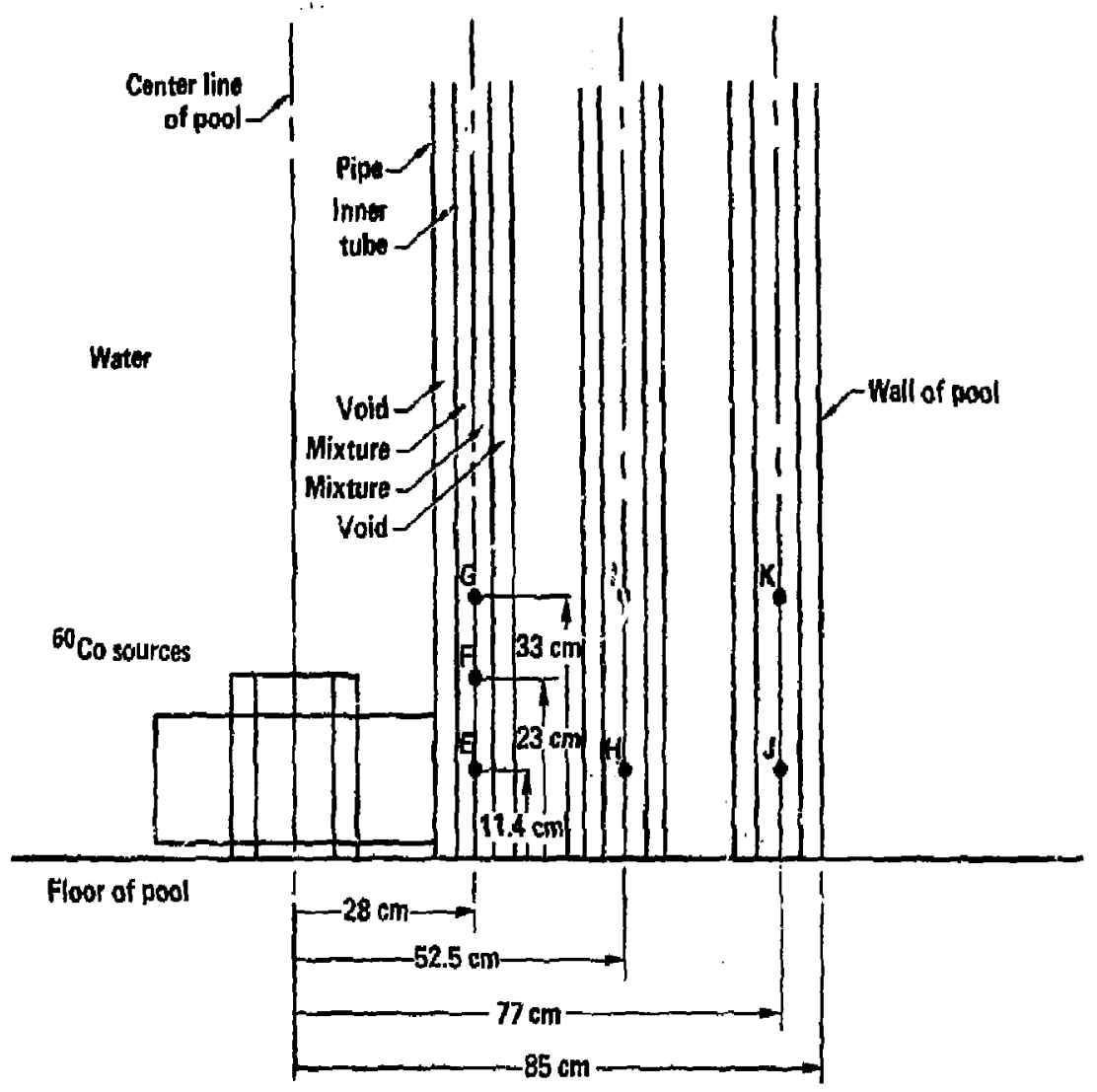

Figure 2. Sketch showing locations of positions E, E, G, J, and K.

Table 2. Dose rales for various positions in $\mathrm{C}$ Cell.

\begin{tabular}{cc}
\hline Position & D (sem/sec) \\
\hline A & 1150 \\
B & 642 \\
C & 150 \\
D & 38 \\
E & 20.6 \\
F & 11.8 \\
G & 0.74 \\
$J$ & 0.299 \\
K & 0.198 \\
\hline
\end{tabular}


Table 3. Encrgy-dependent fluence at position $A$ in C Cell.

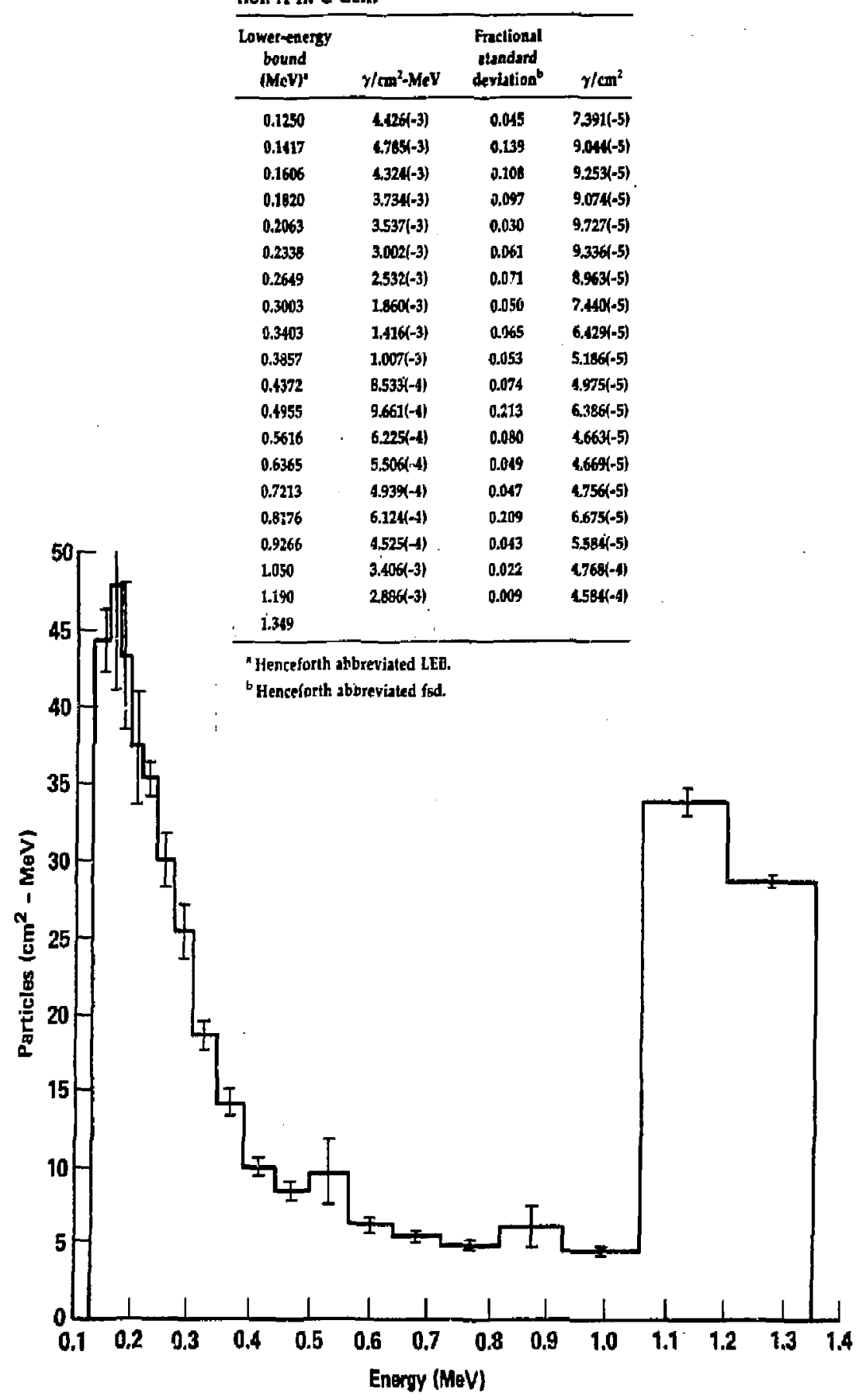

Figore 3. Spectra calculation for position A (C Cell), energy-dependent fluence for detector 1 . 
Table A. Energyrdependent fluerse at position $B$ in C Cell.

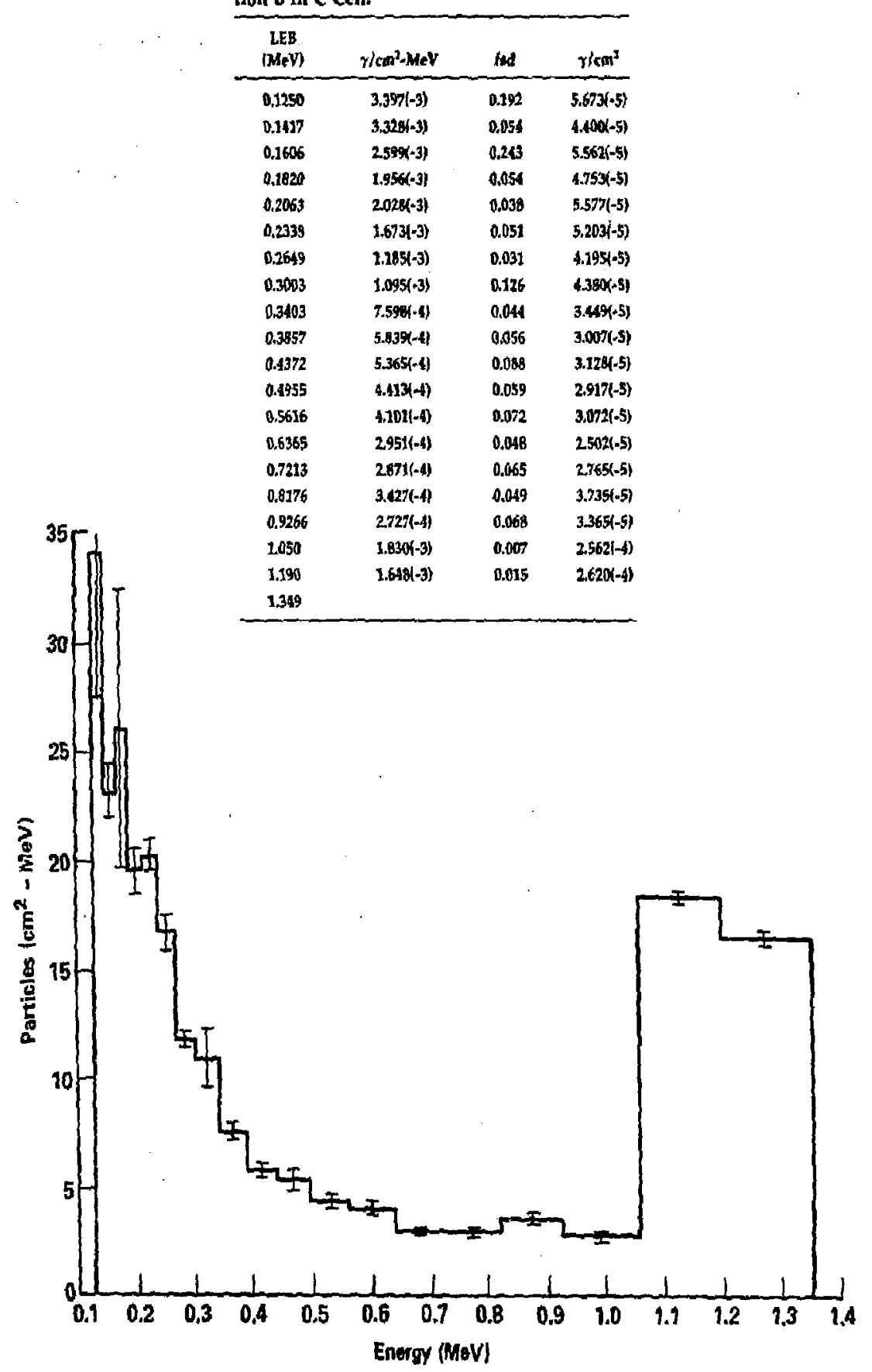

Figure 4. Spectra calculation for position B (C Coll), energy-dependent flaence far detector 1 . 


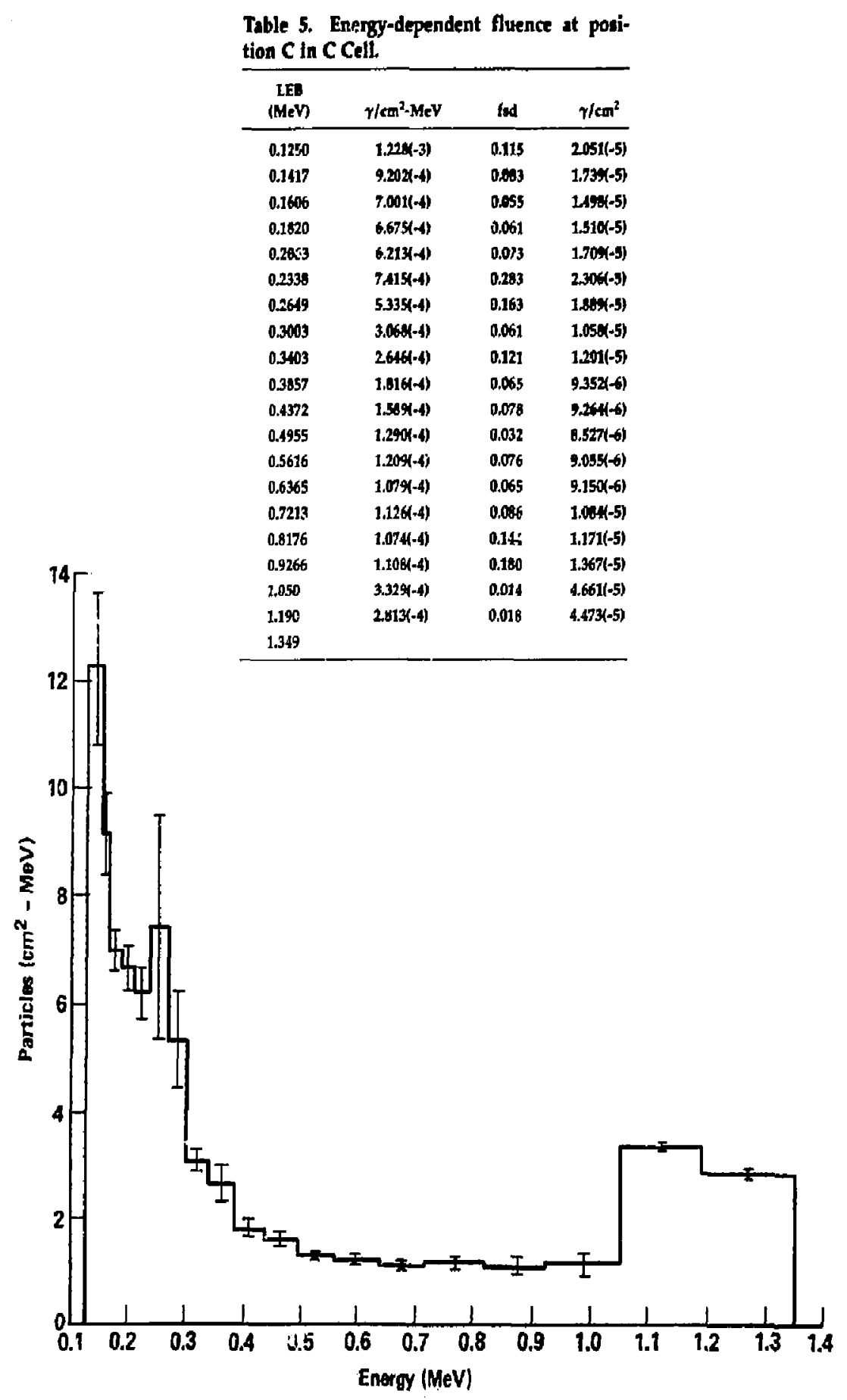

Figure 5. Spectrn calculation for pisition C (C Cell), energy-dependent fiuence for detector 1 . 
Table 6. Energy-dependent fluence at position D in C Cell.

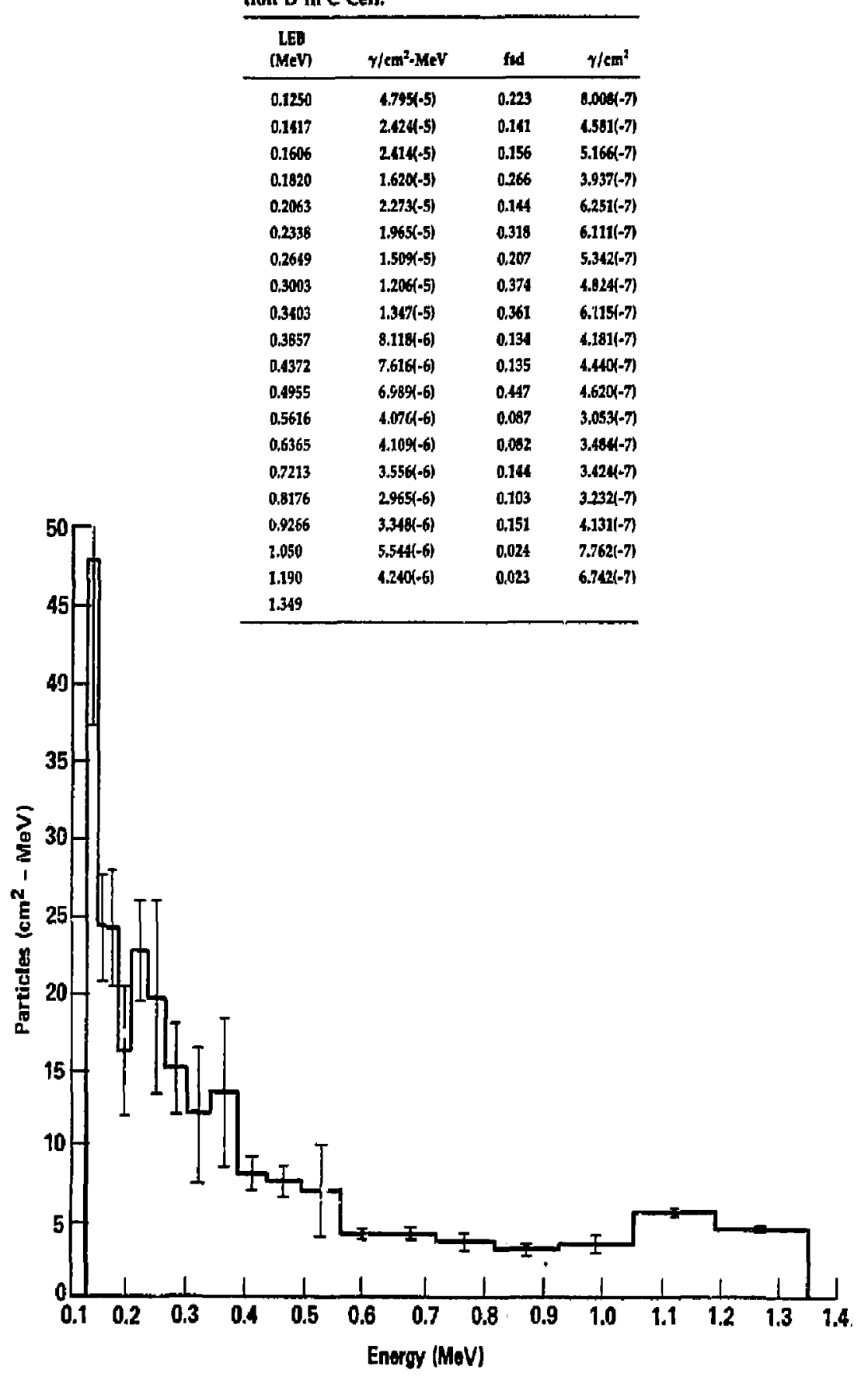

Figure 6. Spectra calculation for position D (CCell), energy-dependent fluence for delector 1 . 
Table 7. Energy-dependent fluence at position $\mathrm{E}$ in C Cell.

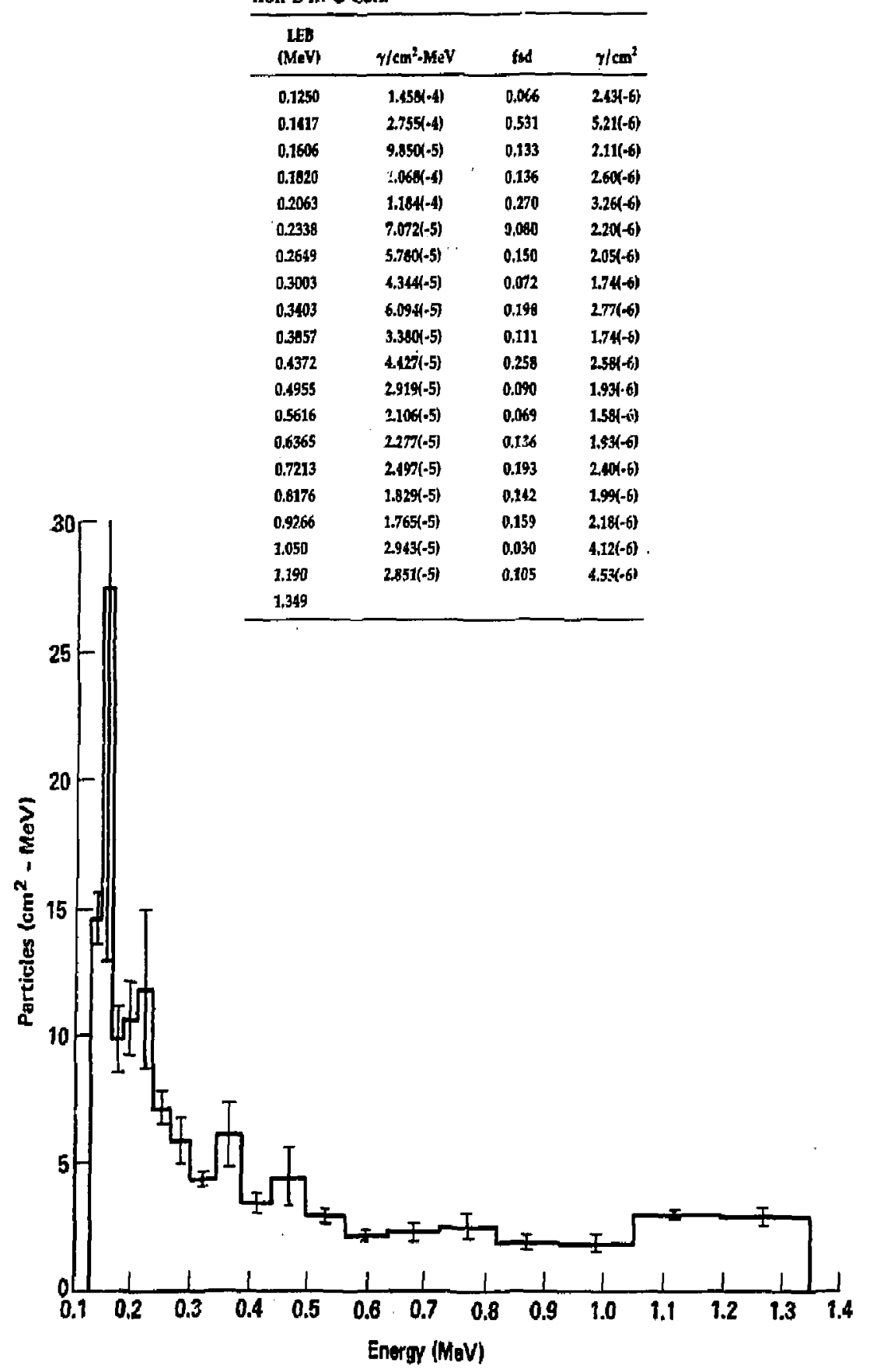

Figure 7. Spectra calculation for position E' (C Cell), energy-dependent fluence for detector 1. 
Table 8. Energy-depandent fluence at pasition $F$ in C Cell.

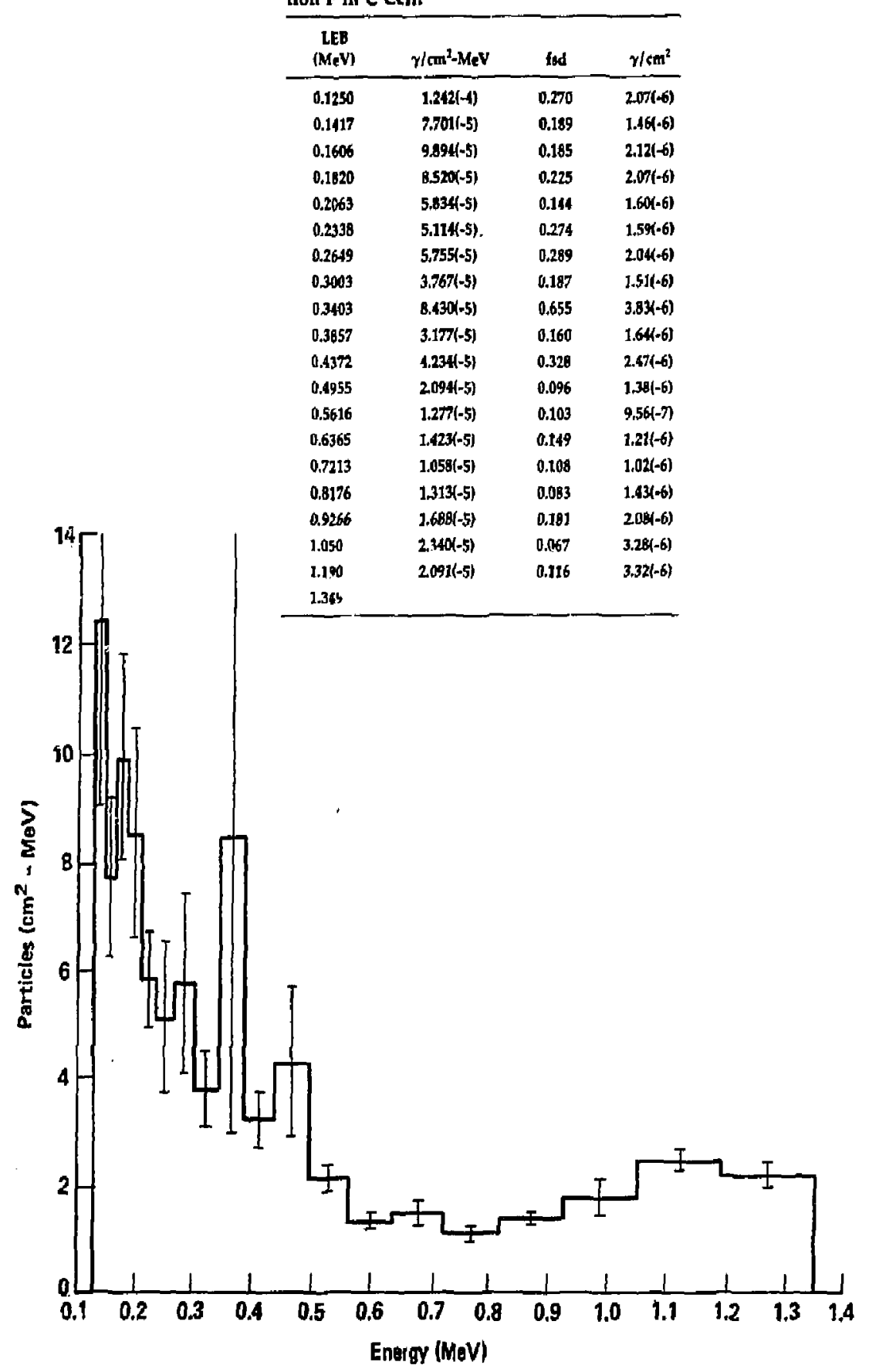

Figure 8. Specta calculation for position F (C Cell), energy-dependent fluence for detector 1. 
Table 9. Energyrdependent fluence at position $\mathrm{G}$ in C Cell.

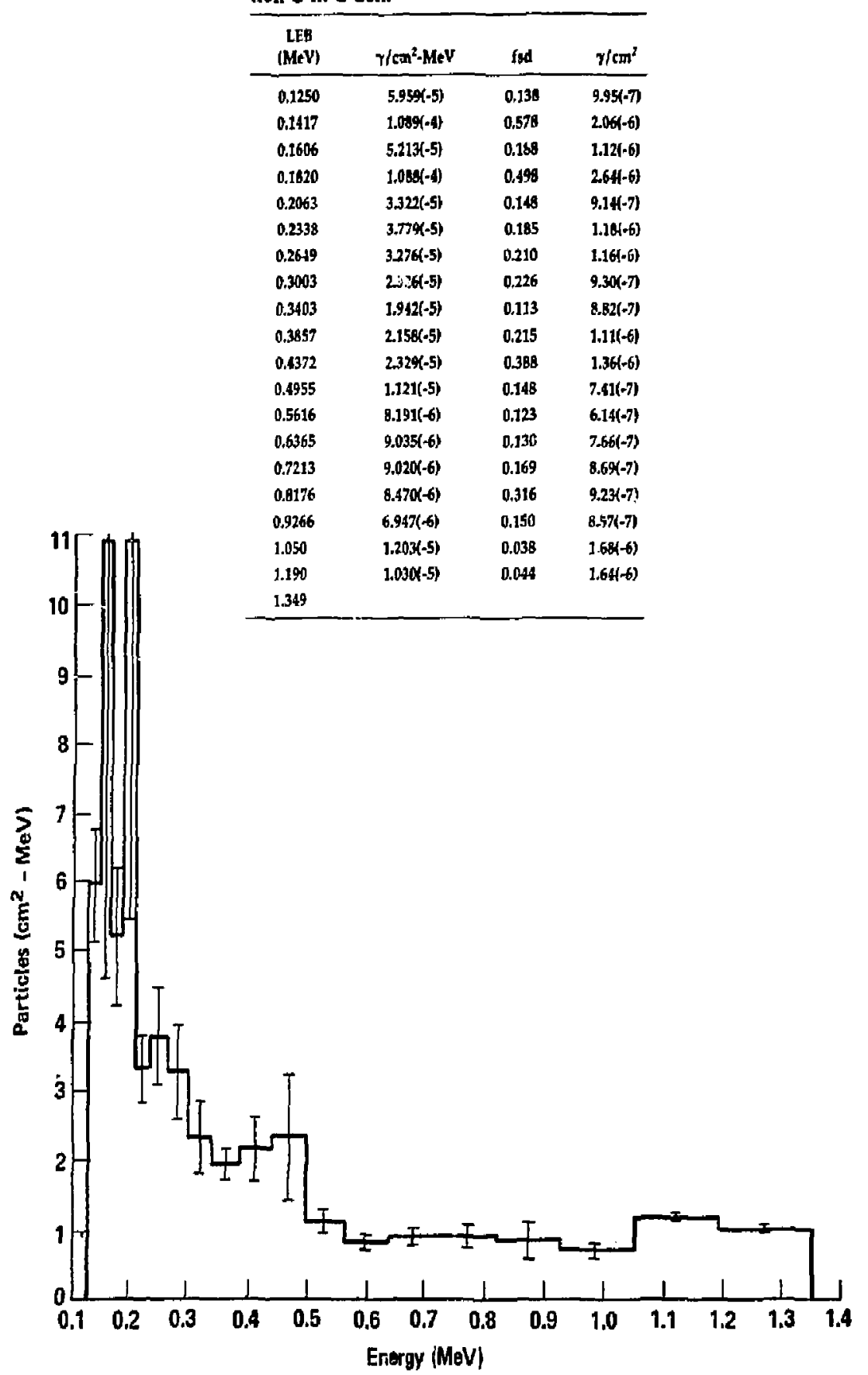

Figure 9. Spectra calculation for position G (CCell), energy-dependent fluence for detector 1. 


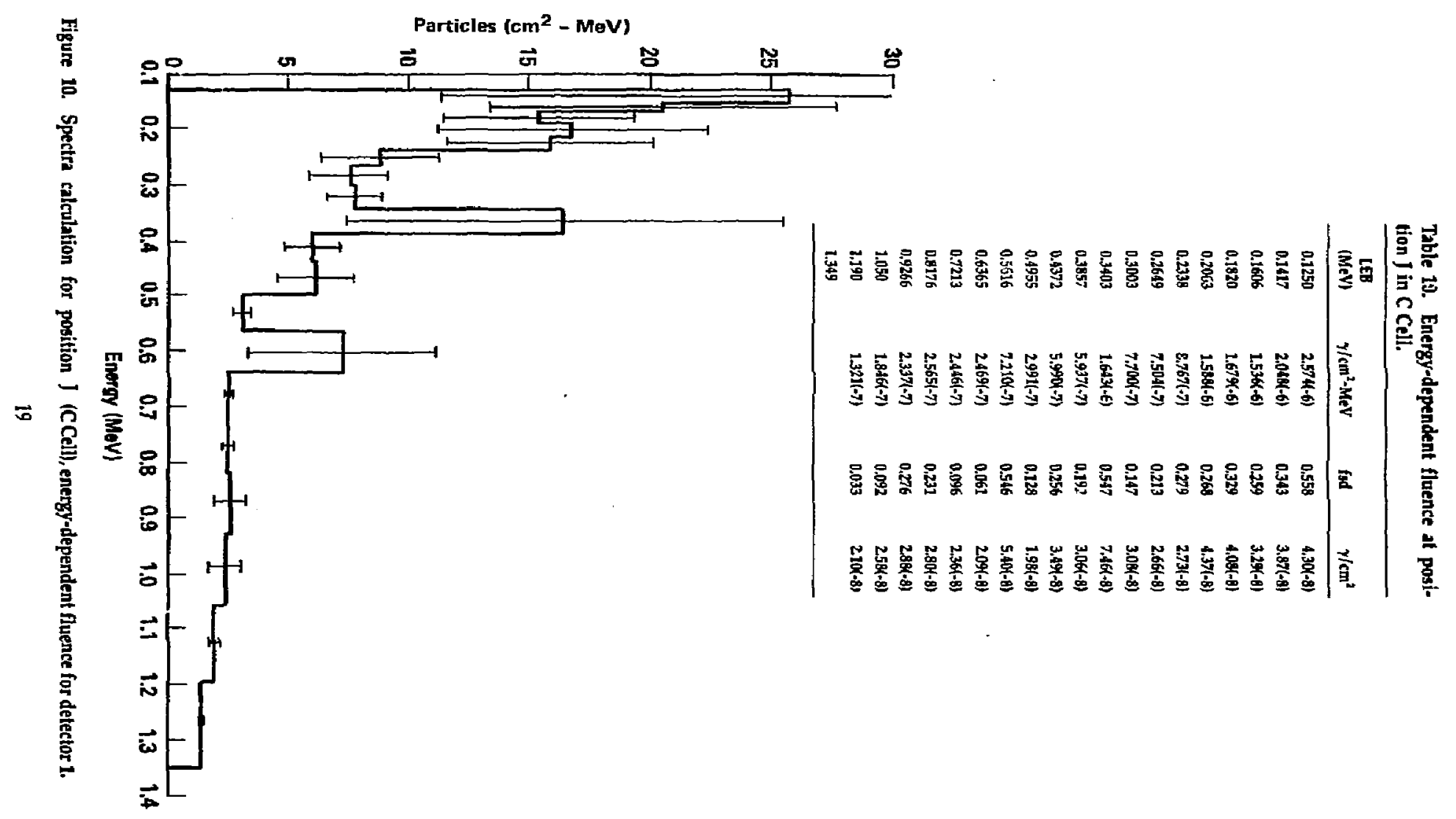


Table 11. Energy-dependent fluence at position $\mathrm{K}$ in C Cell.

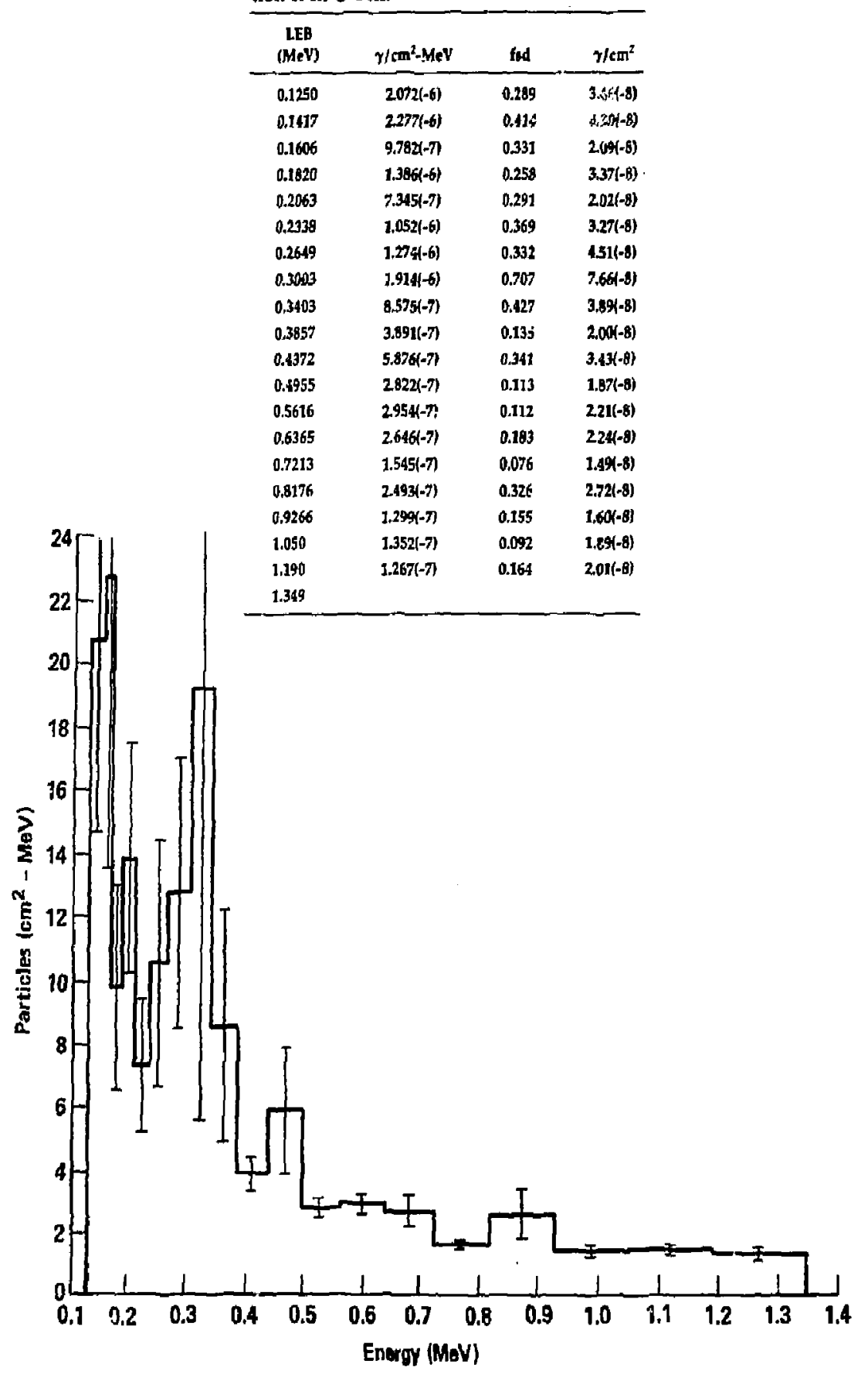

Figure 11. Spectra calculation for position $K$ (C Cell), energy-de, andent fluence for detector 1 . 


\title{
Measuring Pu in a Glove Box Using Portable NaI and Germanium Detectors
}

\author{
Dale E. Hankins
}

A NaI trystal or germanium detector inside a portable lead shield can determine the amount of plutonium in a glove box. We define the number of counts required and the locations outside the box where the detector needs to be positioned. The calculated accuracy for measuring the Pu when our locations are used is within $\pm 30 \%$ for most glove buxes. We also disciss other factors that may affect this accuracy, such as gamma-ray absorption $t_{y}$ glove-box materials, self-absorption by Pu, absorption by equipment in the glove box, and the limits of the counting equipment.

\section{Introduction}

Measuring the $\mathrm{Pu}$ present in a glove box is required for inventory and process control, criticality safety, and before removal of a glove box for disposal. In the past, we used a $2 \times 2 \mathrm{NaI}$ crystal with a portable multichannel analyzer. These measurements had several er-ors: our goal was eliminating or evaluating these errors. The inverse square relationship and absorption of gamma rays make an absolute evaluation of residual Pu in a glove box impossible using a $\mathrm{Nal}$ crystal for counting the $380 \mathrm{keV}$ photon complex from Pu. However, strict accuracy is not required for most purposes; ertors of $\pm 50 \%$ to $100 \%$ are often considered adequate. In this study, we modified the lead shield used, iith the Nal crystal. We then determined the counting positions around glove boxes of various sizes that would give the best estimate of the Pu remaining in the glove box. We also evaluated the problem of gamma-ray absorption by glove-box materials, self-absorption by $P u$, lbsorption by equipment in the glove box, and the limits of equipment sensitivity.

We developed a procedure for measuring $\mathrm{Pu}$ in glove boxes up to $4 \times 4 \times 8 \mathrm{ft}$. This procedure evaluated tite amounts of $\mathrm{Pu}$ within an error calculated to be $< \pm 30 \%$. Gamma-ray absorption by the glove-box materials was measured and used to estimate the averaged absorption.

Limited studies with the germanium detector indicated that it was superior to the Nal detector in discriminating between other isotopes that may be present in a glove box, suggesting that we should replace our clirtent setup with a germanium detector.

\section{lead Shield for the NaI Crystal}

We had placed the Nal crystal inside a 1 -in.thick lead shield because it could be transported easily and positioned conveniently near a glove box. The lead shield was used to (1) decrease the detector background and the associated detection limit for Pu in a glove box, (2) shield the crystal from Pu located elsewhere in the room, and (3) act as a collimator to locate the $\mathrm{Pu}$, or other isotopes, within a glove box.

We first determined the directional response of the shielded Nal crystal to Pu gamma rays around $380 \mathrm{keV}$. We were surprised to find that the detected area was much smaller than we had believed, and that only a small, well-collimated area was being detected. This was caused, in part, by the crystal face being recessed $3.25 \mathrm{~cm}$ (1.1/4 in.) inside the crystal mount. We had assumed the crystal face was very near the front face of the mount, and we usually recessed the crystal face an inch or two inside the lead shield. This resulted in a very well-collimated beam which missed measuring a large part of the $\mathrm{Pu}$ in the glove box.

The lead shield is made of several rings that make it easier to move. One of the end lead rings was modified by cutting a $45^{\circ}$ bevel on the inside of the ring to increase and define the angle that gamma rays could seach the crystal. When the NaI, crystal is inserted backwards in the shield, it still provides an excellent collimator for locating sources inside a box, especially if the crystal is recessed two or more inches in the shield.

The 60-keV gamma ray from the ever-present ${ }^{211}$ Am can be a problem. If it is too abundant, it 
causes excessive dead time and peak energy shift in the analyzer. We investigated the use of a copper or cadmium filter over the end of the lead shield to reduce the effect of this gamma ray, Both copper and cadmi:tm have large absorption crosssections at $60 \mathrm{keV}$ and small aoss-sections at $280 \mathrm{keV}$. We found that 32-mil-thick cadmium was much more effective than 42 -mil-thirk copper in reducing the $60-\mathrm{keV}$ gamura rays, while both materials reduced the count rate at $380 \mathrm{keV}$ by the same amount. We installed the 32-mil-thick cadmium over the end of the lead shield.

A large and well-defined detertion angle for the crystal and shield combination is important for measurements. Therefore, we moved the crystal forward in the lead shield until the front of the crysta! mount touched the cadmium filter. This provided accurate reproduction of the measurement geometry. The directional response of this configuration was determined using a Pu source
(Fig. 1). Although the resolution is not sharp, the detection angle is approximately $90^{\circ}\left(45^{\circ}\right.$ to either side of center). This modification of the lead shield increased the crystal background which increased the minimum detectable mass of $\mathrm{Pu}$. The increased angle of detection also allowed more of the Pu from other glove boxes in the room to be detected. These adverse effects must be accepted, however, since the original shield-detector zonfiguration was so namowly collimated that the whole glove box could not be viewed.

\section{Initial Field Evaluation}

Determining the amount of Pu at any location in a glove box to within $\pm 30 \%$ was our objective. We began vy measuring a typical glove box (Fig. 2). Important features of the box are its sloping sides and the varying absorption of the

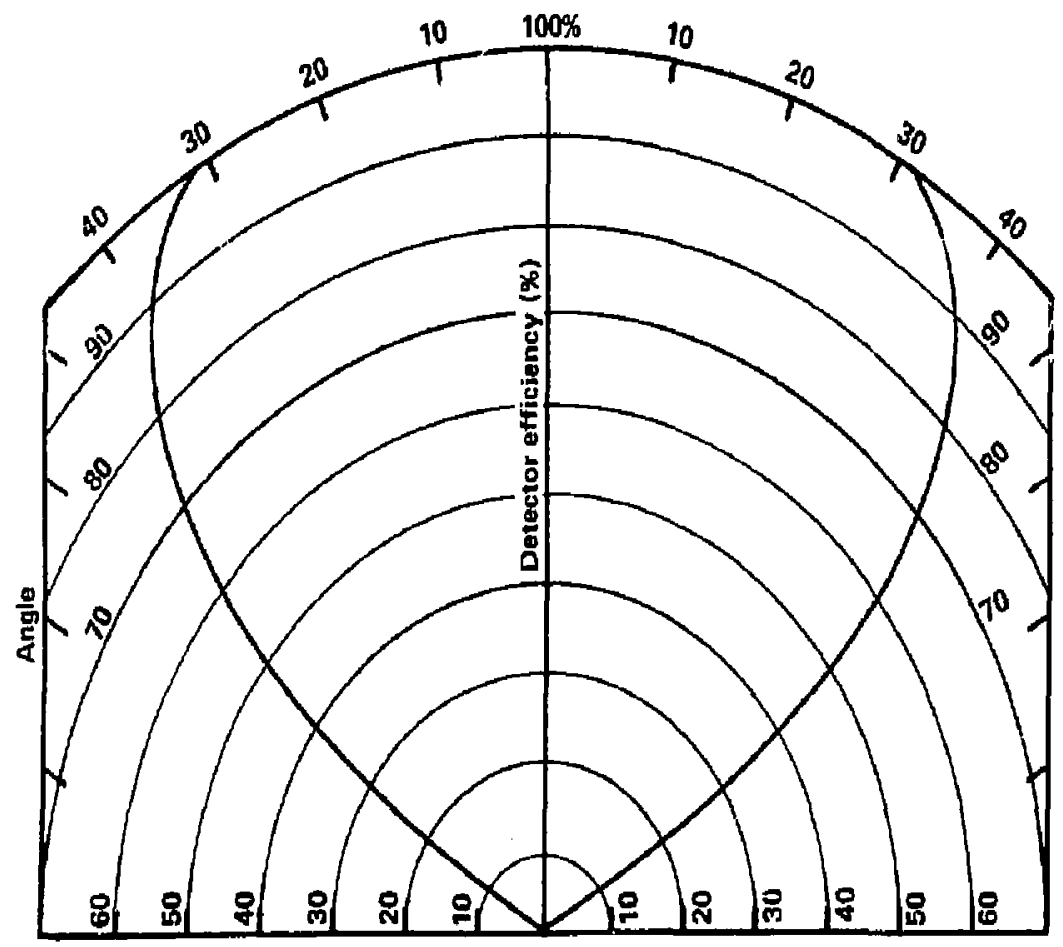

Figare 1. Directional responet of NaI crystal to the gamma rays from $\mathrm{Pu}$ in the $380 \mathrm{keV}$ complex. The detector efficiency is given as a function of angle. 

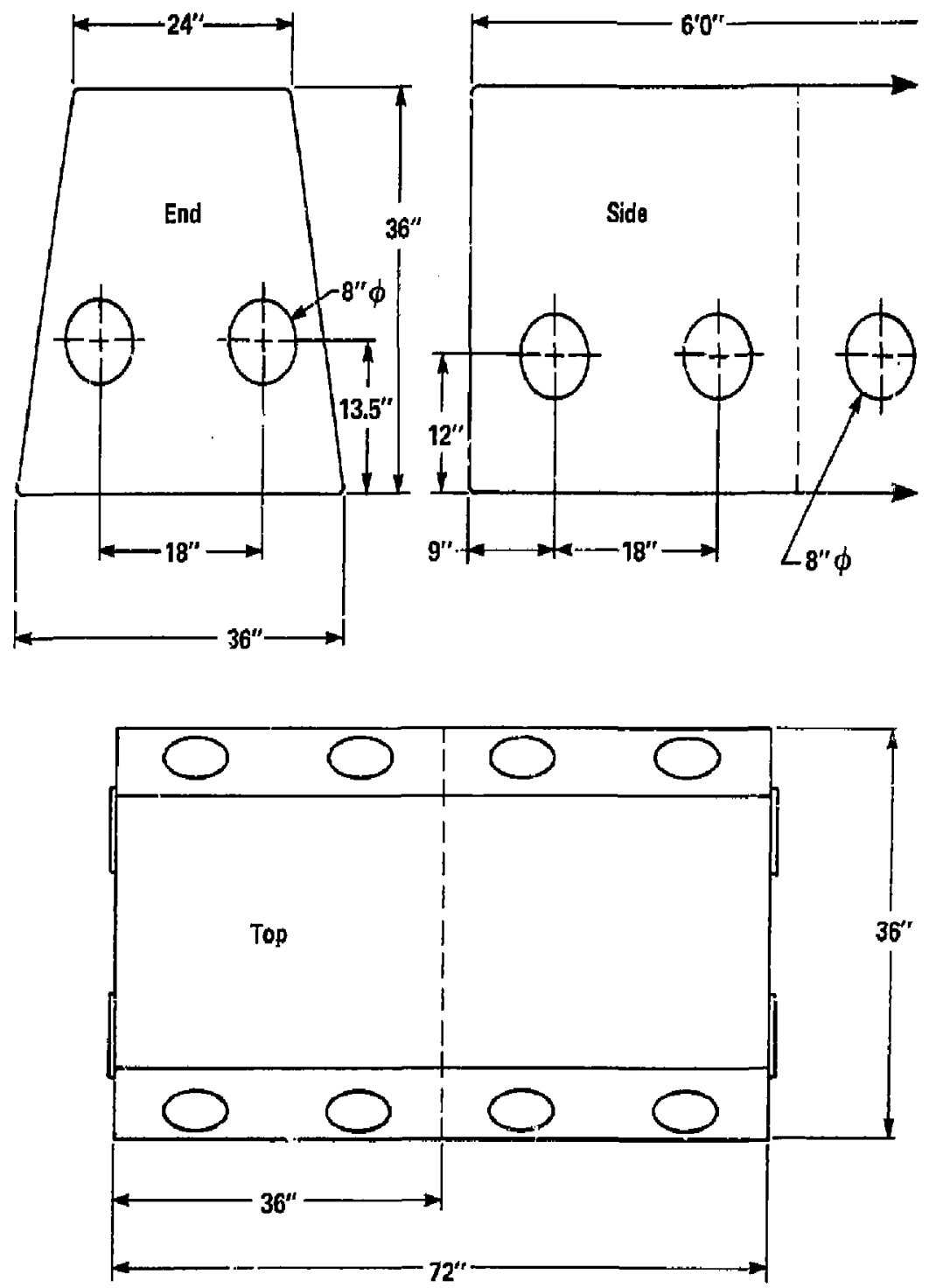

Figure 2. Schematic of a typical gove box.

$380-\mathrm{keV} \times$ rays by the glave-box materials (Lucite, stainless steel, aluminum, gloves, glove port covers). The sloping sides cause wall contamination at varying distances from the detector location, deperding on whether the contamination is near the bottom or top of the glove box.

We measured $P u$ at eight locations in a glove box similar to the one illustrated in Fig. 2: three along each side, and one at each end. The detector was one meter from the center of the glove box. Pu metal in a small paint can was placed at selected, well-defined positions irside the glove box.

We did not find any combination of measurements that could determine the source quantity to within $\pm 30 \%$ when the Pu was located in the corners of the glove box (low readings), or at the center or ends of the glove box (high readings). It 
appeared that the problem of low responses in the comer could be solved if the detector were positioned at the corners of the glove box.

\section{Response Calculations}

Our HP-85 cor.iputer program calculated the effects of geometry and directional response of the detector for a geometry similar in size and shape to the glove box used experimentally. These calculations were intended to guide the optimun selection of detector positions. The separation between detector and glove box is an important parameter in these calculations. If the separation is too small, the inverse-square relationship causes large variations in detector response for sources located at different positions in the box. If the separation is too large, inverse-square errors become less severe, but the detector count rate is significantly reduced. This, in tum, increases the minimum detectable level of $\mathrm{Pu}$ accordingly. Large separations also increase the likelihood that Pu in other glove boxes will be detected.

We calcuiated the Pu with the detector in six differen' positions seach of four comers and each of the two sides). The detector-glove box separation was varied until the sum of responses for the six measurement points was as independent as possible from the position of the source in the glove box. We found that the comers, the center of each side, and the middle of the glove box were the most difficult source positions to evaluate accurately.

\section{Results}

Calculations using the $3 \times 3 \times 6 \mathrm{ft}$ glove box showed that we could obtain an acceptable evaluation if the detector-to-glove box distances were $2.5 \mathrm{ft}$ from the glove box side and $2.0 \mathrm{ft}$ from the glove box comer. When the six counts ( 2 from the side and 4 from the comers) using a single point source were averaged and compared to the average for 33 sources located throughout the box, the single source count wit was within $< \pm 30 \%$, in dependent of source location. If each of the measurement distances was $2.0 \mathrm{ft}$, the errors ranged frotn $+45 \%$ (which is unacceptable) to $-28 \%$.

We repeated these calculations for a number of typical glove-box sizes. In Table 1 , the results of these calculations are given for the geometries that meet the error criterion $< \pm 30 \%$. The exception is a $4 \times 4 \times 4 \mathrm{ft}$ box, where only four counts

Table 1. Measurement error and counting efficiency oblained for various sizes of glove boxes.

\begin{tabular}{|c|c|c|c|c|c|c|c|c|c|}
\hline \multirow{2}{*}{$\begin{array}{c}\text { Size of Box } \\
\text { (width-height-length) }\end{array}$} & \multicolumn{3}{|c|}{$\begin{array}{l}\text { Number of } \\
\text { measurements }\end{array}$} & \multicolumn{3}{|c|}{$\begin{array}{l}\text { Measurement } \\
\text { distance }\end{array}$} & \multirow{2}{*}{$\begin{array}{l}\text { \% Relative } \\
\text { counting } \\
\text { efficiency }\end{array}$} & \multicolumn{2}{|c|}{$\begin{array}{l}\text { Messurement error and } \\
\text { Pu location in box }\end{array}$} \\
\hline & side & cornet & end & side & cortter & $\overline{\text { end }}$ & & \% high reading & \% low reading \\
\hline $3 \times 3 \times 3^{4}$ & 4 & & & 2 & & & 0.84 & 22 side, midplane & 22 corner, bottom \\
\hline $3 \times 3 \times 3$ & 4 & & & 2.5 & & & 0.71 & 15 side, midplane & $\begin{array}{l}16 \text { center, top } \\
\text { or bottom }\end{array}$ \\
\hline $3 \times 3 \times 6^{4}$ & 2 & 4 & & 25 & 2 & & 0.50 & 27 side, midplane & 25 end, botrom \\
\hline $3 \times 3 \times 6$ & 2 & 4 & & 2.5 & 2 & & 0.51 & 24 side, midplane & 27 end, boltom \\
\hline $3 \times 3 \times 9$ & 4 & 4 & & 2.5 & 2.5 & & 0.38 & 25 side, midplane & $\begin{array}{l}23 \text { end, top ot } \\
\text { bottom }\end{array}$ \\
\hline $3 \times 3 \times 12$ & 6 & 4 & & 2 & 2 & & 0.37 & 28 side, midplane & $\begin{array}{l}27 \text { end, top or } \\
\text { boltom }\end{array}$ \\
\hline $4 \times 4 \times 4$ & 4 & & & 2.5 & & & 0.54 & 34 side, midplane & $\begin{array}{l}30 \text { corner, top or } \\
\text { bottom }\end{array}$ \\
\hline $4 \times 4 \times 4$ & 4 & 4 & & 2.5 & 25 & & 0.47 & $\begin{array}{l}28 \text { corner, } \\
\text { midplane }\end{array}$ & $\begin{array}{l}18 \text { center, top or } \\
\text { bottom }\end{array}$ \\
\hline $4 \times 4 \times 6$ & 2 & 4 & & 2.5 & 2 & & 0.44 & 29 side, midplane & $\begin{array}{l}23 \text { end, lop or } \\
\text { botlom }\end{array}$ \\
\hline $4 \times 4 \times 8$ & & 2 & 3 & 3 & & 3 & 0.33 & $\begin{array}{l}24 \text { oide, in Iroal } \\
\text { of detector, } \\
\text { midplane }\end{array}$ & $\begin{array}{l}21 \text { corner, top or } \\
\text { bottom }\end{array}$ \\
\hline $4 \times 4 \times 7$ & 1 & & 2 & 3 & & 3 & 0.34 & $\begin{array}{l}30 \text { side in front } \\
\text { of detector, } \\
\text { midplane }\end{array}$ & $\begin{array}{l}20 \text { comer, top } \\
\text { or bottom }\end{array}$ \\
\hline
\end{tabular}

"These boxes trad sloped sides, All others were stright. 
were used and the errors range from $+34 \%$ to $-30 \%$. The erro range could be reduced to meet our criterion only if 8 counts were made $(+28 \%$ to $-18 \%$ ). The improved accuracy does not justify doubling the counting effort.

We show schematically in Fig. 3 acceptable counting locations and distances. To avoid cluttering the figure, we have shown simply the distance and direction from the glove box for only one of each symmetric location.

Also given in Table 1 are the relative counting efficiencies. This is the average counting effciency for one gram of $\mathrm{Pu}$ placed uniformly throughout the glove box. We approximated this distribution by calculating the efficiency from sources placed on a one-foot matrix within each of the glove boxes. The calculated counting efficiency is relative to that obtained from a one-gram Pu source at one meter from the face of the detector shield. The counting efficiency decreases as. the glove box size increases, which is the result expected from inverse-square considerations. The sensitivity of this counting proceduse is considerably less for the larger glove boxes, and, consequently, more $\mathrm{Pu}$ goes undetected in the larger glove boxes.

As an aside, a glove box that is smalier than the ones shown in Fig. 2 can be counted by assuming it has the dimensions of one of the sizes shown in Fig. 2 . The detectors could be positioned at the locations showr. The smaller glove box could be placed in the center of this area, and a series of counts could be obtained and evaluated as if it were the larger glove box.

\section{Accuracy of Measurements}

The measurement erro: in percent is the largest enor that we obtained (Table 1). This required that all the Pu in the glove box was located in the worst possible location. In practice, this would never orcur, and most measurements would have less error, probably within $\sim \pm 10 \%$ (without glove-box attenuation and sel(-absorption).

\section{Absorption by Glove-Box Materiald}

The absorption of the $380-\mathrm{keV}$ complex gamma rays by the materials used in glove box is significant, and a correction for absorption must be made. We measured the decreased response caused by these materials using the $2 \times 2 \mathrm{NaI}$ crystal and our one-gram Pu calibration source
(Table 2). Fortunately, the differences in the response caused by absorption of the glove-box materials are not large. The greatest error would come from gamma rays exiting through the glove ports where the 15-mil glove absorption is negligible but the glove port cover absorbs $21 \%$ of the gamma ravs. When assaying a glove box, the glove ports should all be the same, either ali open or covered. An average correction for glove-box absorption can be made based on the materials used in the glove box and the coverings over the glove ports. The use of an average absorption will introduce an error but its magnitude is small.

\section{Absorption by Plutonium}

We had used a 27.2-gram piece of Pu metal as a source. We selected this large piece to provide a high count rate, and thereby reduce the count times required to attain reasonable counting statistics. The Pu was scrap material and it was not symmetric. It was slightly elongated, and when rotated, we observed a variation in the counting rate of $20 \%$ caused by self-absorption of the $380-\mathrm{keV}$ complex gamma rays in the Pu. The averaged count from this source was only $29 \%$ of the expected count rate based on the count rate from our one-gram Pu calibration source. (The calibration source is a disk oriented with the flat side facing the detector.)

Most surveys of glove boxes being sent for salvage would not involve a large mass of $\mathrm{Pu}$ metal. Self-absorption in these boxes should be small and can be ignored. For operational glove boxes, this may not be true, and the glove-box contents should be inspected for large pieces of

Table 2. Decrease in detector count rate caused by absorption of 3BO-keV complex gamma rays via glove-box construction materials.

\begin{tabular}{lc}
\hline \multicolumn{1}{c}{ Material } & $\begin{array}{c}\text { Decreased count rate } \\
\text { (\%) }\end{array}$ \\
\hline $3 / 8$ in. thick Lucite & 9 \\
$1 / 16$ in. stainiless steel & 14 \\
1/4 in, Al end-port plate & 12 \\
Glove port cover & 21 \\
Sleel shipping glove box & 16 \\
Plywood (3/4 in.) shipping glove box & 6 \\
15-mil glove & 0 \\
\hline
\end{tabular}




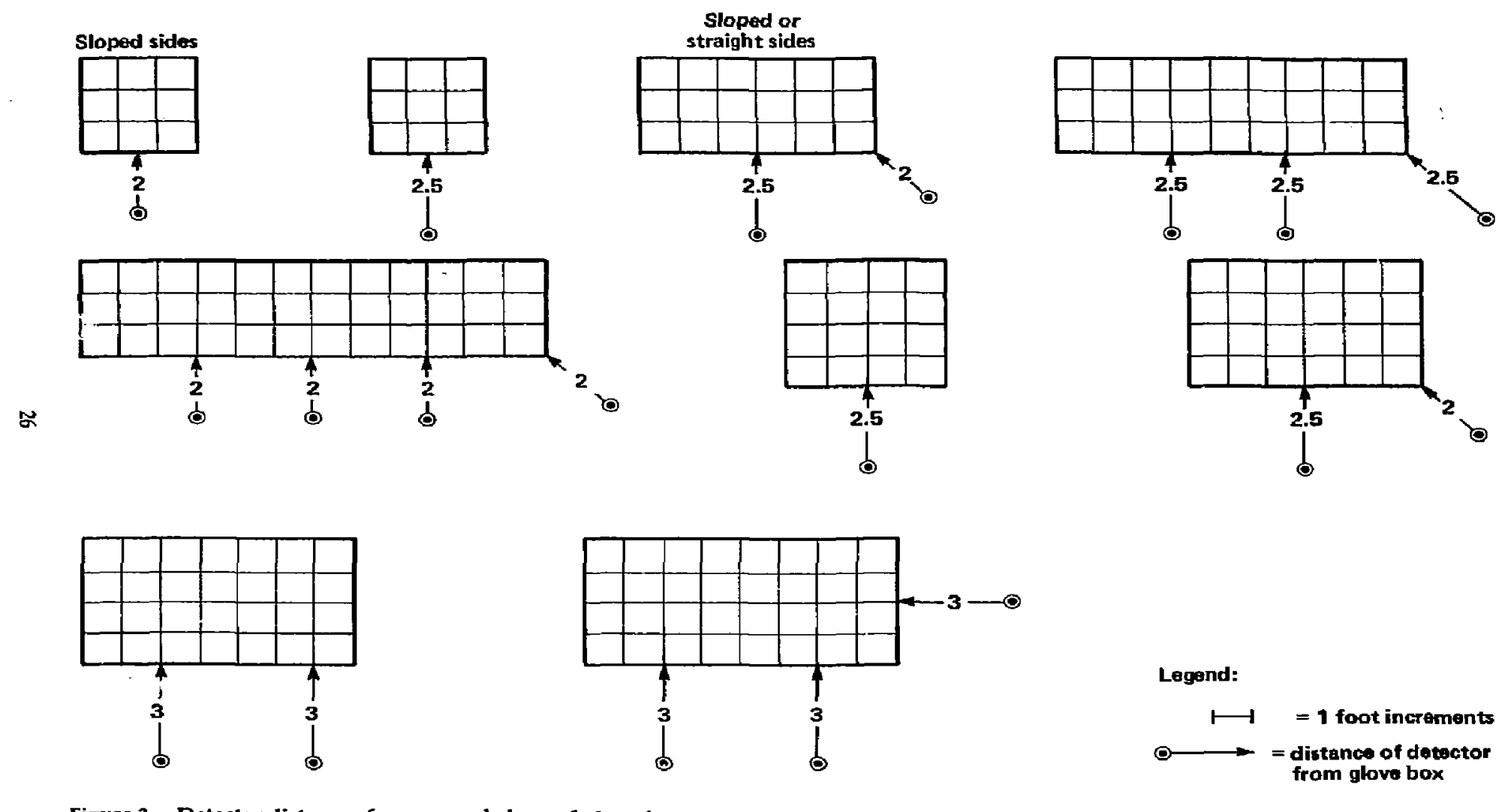

Figure 3. Detector distances from several sizes of glove boxes. 
Pu before an estimate is made of the glove-box contents based on count rate.

\section{Absorption by Materials in the Glove Box}

By far, the largest error expected is caused by absorption of the gamma rays by other items in the glove bi.x. Equipment commonly present in glove boxes includes drill presses, lathes, planers, bandsaws, and other large steel equipment. Any plutonium located behind one of these pieces of equipment will not be detected at a single detector location. Our detector positions allowed the detection of Pu behind such items. In some cases, the equipment has holes, ctevices, or other recesses that can hide Pu. Occasionally, we have measured above or below the glove box tc ensure this did not occur.

When the glove box contains materials that absorb the $380-\mathrm{keV}$ complex gamma rays, the experimenter should estimate the extent of this absorption. This estimate will normally be the largest error. Little guidance can be given for these situations since each is unique.

\section{The Germanium Detector and Its Advantages}

Following the experimental procedure we have discussed so far will provide accurate counts. However, placing a cadmium shield over the face of the detector reduces the intensity of the $60-\mathrm{keV}$ gamma rays from ${ }^{241} \mathrm{Am}$, but does not reduce its higher energy gamma rays. When large amounts of ${ }^{241} \mathrm{Am}$ or other isotopes are present in a glove box, it becomes impossible to evaluate the $\mathrm{Pu}$ with the Nal detector because it cannot distinguish between photons due to $\mathrm{Pu}$ and those due to other isotopes, and thus, the amount of Pu will be overestimated. The spectrum viewed on the multichannel analyzer display will be distorted, usually at the low energy end of the channels being summed.

We recently measured boxes that contained ${ }^{239} \mathrm{Pu},{ }^{251} \mathrm{Am},{ }^{238} \mathrm{~Np}$, and other heavy elements. We used the NaI crystal discussed previously and an Ortec GMX series, Gamma- $X$, HPGe coaxial germanium detector $(45.4 \mathrm{~mm}$ diam by $36.5 \mathrm{~mm}$ length). We could, in all cases, determine the presence of Pu using the germanium detector, but we could not evaluate the Pu with the Nal crystal. The germanium-detector results for one of the boxes that contained considerable quantities of the other isotopes had ${ }^{239} \mathrm{Pu}$ peaks at 375 and $414 \mathrm{keV}$ located on top of a signitkant Compton continusm. Corrections for the added counts in the peaks were made using the continuum on either side of the peak. Many of the new analyzers have features that will perform this subtraction.

The detection efficiency of the germanium delector gave us a count rate of $0.37 \mathrm{cts} / \mathrm{sec}$ and $0.21 \mathrm{cts} / \mathrm{sec}$ for the 375 and $415 \mathrm{keV}$ peaks, respectively, from our one-gram calibration source at a source-to-detector-face distance of 1 meter. The sensitivity limit for Pu in a glove box would be between 0.5 and $1.0 \mathrm{~g}$ for count times of $\sim 5$ minutes at each counting location. This sensitivity is similar to that obtained previously with the $\mathrm{NaI}$ crystal. This limit for the germanium detector would increase for boxes containing other isotopes in significant quantities, but it would be superior to the NaI crystal which could not be used to evaluate the $\mathrm{Pu}$.

Our limited comparison study with the germanium and $\mathrm{Nal}$ crystals indicates that the germanium should be considered for future use. Its high resolution gives it the advantage of being able to discrimi $i^{-}$te other isotopes from $P u$ and has essentially the same sensitivity as the $2 x$ 2 in. NaI crystal. A lead shield would have to be made, the directional dependence measured, and the detector sensitivity calculated for sources at various locations in different size boxes similar to those described previously.

\section{Limit of Sensitivity}

For measurements made under various field conditions, the limit of sensitivity for small quantities of $P u$ in a glove box is difficult to establish. The background count in a room containing little $P u$ is about $160 \mathrm{cpm}$ with our counting equipment and an analyzer window set to detect gamma energies between 330 and $430 \mathrm{keV}$. If the count is made in a room which has other glove boxes containing $\mathrm{Pu}$, the background will be higher and variable throughout the room. At any given location, the background will be dependent on the orientation of the lead shield. In the past, we have pointed the lead shield toward a wall to obtain a background count.

The count rate of the NaI detector from our one-gram Pu source at one meter from the source is $\sim 730 \mathrm{cpm}$. If one assumes that a counting rate of twice background is valid, the smallest quantity of $P u$ that can be detected is about 0.2 gram. This assumes ideal counting conditions. In most field applications, it would be difficult to detect 0.2 gram with any degree of confidence. Based on our past experiences, values of $1.0 \mathrm{gram}$ are probably more realistic. 


\title{
Evaluation of Personal Alarm Devices for Firefighters
}

\author{
Jolm Sharry and Rohert A. da Roza
}

Although three of the models of the personal alarm devices (PAD) tested had receivi: letters of acceptability and compliance from the State of California/Occupational Safety and Health Administration (Cal/OSHA), we found that none of the models met all of the Cal/OSHA specifications. Additional tests showed other deficiencies in the PADs' design. This points out the need for the purchaser or user of such devices to specify acceptance criteria and perform his own tests.

\section{Introduction}

The Standards Board of the State of California/Occupational Safety and Health Administration (Cal/OSHA) recently developed and passed a standard that requires firefighters engaged in interior-structure fires use a personal alarm device, or PAD, with a self-contained breathing apparatus (SCBA). The PADs will summon aid in the event of an emergency involving the fircfighter so equipped. The specifications for the PADs are given in the General Industrial Safety Orders from Cal/OSHA (Title 8. General Industry Safety Orders, Artide 10.1). Implementation of these orders was originally scheduled for March 31, 1983, but this was extended to September $30,1983$.

The LLNL Fire Department and Hazards Control's Safety Science Group conducted tests of the four avajlable devices to determine the best device to purchase. The tests determined if the devices complied with the specifications given by Cal/OSHA and also if such a device were useful, i.e., that it accomplish its purpose of aiding rescuer firefighters to find another firefighter who is immobilized (Table 1).

Although three of the models tested had received letters of acceptability and compliance from $\mathrm{Cal} / \mathrm{OSH} A$, our tests showed that none met all of the Cal/OSHA specifications. Also, we revealed other deficiencies in the PADs by some additional tests to which we subjected the units. Our "water-on-the-speaker" test showed that water collected on the diaphragm speakers prevents sound transmission. The "cold-salt-water" test shows how severely some of the units leaked. The "interferring-sounds" test only scratched the surface of this large problem and points out that sound frequency, pulsation rates, and tone changes must be considered as part of a PAD specification. Information gained from a signalattenuation experiment and a field trial show the need for a louder alarm; the $95 \mathrm{dBA}$ alarm was clearly the more desirable alarm.

\section{Results}

At first, we tested four units of each manufacturer's model (Table 2) following the test parameters specified in Table 1. Due to the importance of the water intrusion and $80^{\circ} \mathrm{C}$ tests, a second group of units was purchased and tested; two units were tested in a special oven and all of them were subjected to sea water.

Table 3 summanizes our results, In addition to a pass/fail result, a notation is included to indicate performance. Weak performance means that the unit was emitting an audible sound, but it was below the specified $85 \mathrm{dBA}$. A fail notation without indication of weak performance means that the unit did not emit any sound. We describe specific performance results as against the Cal/OSHA specifications in the following section. 
Table 1. Specifications required by the Cal/OSHA standard and the tests performed to verify PADs.

\author{
Specification (2)(A): \\ Controls shall be incorporated in alarm devices for manual activation and reset, and shall be prolected against accidental \\ deactivation. Such controls shall be designed to be operated by a gloved hand,

\section{Specifieation (2h(B):} \\ Alarm devices shall contrin a motion detector which will activale the alam if the firefighter is motionles for not les than \\ twenty (20) seconds nor more than forty (40) seconds. The alarm shall also include a pre-warning devite to signal the \\ firefighter that the alarm is appraaching the point of attivation.
}

\title{
Specification (3)(A):
}

Alarm devices shaill emit a signal with a sound pressu re level of not less than $85 \mathrm{db}$ me asured at a distance of three (3) melers for not less than one (1) hour using an eighty percen: (809) charged battery. Signal frequengy used shall not be lew than $2000 \mathrm{~Hz}$ nor more than $4000 \mathrm{~Hz}$.

Specification (3)(B):

The alarm shall operate in a temperature range of $-10^{\circ}$ to $80^{\circ} \mathrm{C}$ and for a period of two minutes at $140^{\circ} \mathrm{C}$.

Specification (3)C):

Alarm devices shall be designed to withstand damage created by deterioration of the type ol battery recommended by the n:ziulacturer for use in such devices.

\section{Specification (3)(D):}

Alarm devices shall remain operable alter being submerged in sea water for at least one hour at a depth of two meters. Upan examination, the interior shell shall show no signs of water intrusion or eotrosion. Effective May 12, 1983, this regulation was amended to remove the second senience.

\section{Specification (3)EF:}

Alarm devices shall be impact and shock Jesistant, and shall be designed to remain operable after being dropped six (6) successive times from random positions onto a concrete flanr fram a height of not less than two meters.

Specification (3)(F):

Alarm devices shall not weigh more than 350 grams, including balteries.

\section{Specification (4)(A):}

Alaros devices shall be equipped with a visual or aucible device to indicate when the battery has been discharged to not less than $\mathrm{BO}^{\mathrm{O}}$ percent of its rated capasity.

\section{Discussion}

\section{Spec, (2)(A) Manual Activation}

The switch on the Life Gard Model R-100A hereafter called Life Gard l, did not always function properly when moved gently to the $\mathrm{ON}$ position, but it did when snapped over hard. Manvally activating the Securus S-O-S switch in either the ON or OFF position is difficult, especially with a gloved hand. It must be pressed very hard and held until the alarm starts. The PAL switch was so tricky and difficult to use that the fjrefighters us. ing the PAL asked to have it removed from the tests.

\section{Spec. (2)(B) Motionless Aclivation}

All devices signaled correct warnings after the proper period of stillness by the firefighter. However, a common complaint was that the de-
Table 2. Manufacturer's models tested according to Cal/OSHA specifications.

1. Life Gard Personal Distress Device

Model R-100A

2. Life Gard II Personal Distress Device Model R-200

3. Securus S-0.5 Personal Distress Loctitor Model PDL-3 4. PAL

vice may sound off while the firefighter was moving. After the first warning sound, a sharp rap is needed to keep it from sending the actual alarm. In the lab, the devices were swung on a pendulum with a two-second period, All devices activated themselves while moving thusly, It would be useful to have an engineering standard for defining motionlessness as applied to PADs. 
Table 3. Pass/Fail aummary resuils for the four PADs tested.

\begin{tabular}{|c|c|c|c|c|}
\hline Cal/OSHA Specitlcation & Life Gard & $\begin{array}{l}\text { Uite Gurd } \\
\text { II }\end{array}$ & $\begin{array}{c}\text { Securuit } \\
\text { S-0-S }\end{array}$ & $\operatorname{Pat}$ \\
\hline 2(A) Manusl artivation & $\begin{array}{l}\text { swlich } \\
\text { falled }\end{array}$ & OK & $\begin{array}{l}\text { Hayd to } \\
\text { ase reflipbly }\end{array}$ & $\begin{array}{l}\text { could not itil } \\
\text { position }\end{array}$ \\
\hline 2(b) Motionless activation & OK & OK & OK & OK \\
\hline $\begin{array}{l}\text { अa! Sound tevel } \oplus 22^{\circ} \mathrm{C} \\
\text { Sound frequency } \\
\text { Bottery life }\end{array}$ & $\begin{array}{l}24 \\
2 P \\
P a s s\end{array}$ & $\begin{array}{l}3 P \\
2 P \\
\text { Pas }\end{array}$ & 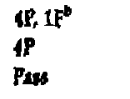 & $\begin{array}{l}2 P, 1 f \\
3 P \\
P 2 s\end{array}$ \\
\hline $\begin{array}{r}3(B) \text { Temperalute }-10^{\circ} \mathrm{C} \\
80^{\circ} \mathrm{C} \\
100^{\circ} \mathrm{C}\end{array}$ & $\begin{array}{l}1 F(W)^{r} \\
2 F(W) \\
1 P\end{array}$ & $\begin{array}{l}3 F(W) \\
2 P, 3 F(W) \\
1 P\end{array}$ & $\begin{array}{l}1 F(W), 3 F \\
3 F(W), 2 F \\
1 P\end{array}$ & $\begin{array}{l}J F(W) \\
\{F(W) \\
\text { IF }\end{array}$ \\
\hline $\begin{array}{l}\text { 3C) Damige by buttery } \\
\text { leskage }\end{array}$ & Eail & Pass & Fail & $P_{243}$ \\
\hline $\begin{array}{l}\text { 3iD) Water intrusion } \\
\text { deionized water } \\
\text { sea ?vater }\end{array}$ & $2 F$ & $\begin{array}{l}2 F, 2 F \\
20 P, 5 F\end{array}$ & $\begin{array}{l}2 P, 2 F \\
6 R, 2 F\end{array}$ & $\begin{array}{l}\text { 4F } \\
2 P, 4 F\end{array}$ \\
\hline अ(E) Inport tesistance & & 39,25 & $2 P_{r} \mathbf{I F}$ & $3 f^{\prime}$ \\
\hline 3(E) Weight & Pass & Pass & Pass & $P$ Pas \\
\hline $\begin{array}{l}\text { 4(A) } 50 \% \text { Baltery capacily } \\
\text { indisator }\end{array}$ & No & Yes & No & No \\
\hline
\end{tabular}

Spec, (3)(A) and (B) Sound Level and

Frequency at Temperatuse of Use

All measurements were made at three meters. Each device was tested for the performance de. scribed in (3)(A) at the three extreme temperatures given in (3)(B) plus room temperature $\left(22^{\circ} \mathrm{C}\right)$.

We assumed that the $-10^{\circ} \mathrm{C}$ temperature simulated the cold soaking of a PAD on the outside of a fire ruck in cold weather and its subsequent use (automatic mode for the PAD). Therefore, after we checked the PADs' operation, we ple. 'd several in a freezel at $-10^{\circ} \mathrm{C}$ for one hour to . will them. Upon removal from the freezer, we sinecked the manual mode (where the firefighter ian signal an alam on his own) and listened for the sound.

The tests at $22^{\circ} \mathrm{C}$ were run for over one hour and then the current drain was measured to estimate the renaining lifetime of an $80 \%$-charged battery. The minimum voltage required to obtain an audible signal was also measused.

The upper end of the temperature range over which a PAD might be used is given as $80^{\circ} \mathrm{C}$. The PAD should produce the signal given in (3)(A) for one hour at $80^{\circ} \mathrm{C}$. Far the test, we turned the switch to its automatic position while at room temperature then set it in an oven preheated to $80^{\circ} \mathrm{C}$. The sound level was checked inmediately and every 15 minutes by opening the oven door. The decrease in sound-pressure level relative to the starting measurement is noted in Table 4.

The U.S. Testing Company, an independent testing agency, had expressed concern that our sound-Jevel measurements with the PADs in an oven might be inaccurate due to reflections from the oven surfaces, We, therefose, designed and built a special oven that could be quickly removed from the PAD whenever a sousnd measurement was made (fig. 1). The results from this new test oven agree well with preyious results from the old test oven. The two tests run with the new oven are the Jast entries shown for Life Gard II and Securus $50 S$ at $80^{\circ} \mathrm{C}$ in Table 4.

The test at $140^{\circ} \mathrm{C}$ simulated a short period of high temperature 10 assess possible damage. We placed a room-teniperalure $P A D$ in an oven preheated to $140^{\circ} \mathrm{C}$ for two minutes. After removing the PAD from the oven, we checked its manual mode of operation.

Table 4 also shows the sound-pressure level at $22^{\circ} \mathrm{C}$ for several units of each make of PAD, A range is given for each unit because the loudness 

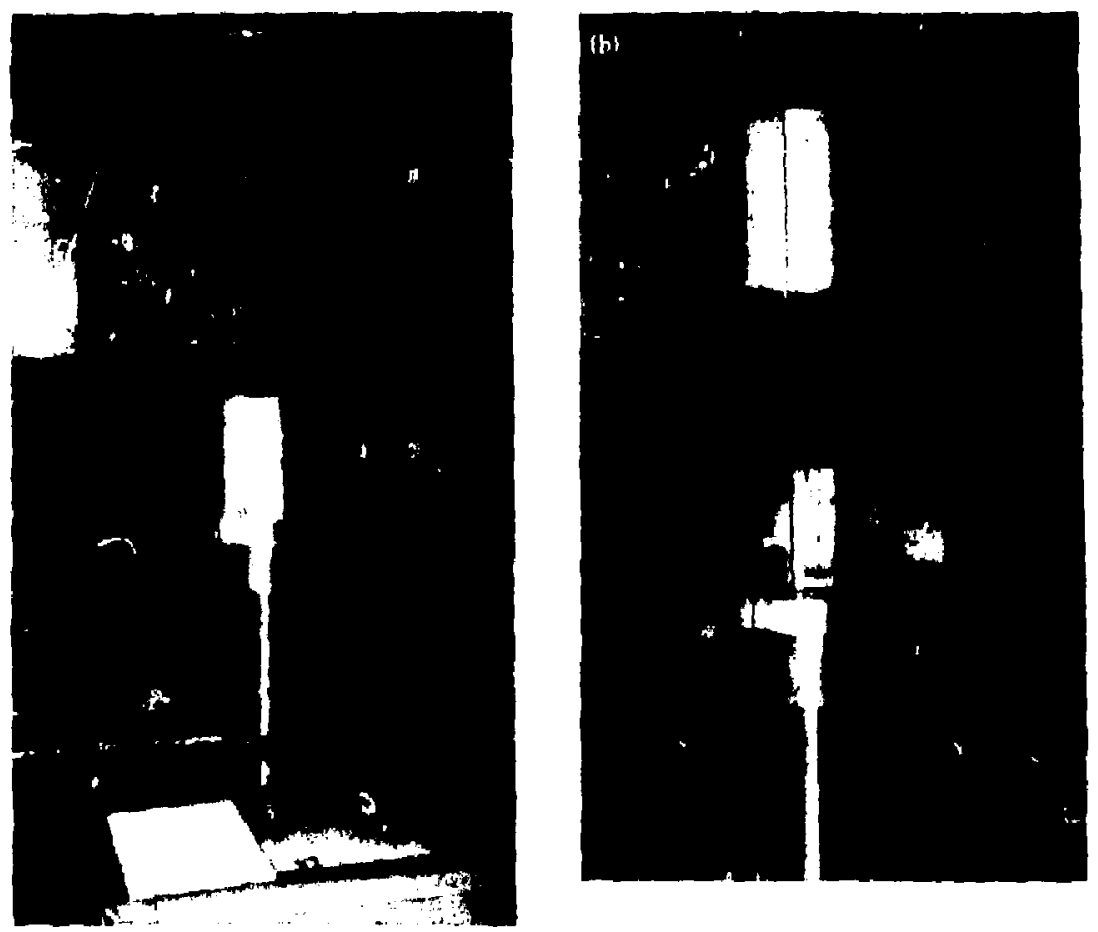

Figure 1. Test oven (a) closed and (b) open, showing PAD.

Table 4. Sound-pressure level and frequency response of the PADs tested.

\begin{tabular}{|c|c|c|c|c|c|c|}
\hline \multirow[b]{2}{*}{ PBD } & \multirow{2}{*}{$\begin{array}{l}\text { Signal } \\
\text { frequenty } \\
\mathrm{db} @ \mathrm{kHz}\end{array}$} & \multicolumn{4}{|c|}{ Sound level at 3 m, dBA slow response } & \multirow{2}{*}{$\begin{array}{c}\text { Pulse } \\
\text { zale } \\
\text { (pulses/s) }\end{array}$} \\
\hline & & $-10^{\circ} \mathrm{C}$ & $22^{\circ} \mathrm{C}$ & $\mathrm{BO} 0^{\circ} \mathrm{C}$ & $140^{\circ} \mathrm{C}$ & \\
\hline \multirow{4}{*}{ Lite Gand I } & & $\operatorname{lP}(W)$ & & $2 \mathrm{~F}$ & IP & 24 \\
\hline & $76 @ 2$ & & $84-85$ & -17.5 & & \\
\hline & $84 @ 4$ & & 85-86 & -11 & & \\
\hline & $76 @$ & & & & & \\
\hline \multirow[t]{6}{*}{ Lift Gard II } & & $3 P(W)$ & & $20,3 \mathrm{~F}$ & IP & 20 \\
\hline & $95 @ 2$ & & $94-96$ & -11.5 & & \\
\hline & $87 @ 4$ & & $94-95$ & -12 & & \\
\hline & & & & -4 & & \\
\hline & & & & -19 & & \\
\hline & & & 94-95 & -10 & & \\
\hline \multirow[t]{6}{*}{ Securus S-0.S } & & $\mathbf{I F}$ & & $5 \mathbf{F}$ & 19 & 1,8 \\
\hline & $61 @ 2$ & $\mathbf{I P}(\mathbf{W})$ & $84-90$ & (2ail, 25 min & & \\
\hline & $90 @ 4$ & & 80-84 & -27 & & \\
\hline & & & $86-90$ & -14 & & \\
\hline & & & 88-89 & fail, $30 \mathrm{~min}$ & & \\
\hline & & & 85.86 & -16 & & \\
\hline \multirow[t]{5}{*}{ PAL } & & $\operatorname{sP}(W)$ & & $4 \mathbf{F}$ & IP & 1.2 \\
\hline & $81 \otimes 2$ & & 81-מด & -5 & & \\
\hline & $88 @ 4$ & & $82-84$ & -12 & & \\
\hline & 7708 & & 82-86 & -10 & & \\
\hline & & & & -5 & & \\
\hline
\end{tabular}


drifted up and down during the two-minute observation. This varying amplitude is in addition to the intentional pulsing of each model. The approximate pulse rate is also given in Table 4. The signal frequencies were measured with an octaband analyzet, so they are rather coarse. Entries of $P(W)$ for the $-10^{\circ} \mathrm{C}$ test meant that the alarm was a jittle weak - no measurements were taken. An entry of $\mathrm{F}$ at $-10^{\circ} \mathrm{C}$ meant that no alarm could be heard. The entries of $\mathrm{F}$ for the $80^{\circ} \mathrm{C}$ test meant that the sound pressure level was below $85 \mathrm{dBA}$ at 3 meters at the end of one hour. The negative numbers indicate in decibels how far it was below its sound level at $22^{\circ} \mathrm{C}$. Only one unit, a Life Gard II, had a sound level above $85 \mathrm{dBA}$ after one haus at $80^{\circ} \mathrm{C}$. Exposing the PADs to a temperature of $140^{\circ} \mathrm{C}$ for 2 minutes had no noticeable effect. They were just as loud afterwards and s: ffered no physical damage.

\section{Spec, (3)(C) Damage by Battery Leakage}

The Life Gard I has a large opening between the battery compartment and the electronics compartment, measuring 4 by $11 \mathrm{~mm}$. The Secunus S-O-S has a long ( 2.5 by $52 \mathrm{~mm}$ ) open slot connecting the two compartments, plus a 6 by $15 \mathrm{~mm}$ opening at one side. The openings in these two devices are large enough so that any corrosive liquids formed by the battery could damage the electronics. The Life Gard II and PAL have small holes in tive compartment divider just large enough for the battery connector wires. Also some sealant is placed where the wires go through the holes. It is unlikely that liquid would go from one compartment to the other.

\section{Spec, (3)(D) Water InIrusion}

The first group of devices we tested were submerged under two meters of deionized water for one hour. Upon removal, they were dried externally, checked for operation, then opened to see any water leakage. We tid not use sea water on this first batch 50 we could save units from being severely damaged. $A$ second group of units was tested by the revised $\mathrm{Cal} / \mathrm{OSHA}$ spec; i.e, sea water was used and nuly operation of the unit after submergence was checked.

The battery in each unit of the first group had been changed at least once before the water intrusion test. All gaskets and seals were inspected before the test to assare that they were as the manufacturer intended. Even though deionized water was used for this group, about half of thase units that leaked never operated properly after being dried out. In the second group of submerged
$P A\left[s_{\text {s, }}\right.$ the cover on the electronics compartment of the Life Gard II was not touched. These were all brand new units. The results of these tests are shown in Table 3.

\section{Spec. (3)(E) Impact Resistance}

Three units of each model were drop-tested except the Life Gard 1. Only two Life Gard I were avaitable and both were inoperable after the water submergence test. The speaker diaphragms were dislodged from one of the Life Gard II units on the fourth drop and the sound stopped after the fifth drop of the other unit. The yellow part of the case broke on the second drop of the Secunis S-O-S unit; the oreak was in an unlikely place and was probably due to a rare flaw in the plastic.

\section{Spec (3)(F) Weight} allowed.

All devices weighed less than the 350 grams

\section{Spec (4)(A) B0\% Battery Capacity Indícator}

For this test, the battery was replaced by a variable voltage de power supply capable of supplying sufficient current to operate the PAD. Only the Life Gard II gave a clear and accurate indication of when the battery was discharged $1080 \%$ of its rated capacity. Its LED flashed brightly until the $80 \%$ voltage was reached then it quit flashing. On the Life Gard I, the LED just fradually decreased in brightness until the battery was aimost dead. On the PAL originally tested, serial number 4027, the LED noticeably dims too soon. Batteries would be replaced too often. More recent PAL units operate like the Life Gard II. The Securus S-O-S has no LED. Below $80 \%$ voltage, it emits a constant tone instend of the pulsing alarm tone to indicate low voltage. How zver, the sound. pressuse level is so low that the tone cannot be heard in a moderately noisy environment.

\section{Specir.l Tests}

To evaluate the usefuiness of the PADs, we aiso evaluated several additional conditions:

(1) We poured a few milliliters of water on the PAD as it lay with its speaker aimed upward. The Life Gard II and Securus S-O-S units, with vibrating tisk speakers, completely str pred producing sound during this test. They recovered as soon as the water was poured off. The two PADs with cone-shaped speakers protected by a thin plastic sheet continued to sound during this test but the sound level was too low to be usefut. 
(2) The PAD was allowed to float in a tub of water, salt, and ice for one and one-half hours at a temperature of $-6^{\circ} \mathrm{C}$. This was actually our first attempt to test the PADS at $-10^{\circ} \mathrm{C}$. None of the PADs worked properly when first removed from this cold bath. When warmed up, the Securus S-O-S worked properly and was dry inside. The other three models had leaked severely resulting in corroded electronics. Even after washing in deionized water and drying thoroughly, none recovered.

(3) A firefighter might encounter noises that would mask the alarm of the PAD or that might sound the same as or similar to a PAD alarm. These two situations could hamper the rescue of an immobile firefighter. In a residential fire, it is very likely that a residential-type smoke detector would be sounding continuously during a fire the national standards on residential smoke detectors are ANSI/UL 217-1979 and ANSI/NFPA 74). The specification for the sound-pressure level is $83 \mathrm{dBA}$ at 10 feet with no mention of sound frequency. We measured the sound-ptessure level and frequency on seven residential smoke detectors. Most smoke-detector alatms were louder than the standard and the sound is almost all in the 2000 and $4000 \mathrm{~Hz}$ frequency range. This is the same frequency range specified for PADs. All gave a continuous signal except the Fisst Alert which had a pulse overlaying a continuous signal. It would be very hard to detect a PAD signal when near asy smoke detector, especially a First Alest.

The signal from the Securus S-O-S was attentuated by $\mathrm{Jl} \mathrm{dBA}$ by an interior stud and plasterboard wall, In a quiet hallway with a background noise level of $58 \mathrm{dBA}$, this is teadily discemable at 10 leet. In a lab with equipment and a operating fume hood, it was barely detectable at 10 feet.

(4) We combined some of these eflects in a field trial in a large equipment penthouse that contained several rooms and contained two boilers, several compressors and many blowers. The sound level in the penthouse varied from $72 \mathrm{~dB} A$ at the entry door to $91 \mathrm{dBA}$ in a far room. The dividing walls were made of sheet metal and all the doors were open An alarming PAD was placed somewhere in the penthouse and an alaming smoke detector, Semhart Smoke Alarm, was placed about in the center of the complex of rooms,

A firefighter using an SCBA enterd the pent: house and searched for the alarming PAD. The PADs emitting an $85 \mathrm{dBA}$ signal could not be heard until the searcher was past the smoke detector and within about 20 feet of the PAD. The PAD emitting a 95 NBA signal could be heard as soon as the searcher entered the penthouse unless the PAD was in the furthest corner. A firefighter on the outside of the penthouse with the outside doors closed did not hear the alarming PAD.

\section{Specific Unit Faults}

\section{Life Gard 1}

- The switch failed to operate properly.

- The sound level was too low at $80^{\circ} \mathrm{C}$.

- It leaked badly and the electronics are not protected from a leaking battery.

- It has no weak battery indicator.

- This unit is not certified to meet Cal/ OSHA specs.

\section{Life Gard II}

- The sound level at $80^{\circ} \mathrm{C}$ was too low on one of the five units tested, slightly low on two units and satisfactory on tw'o units.

- Seven of the nineteen units leaked.

- Two out of three units were damaged in the drop test.

\section{Securus S-0-S}

- The switch is hard to use for the manual ON operation.

- Three out of four units tested would not work at $-10^{\circ} \mathrm{C}$.

- At $80^{\circ} \mathrm{C}$ two units quit alarming after onehalf hour and the other three were too quiet after one hour.

- four out of twelve units failed the water intrusion test, and one out of three failed the impact test.

PAL

- The switch is difficult to use and was disliked during both field testing by the firefighters and lab testing by the experimenters.

- One of three units was a little quiet at $22^{\circ} \mathrm{C}$, and all four tested at $80^{\circ} \mathrm{C}$ were too quiet.

- The battery drain while alarming is twice that of other models.

- Eight out of the ten failed the water intrusion test. 


\section{Conclusions}

It is obvious from ont work that a redesign effort is needed on all devices as well as better design and quality control standards established. While the authors agree with NFPA President Robert Grant's call for such devices (See Fire Command, October 1979), the devices currently on the market do not meet the demands of the fire service and the expenditure of funds on such devices would be a waste. Although each fire department that purchases PADs cannot put their devices through all the Cal/OSHA specification tests, they should do the water-intrusion test at least and return to the vendor all units that fail. The need for such devices is obvious; however, the devices, to serve a useful purpose, must be reliable, easy to use, and sound an alarm of sufficient loudness to be heard in the firefighting environment.

Our test results have been shared with $\mathrm{Cal} /$ OSHA and the PAD manufacturers. It is expected that the manufacturers will make improvements in their products. The results reported here are on units purchased on the open market between May and October, 1983.

\section{Acknowledgments}

The authors wish to acknowledge the assistance of Lab-oratory Technician Beverly Lum who conducted most of the tests, and LLNL Firefighters Wade Diebner, Gary Linney and Dave Galloway who coordinated field testing and served as an advisory committee for the tests. 


\title{
Evaluating Electrical Cables by the LLNL. Ease-of- Ignition Apparatus
}

\author{
H. K, Hasegawa, S. Van Bemmel," and R. White*
}

Using the LLNL Ease-of-lgnition apparatus, we examined three physical characterislics of cables commonly used at LLNL: (1) mass per unit length of cable, (2) the outside diameter, and (3) the percentage of conductor material. We observed trends in tests determining times-to-ignition that larger conductor diameters and ratios of conductor-tooutside diameter have ignition times dependent on the chemical composition of the jacket material.

\section{Intreduction}

Our fuel-load surveys of DOE fusion facilities have identified a variety of wise and cable insulations as dominant potential fuels, In terms of fire perfornance, one very important characteristic of these cables is how resistive they are to ignition. The LLNL Ease-of-Ignition apparatus is a smallscale experiment that tanks materials as a function of their times to ignition. These results also identiry relative ignition energies of materials which can indicate what sources pose ignition threats around such materials. For fire-modeling purposes, ignition information could add a data point for stochastic ignition predictions and initial-firegrowth calculations.

One of the obvious problems with our previous small-scale tests of cables was the wide variation of physical characteristics as well as insulation types, the combination of which made any realistic cornparison of performance impossible. Therefore, we opted to evaluate the individual effects of cable size, geometry, composition, and materials on a matrix of several commonly used cable types. In order to determine changes in performance due to the jacket material or to the conductor configuration (i.e., whether they were multiconductor, stranded, solid, etc,), we identified and tested cable types all the same size but made of different jacket materials. To deternine the effect of cable size alone (diameter, jacket thickness, etc.), we kept the cable material and composition constant but varied the sizes.

\footnotetext{
- Cogswell Collegr San Francisco, Calliomia.
}

\section{Experimental Design}

Since our objective was to establish a correlation between a cable's physical characteristics and its tirne-to-ignition, we identified a matrix of cable types available in several different sizes, Our previous studies identified polyvinylchloride (PVC). Neoprene, and rubber as the most commonly used cable-jacketing materials at LLNL (Table 1). To ensure uniformity of jacket composition for each of the insulating materials, we analyzed chemically the different cable sizes.

\section{Ease-of-Ignition Test Method}

Figures 1 and 2 show the test ?pparatus and related instrumentation. The only sensors used in this series were the thermopile and water temperature thermocouple (abbreviated T.C.). Two parallel vertical specimens, 140 wide and $152 \mathrm{~mm}$ high, face each other at a separation of $53 \mathrm{~mm}$. The facing surfaces of both specimens are exposed to a methane diffusion flame supplied from a multiported burner located below the lower edge of the specimens. The gas flow rate through each of the independently controlled burners is set to $100 \mathrm{ml} / \mathrm{s}$ (12.5 SCFH) of technical-grade methane, producing a heat flux of $3.2 \mathrm{~W} / \mathrm{cm}^{2} \pm 0.2 \mathrm{~W} / \mathrm{cm}^{2}$ from a totz? gas flow of $200 \mathrm{ml} / \mathrm{s} \pm 10 \mathrm{ml} / \mathrm{s}$ (25 SCFH $\pm 1,3$ GCFH) resulting in an energy release of $7 \mathrm{kl} / \mathrm{s}$. The reason for having the two specimens face each other was simulating the reinforcement that would occur in a worst-case fire situation.

The time-tr-ignition is the time at which flame attaches to a specimen surface and when 
Table 1. Commoniy wed coble-jacketing materials at LLNL.

\begin{tabular}{|c|c|c|c|c|c|c|c|c|c|}
\hline Cable & $\begin{array}{l}\text { Jacket) } \\
\text { dlelectric } \\
\text { materials }\end{array}$ & $\begin{array}{l}\text { Jaskel } \\
\text { thicknets } \\
\text { (mit) }\end{array}$ & o.d. & $\begin{array}{l}\text { Mane of } \\
\text { jucket } \\
\text { (g/ent) }\end{array}$ & $\begin{array}{c}\text { Mim of } \\
\text { dielefente } \\
\text { (g/cml }\end{array}$ & $\begin{array}{l}\text { Tokal } \\
\text { able } \\
\text { mam } \\
\text { (g/cm) }\end{array}$ & $\begin{array}{c}\text { No. } \\
\text { of } \\
\text { condurtors }\end{array}$ & $\begin{array}{c}\text { Conductoris) } \\
\text { ize } \\
\text { (mm) }\end{array}$ & $\begin{array}{c}\text { intolation } \\
\text { material }\end{array}$ \\
\hline RG, $213 \mathrm{~A} / \mathrm{U}$ & PVC/PE & 1 & 10 & 0.369 & - & 1.57 & 1 & $=$ & 21.5 \\
\hline RG $598 / U$ & PVCIP.E. & 1.02 & 6 & 0.22 & 0.0925 & 0.56 & 1 & - & 56 \\
\hline RG $58 \mathrm{C} / \mathrm{U}$ & PVC/R,E & 0.14 & 4.95 & 0,14 & 0.05 & 0.38 & 1 & 0.9 & 52 \\
\hline Trlephone cable & PVCIPE & 0.3 & 7,62 & 0.561 & - & 1.37 & 4 & - & 568 \\
\hline $\begin{array}{l}\text { Welding } \\
\text { cable AWG } 6\end{array}$ & Neopretis & 254 & 10.24 & 0.68 & - & 1.94 & 1 & 5.3 & 36 \\
\hline Welding AWG $4 / 0$ & $\begin{array}{l}\text { Neopienel } \\
\text { rubber }\end{array}$ & 3.5 & 23 & 4.195 & - & 14 & 1 & 14 & 29.4 \\
\hline Power cord & $\begin{array}{l}\text { Neoprenef } \\
\text { Neoprent }\end{array}$ & - & 15.2 & 0.135 & $\begin{array}{l}\text { conductor } \\
\text { jacket } \\
0,085\end{array}$ & 0.315 & 4 & - & $\boldsymbol{z}$ \\
\hline Test prod. & $\begin{array}{l}\text { rubberl } \\
\text { rubber }\end{array}$ & 2 & 4.75 & 0.13 & - & 0.20 & $t$ & - & 65 \\
\hline Welding 210 & $\begin{array}{l}\text { nubbetl } \\
\text { nubbers }\end{array}$ & 2,7 & 19.05 & 1.22 & $\rightarrow$ & 7.85 & 1 & 3325 stronds & 20,9 \\
\hline Welding AWG 2 & $\begin{array}{l}\text { rubber/ } \\
\text { rubber }\end{array}$ & 0.3 & 14.2 & 1.07 & - & 4.14 & 1 & 1666 strands & 25.8 \\
\hline Audio coble & $\begin{array}{l}\text { rubber/ } \\
\text { rubber }\end{array}$ & 0.26 & 1.1 & 0.29 & - & 0.76 & 3 & - & 37 \\
\hline
\end{tabular}

the specimen begins to contribute a significant quantity of fuel, as indicated by a rise in voltage of a thermopile. The thermopile consists of a bank of thermocouples located $6.4 \mathrm{~mm}$ above the top edge of each specimen and $6.4 \mathrm{~mm}$ out from the plane of their surface.

\section{Test Specimens}

We tested eight, rectangular cable array samples, 140 wide and $152 \mathrm{~mm}$ high. Two arrays were required for each test, and four replicate tests were conducted. The specially designed specimen holders gripped cable samples at their ends (Fig. 3), and this provided sufficient tension to prevent large deformation of the individual cables due to heating, which ensured reasonable reproducibility among the samples.

\section{Test Procedure}

At the beginning of each test day, cooling water was set to a predetermined flow rate and the hood draft was turned on. Two pieces of noncombustible mitranite were mounted in the test flame. We started the data acquistion system, en:rgized the electrical spark igniter, and opened the gas sojenoid valves. This procedure provided a baseline trace and also brc" oht the cooling water temfera. ture within the range prescribed in our standard. After this initialization, the burners were shut off, the miranite boards were replaced by actual samples, and we started the formal testing.

The time to flame attachment (visual) was noted with an event marker on a strip-chart recorder. Generally, just before the flame attachment was noted, the thermopile voltage increased, indicating the onset of fuel contribution (time-toignition). We took the time to fuel contribution from the recorder trace as the time at which the trace began to rise above the baseline. This was determined by a straight-line projection of the rising part of the thermopile trace back to the baseline. Sroll increases in voltage (less than $10 \%$ of the baseline) were ignored.

We terminated the test three seconds or more after (1) the trace either exceeded the baseline by $30 \%$ or a maximum temperature had been reached. and (2) flame altach ment had occurred. Otherwise, the test ran for 5 minutes. We conducted four tests of each cable type listed in Table 1 .

\section{Results}

We intended to establish a correlation between a cable's physical characteristics and its 


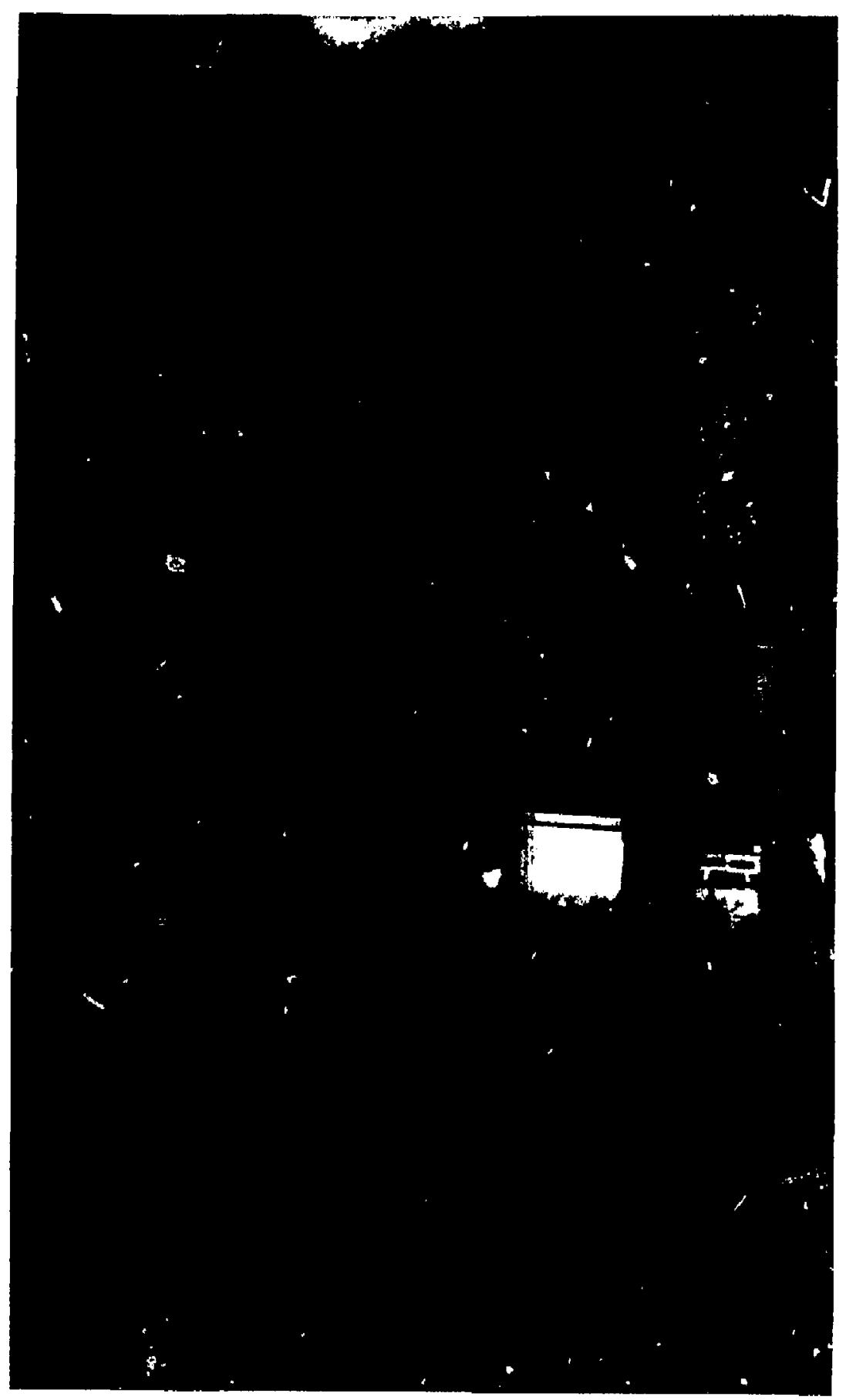

Figure 1. Actual experinental setup of Ease-of-Ignition apparatus. 


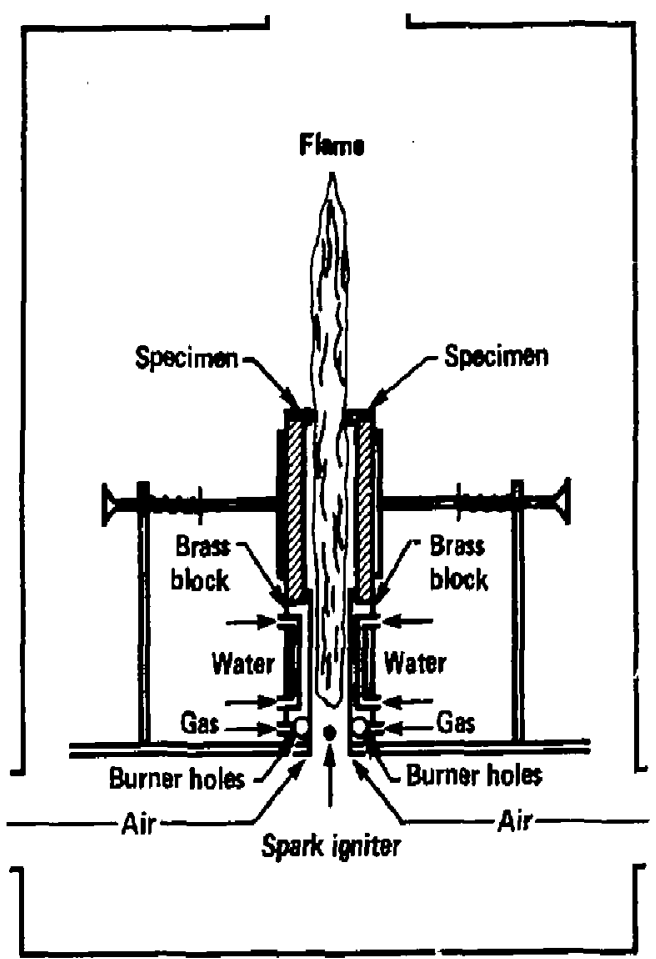

Front view of apparatus

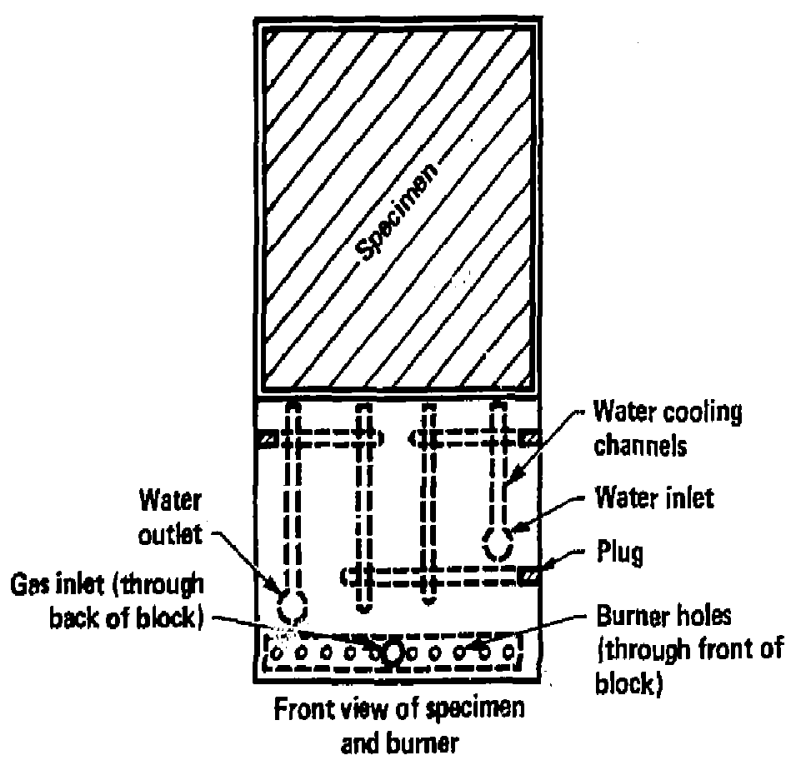

Figure 2. Schematic detailing experimental setup and sampling porls. 


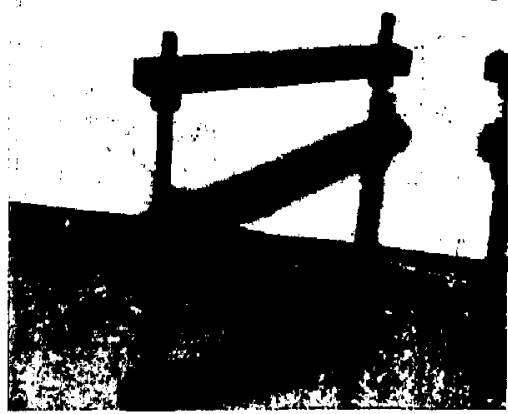

Figure 3. Specially designed speciment holders. time to fuel contribution. We considered the outside diameter, the total mass (grams) per centimeter, and the percentage of insulating material as the cables' physical characteristics. These properties were then plotted against their respective times to fuel contribution. We also determined the change in performance from a single conductor to a multiconductor. PVC, Neoprene, and tubber were analyzed separately, and our conclusions are based on a comparison of the performance of all three materials.

\section{PVC Analysis}

As shown in Fig. 4, the PVC cables tested, with the exception of the multiconductor, were
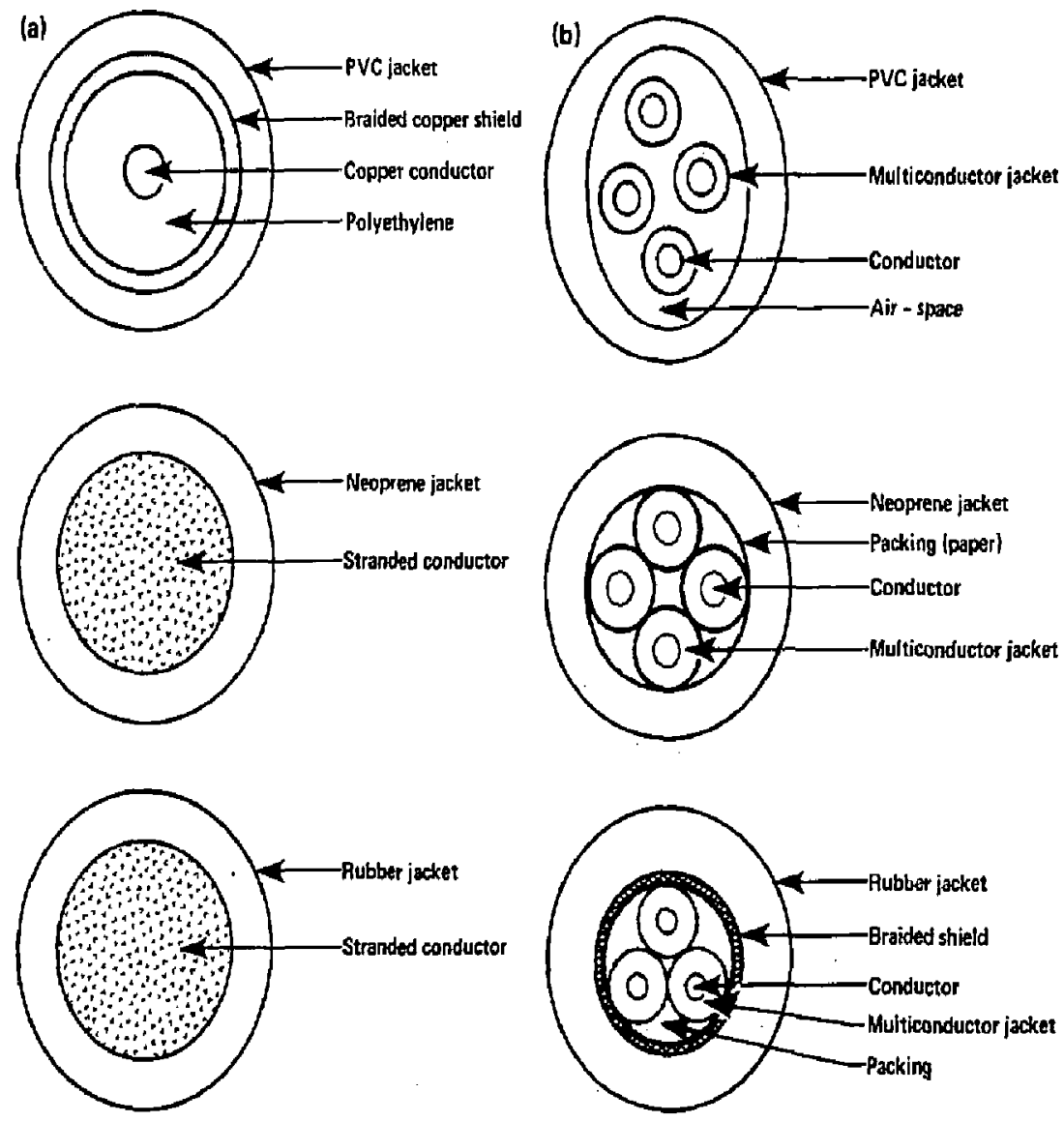

Figure 4. Cross sections of (a) single conductor cables and (b) multiconductor cables. 
coaxial types using polyethylene as the dielectric material, Of the three insulating materials tested, PVC was the only one to exhibit a near linear relationship between its physical characteristics and its time-to-ignition. Figures 5(a) through (c) show the following relationships:

- Decreasing the outside dianneter reduces the time-to-ignition [Fig. 5(a)].

- Although it is not a linear relationship, it appears that decreasing the mass also reduces the time-to-ignition [Fig. 5(b)].

- There is no correlation between the percentage of insulating material and the time-toignition [Fig, $5(c)]$.

Although a larger sample of cables must be evaluated to verify these relationships condusively, our preliminary findings seem logical, based on heat-transfer principles. In order to achieve ignition of cable insulations, they must be heated to their ignition temperature. The greater the mass, the more energy, or in this case, the more time is needed to bring the jacket material to its critical temperature. Conversely, reducing the mass reduces the heating time.

Testing the multiconductor seemed to confirm this relationship between physical characteristics and time-to-ignition. The four conductor telephone cables were loosely wrapped with a PVC jacket which resulted in substantial air space between the outer jacket and the conductors. This elliptical cable had a major axis diameter of $0.76 \mathrm{~cm}$ and a time-to-ignition of $10.75 \mathrm{sec}$. By comparison, the RG $59 \mathrm{~B} / \mathrm{U}$ cable (single conductor) with an outside diameter of $0.6 \mathrm{~cm}$ had a time-to-ignition of $78.75 \mathrm{sec}$. The greatly reduced ignition time for the multiconductor cable can be directly atributed to the air space that allowed the outer jacket material to heat up rapidly (i.e., only the mass of the jacket absorbs the heat as opposed to heating up the jacket and insulator in the coaxial). It appears that we may roughly predict the times-to-ignition of PVC-jacketed coaxial cables with respect to the scale of the Ease-of-Ignition apparatus.

\section{Neoprene Amalysis}

Due to limited availability, only three of the four planned Neoprene-insulated cables were tested and one of these was a multiconductor. Unfortunately, since multiconductors are not plotted, we had to use just two data points. This degraded the quality of our analysis so that we could draw no clear conclusion. However, the two data points shown in Figs. 6(a) and (b) seem to indicate that Neoprene has a time-to-fuel contribution inde-
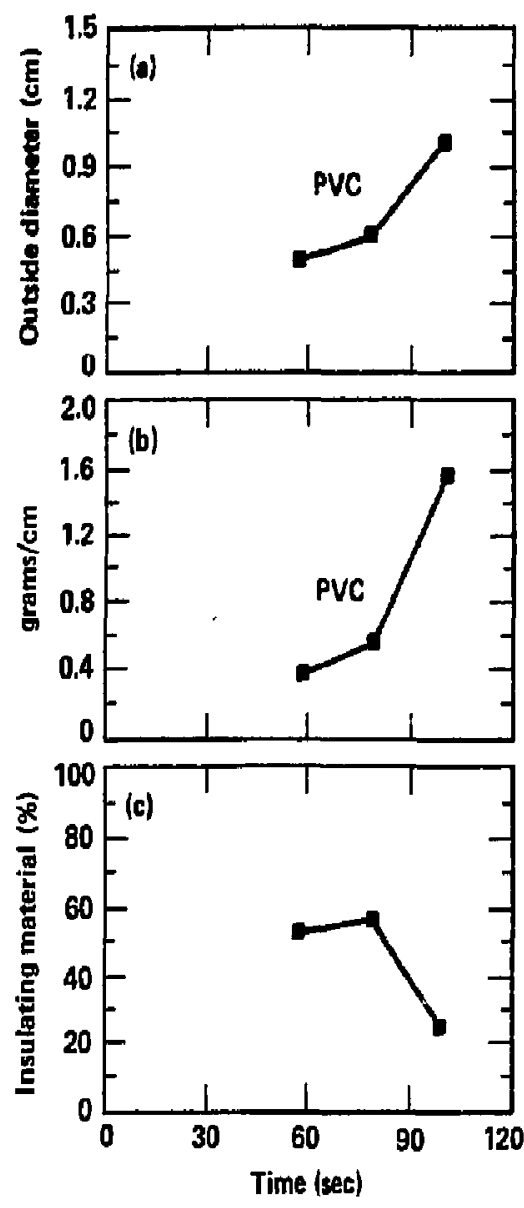

Figure 5. Times to fuel contribution for PVC as a function of (a) decrease in outside diameler, (b) decrease in mass, and (c) percentage of insulating material and the time to ignition.

pendent of the cables' physical properties. Both plots show that cables with vastly different outside diameters and masses had almost identical times-to-jgnition. Yet, Jike PVC, the Jarger diameter Neoprene multiconductor displayed a time-toignition of nearly half that of the single conductor. $47 \mathrm{~s}$ and $85 \mathrm{~s}$, respectively.

This indicates that, in our choice of single conductor cable sizes, we have exceeded a size threshold where the conductor absorbs most of the thermai energy. This makes the ignition time solely dependent on the chemical composition of the jacket. Again, the energy dissipation in the 

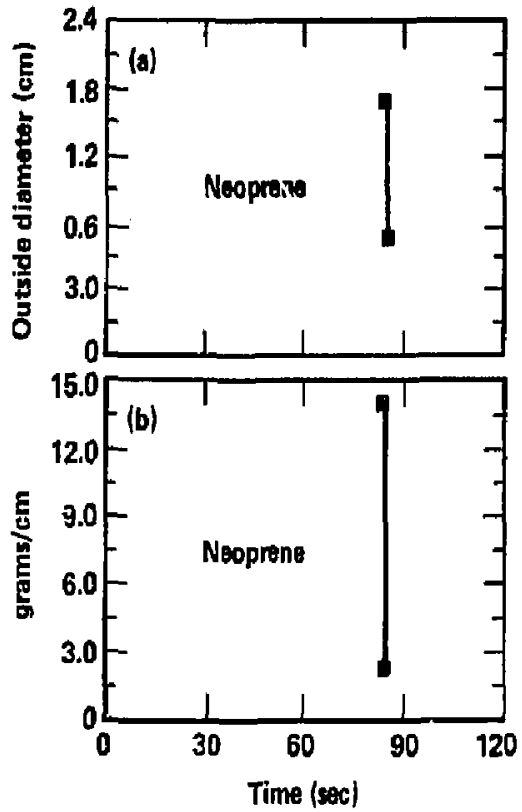

Figure 6. Times to fuel contribution 10 Neoprene showing (a) the outside diameler and (b) decrexsing mass.

multiconductor is not as pronounced as in the single conductor. Further experiments will have to substantiate this hypothesis.

\section{Rubber Anslysis}

Preliminary examination of the rubberinsulated cables shows no correlation between its physical characteristios and the time to fuel contribution [see Figs. 7(a) and (b)]. The AWG 2 cable, with an outside diameter of $1.37 \mathrm{~cm}$, had an average time-to-ignition of $146.35 \mathrm{sec}$, while the larger AWG $2 / 0$ cable, with an outside diameter of $1.9 \mathrm{~cm}$, had an average ignition time of $120 \mathrm{sec}$. Our third data point was an $0.495-\mathrm{cm}$ wire with a short time to fuel contribution of $67.35 \mathrm{sec}$. And like the previous cables, the rubber multiconducductor had a seduced time-to-ignition of $69.4 \mathrm{sec}$.

\section{Conclusions}

Because of the insufficient number of cable sizes for each cable type and the choice of sizes (i.e., not a wide enough spread antong sizes), we cannot say anything definite about the relation- ship between a cable's physical characteristics and its time-to-ignition. However, we have enough information to indicate performance trends that could be applied to a larger and more comprehensive research effort.

It is apparent that the Ease-of-Ignition apparatus, in its present form, cannot be used to proceed with this more comprehensive effort. A major problem is that the fire exposufe fluctuates a great deal because it is a diffusion flame. Since the times to fuel contribution, in most cases, differ by only seconds, the nonuniform exposure can produce illogical and aromalous results. Furthermore, the igntition time is calculated as the average of four runs. If one or more times-to-ignition are extreme, the average time-to-ignition can be very inaccurate. Although we took great pains to ensure uniformity among the specimens before and during testing, it is highly probable that individual cables deformed during the fire. This would change the amount of surface area exposed to the flame, which would alter its time-toignition.

We believe that the combination of the above variables is significant enough to cause the seemingly ilogical results obtained from the rubberjacketed cable tests; the larger and more massive AWG 2/0 cable had a time to fuel contribution $26 \mathrm{sec}$ less than the smaller AWG 2 cable. The following times-to-ignition for each of the burns for

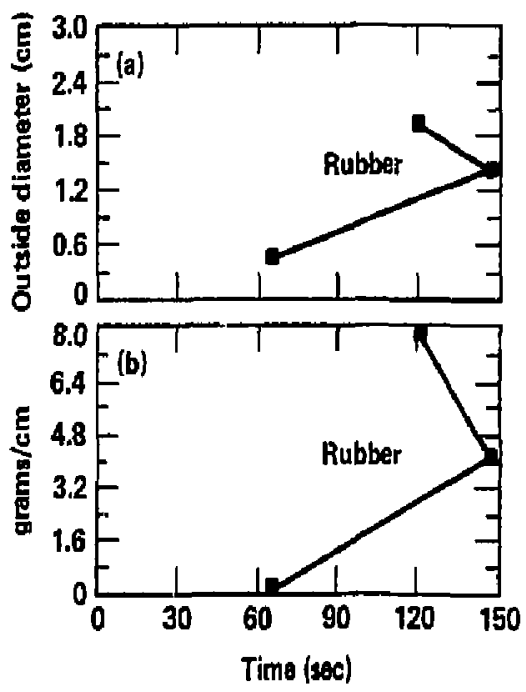

Figure 7. Rubber test result showing (a) increasing outside diameter and (b) decreasing cable mass. 
the two cable types illustrates the wide variation in times:

\begin{tabular}{llr} 
& AWG 2 & AWG 2/0 \\
\hline Bum 1 & $135.0 \mathrm{sec}$ & $95 \mathrm{sec}$ \\
Bum 2 & $119.0 \mathrm{sec}$ & $145 \mathrm{sec}$ \\
Bum 3 & $172.0 \mathrm{sec}$ & $105 \mathrm{sec}$ \\
Burn 4 & $159.4 \mathrm{sec}$ & $135 \mathrm{sec}$ \\
\hline
\end{tabular}

Both sets of data have a spread of about $50 \mathrm{sec}$ from the shortest to the longest time-ta-ignition. Substituting a radiant paral (the same size as a specimen) for one of the specimens and eliminating all existing burner ports except for one under the sample to serve as a pilot flame is a possible improvement. The radiant panel would provide a unilom and steady thermal flux on the specimen and should provide more repraducible results.

Although not proven in this study, we feel that the three major physical characteristics that govern a cable's time-to-ignition are the mass per unit length, the outside diameter, and the percent- age of conductor material. Blased on our results, it appears that cables with a conductor ditsmeter of approximately $0.8 \mathrm{~cm}$ and greater, and a ratio of conductor-to-outside diameter of $60 \%$ or more will have times-to-ignition dependent primarily on the chemical composition of the jacket material. In other words, if the conductor's mass dominates the cable composition, it is as if the jacket material is attached to an infinitely insulating slab. Cables containing smaller conductor sizes will probably perform according to relationships derived from a cable's chemical composition, physical makeup, and physical dimensions, as was indicated by the PVC coaxials we tested in this study. Similarly, PVC four-wire multiconductors would perform accotding to one relationship, triaxials to another, and so on.

After modifications to the Ease-of-Igrition apparatus have been completed, more extensive research should be carried out to confirm or dis. prove the above hypotheses. More runs of each cable type should be done to improve the accsracy of the data and to eliminate or smooth out extremes. 


\section{Zone-Model Correlations with Experimental Enclosure Fires}

\section{N. Alvares and K. Foote}

We are ' 'vveloping risk analyses for fires in enclosures where mathematical models provide the initial conditions of fire damage to facilities at risk. The several models we surveyed for this purpose are zone models that are essentially analytical descriptions of control volumes having uniform properties within defined, time-dependent boundaries. We describe some model-validation studies using our experimental data from FY-82 work. We also include results from FY-83 experiments, showing data for conditions where the fire soutce is moved to different sites in the test cell.

\section{Model-Validation Studies from FY 82}

We compare model output to results from FY. 82 experiments in the LNL fire-test cell, where ventilation rates, fire strengths, and fire-5ource positions were conirolled and changed within the test-cell volume. To date, all experiments have had air introduced at floor level and air extracted in a wall near the ceiling to approximate standard ventilation geometry (Fig. 1). Figures 2(a) and (b) show data from two tests used to validate enclosure-fire models. Both fires are sometwhat ventilation-controlled, as indicated by the hydrocarbon $\left(\mathrm{CH}_{4}\right)$ and carbon monoxide $(\mathrm{CO})$ production. Howe ver, Test $27 \mathrm{~B}$ is much closer to having adequate ventilation because the oxygen consumption and formation of combustion gas reach a constant level; in Test 9A, though, gas data is continuously increasing until the fire is termirated. Also, the shape of the inlet and extraction flow shows a decreasing trend through Test $9 \mathrm{~A}$ that does not appear in Test 27B, indicaling the selative difference in vertilation control between the tests.

Tabie 1 describes characteristics of several enclosure-fire models we are considering for enclosure-fire risk anaiysis, and Table 2 compares experimental results from Tests $9 \mathrm{~A}$ and 278 to model predict.jns at specified times. Each of these models have some parameters that they predict well, and others that appear to be far off target. We wished to gain experience in applying model results to unique conditions and experimental fire variations. To this end, we chose the single-zone model developed by Professor E. E. Zukoski at Califomia Instifute of Technology. This model
(Cal Tech I) is easy to apply and adapt, and it gives reasonable predictions of our experimental results.

\section{Comparison of Models and Test Data}

Figure 3 compures Cal Tech I predictions with oxygen consumption data for Tests $27 \mathrm{~B}$ and $9 \mathrm{~A}$. The shape of these predicted curves are encouraging, but it does not constitute a direct correlation with measured data, i.e., at no time in the modeled $\mathrm{O}_{2}$ consumption would the prediction match real conditions. Cal Tech 1 predicts less available oxyzen than was actually measured for the two tests. Even though this model inaccurately predicts the oxygen concentration, it is still a valuable tool for risk assessment in that it consistently gives a pessimistic prediction.

Figure 4 compares gas-temperature predictions with test data that indicate too low a ternperature rise early on, and too great a rise when the fire approaches equilibrium. This model cones to temperature equilibrium too slowly. Thus, it is not very useful lor predicting gas temperature.

\section{Examples of Results from FY-83 Tests}

FY. 83 experiments locused on the characteristics of room geometry such as ventilation dust locations, fire elevation and position, whereas, the FY-82 work explored the effects of changes in the fire itsell.

Figure 5 shows the floor plan's horizontal fire-source positions for three $\mathrm{FY}-\mathrm{B} 3$ :ests. Here, 
fire output is modified by the proximity of the wall and comer to the fire plume. All these fires were ventilated at 250 liters/sec with a fire strength of $400 \mathrm{~kW}$, and only the horizontal position was changed. Figures 6 (a)-(d) shows $\mathrm{O}_{2}$ depletion and product gases ( $\mathrm{CO}, \mathrm{CO}_{2}$, and $\left.\mathrm{CH}_{4}\right)$ for three tests (11, 2B, and 9). Except for the $\mathrm{CH}_{4}$ curves, the correspondence of the data to the $\mathrm{Cal}$ Tech I model is remarkable, making the task of Trodelers who have good chemistry algorithms much easier. The more interesting $\mathrm{CH}_{4}$ curves probably demonstrate flame-quenching effects of surface proximity, e.g. Test 11 consistently puts out less $\mathrm{CH}_{4}$ than do either Test $2 \mathrm{~B}$ or 9 . Test 9 is quite noisy because of the fire proximity to the extraction duct, which may also be the reason for the greater $\mathrm{CH}_{4}$ production. We believe this increased production is caused by pyrolyzing gases entering the exit duct which stops the hycrocarbon conversion to $\mathrm{CO}$ and $\mathrm{H}_{2} \mathrm{O}$. Note that the discontinuities in the $\mathrm{CH}_{1}$ curves past 1400 sec are due to condensation in the sample lines to the analyzer.

\section{Summary}

In the next fiscal year, we will apply all of the models to our data. We should be able to discern (after enough experience with inodel manipula. tion and data analysis) the correct physical parameters to create "general" adjustments to model algorithms for fires in our enclosures. From these comparisons, we will then select the modeling procedure that can best be employed as the start. ing point of our risk analysis.

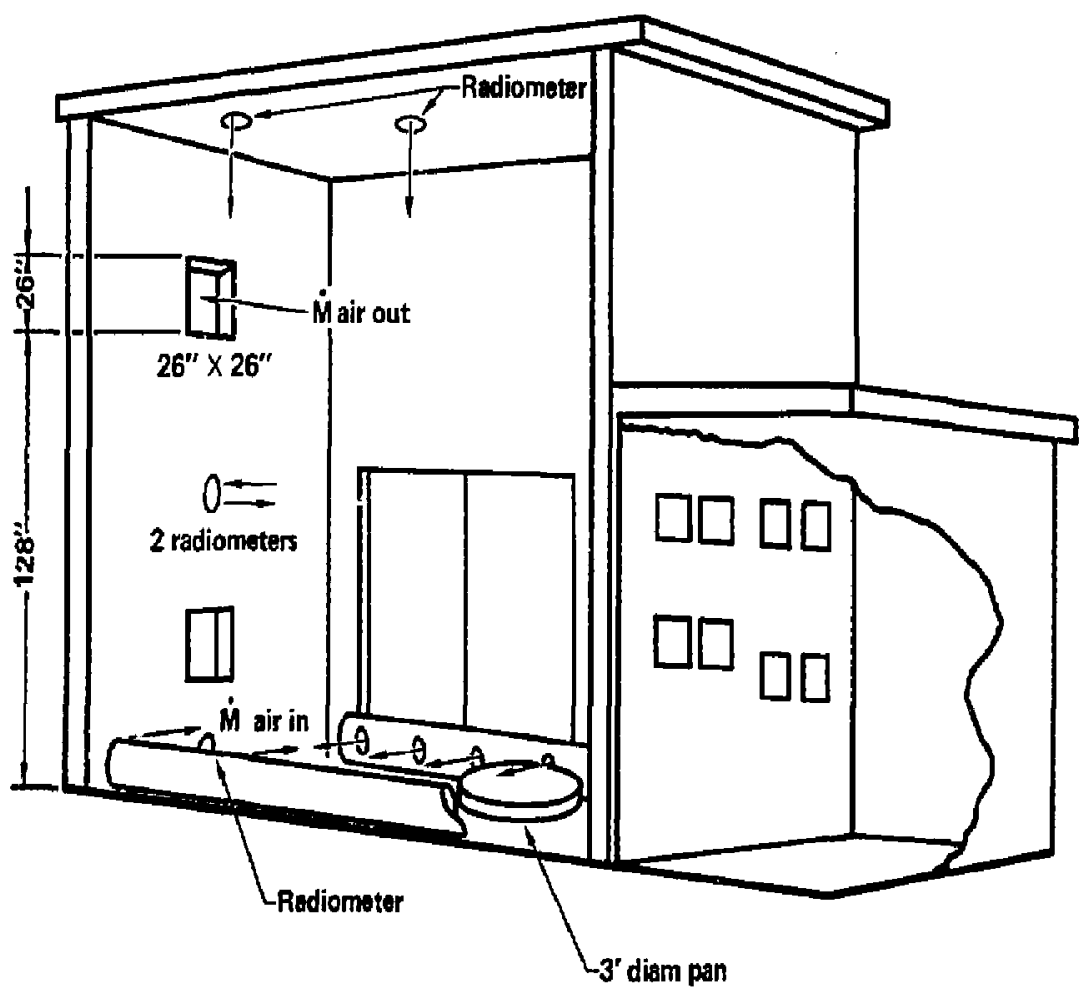

Room dimension $20^{\prime} \mathrm{L} \times 13^{\prime} 6^{\prime \prime} W \times 15^{\prime} \mathrm{H}$ Door dimonsion $7^{\prime} W \times 8^{\prime} \mathrm{H}$

Figure 1. Sextion view of the LLNl fire-test cell. 


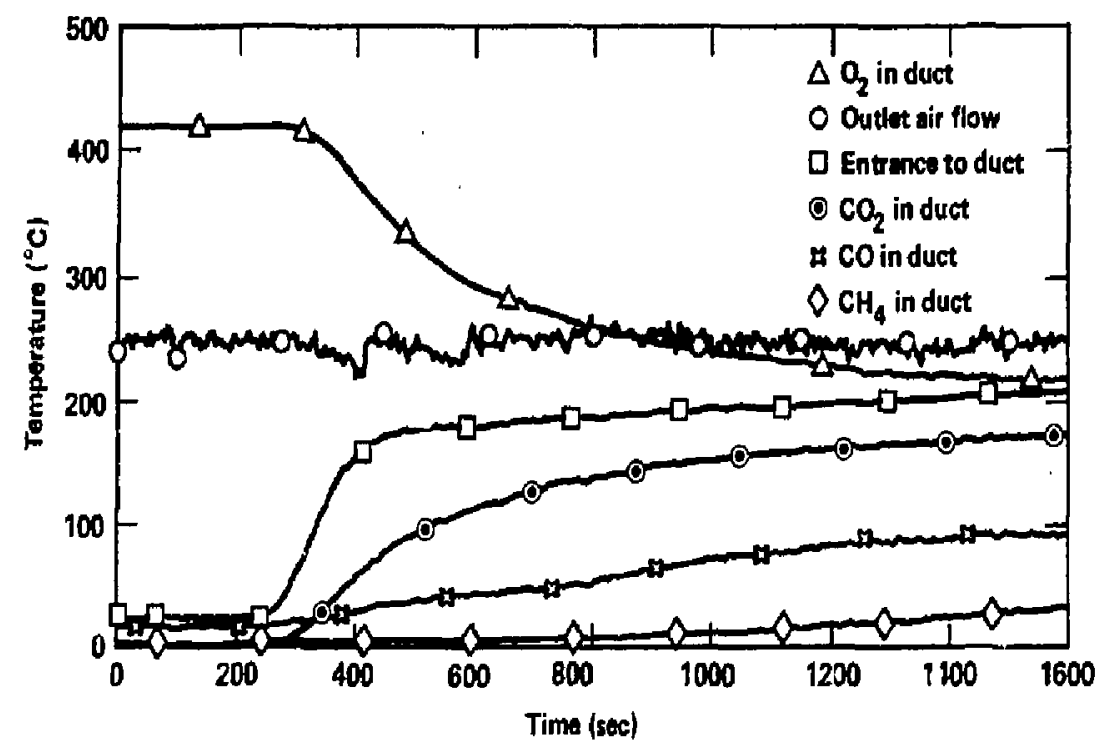

Figure 2(a). Test $27 \mathrm{~B}$ at $\mathbf{4 0 0} \mathrm{kW}$ and 250 liters/sec.

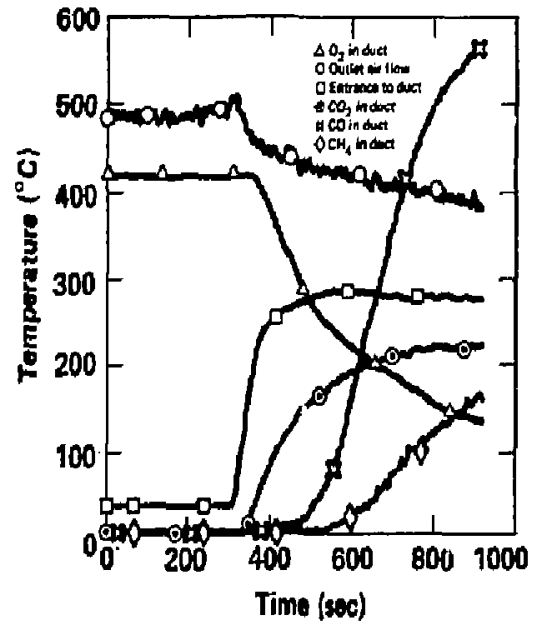

Figure 2(b). Test $9 \mathrm{~A}$ at $800 \mathrm{~kW}$ and 500 liters/sec.

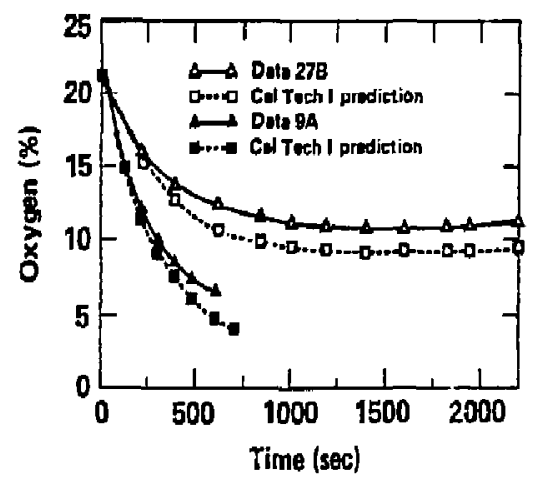

Figure 3. Comparison of Cal Tech I oxygen depletion predictions for Tests $9 \mathrm{~A}$ and $27 \mathrm{~B}$. 
Table 1. Enclonure-fire parameters of the 6 models tested for risk analysis.

\begin{tabular}{|c|c|c|c|c|c|}
\hline Harvard & LANL & PNL & Cal Tech I & Cal Tech II & ILNL \\
\hline Two layer & Two layer & Two laye. & One layjer & Two-loyer & Two-layer \\
\hline Ambient lower & Heated lowet & Ambient lower & No lower & Ambient lower & Ambient lower \\
\hline $\mathrm{O}_{2}$ depletinn & & $\mathrm{O}_{2}$ depletiont & & & \\
\hline Fixed mass & & Fixed mase & & & \\
\hline Multiple rooms & Single room & Single room & Single room & Multíple rooms & Single room \\
\hline Complicated & Crmplieated & Complicated & Simple & Complicated & Simple \\
\hline Large & Large & Large & Small & Large & Small \\
\hline
\end{tabular}

Table 2. Model parameters.

Test 27B

\begin{tabular}{|c|c|c|c|c|c|c|c|}
\hline Parameters & Data & Harvard & Cal Tech I & PNL & LANL & C.l Tech Il & LLNL \\
\hline Time (sec) & 2200 & 2200 & 2200 & 2200 & 1800 & 800 & 300 \\
\hline Ambient temp $\left({ }^{\circ} \mathrm{C}\right)$ & 18 & 18 & 22 & 18 & 18 & 18 & 10 \\
\hline Hol hyer temp $\left({ }^{\circ} \mathrm{C}\right)$ & 252 & 158 & 287 & 222 & 282 & 287 & 287 \\
\hline Cold layer temp $\left({ }^{\circ} \mathrm{C}\right)$ & 136 & 18 & 287 & 18 & 111 & 18 & 18 \\
\hline Wall temp $\left({ }^{\circ} \mathrm{C}\right)$ & - & 123 & 206 & - & - & - & - \\
\hline Heat lnss to wall (kW) & 270 & 15 & 329 & 164 & $\$ 13$ & 320 & 320 \\
\hline Fire sinength (kW) & 330 & 341 & 399 & 259 & 391 & 400 & 400 \\
\hline$O_{2}(\%$ vol $)$ & 11.0 & 6.8 & 9.4 & 11.3 & 9.6 & - & - \\
\hline $\mathrm{CO}_{2}(\%$ vol) & 7.5 & 9.1 & - & 5.4 & 5.9 & - & - \\
\hline $\mathrm{CO}(\%$ vol $)$ & 0.1 & 0.02 & - & 0 & 0.1 & - & - \\
\hline Flow reversal pask (g/sec) & -200 & -210 & -300 & -410 & -210 & 34 & - \\
\hline Time of peak & $15 \mathrm{sec}$ & 2 sec & $20 \mathrm{sec}$ & $20 \sec$ & $20 \mathrm{sec}$ & 30 sec & - \\
\hline
\end{tabular}

Test 9A

\begin{tabular}{|c|c|c|c|c|c|c|c|}
\hline Parumeters & Data & Hervard & Cal Tech I & PNL & LANL & Cal Tech Il & ULNL \\
\hline Time (sec) & 600 & 600 & 600 & 600 & 630 & 800 & 300 \\
\hline Ambient temp ( $\left.{ }^{\circ} \mathrm{C}\right)$ & 34 & 34 & 22 & 34 & 34 & 34 & 34 \\
\hline Hol Jayer temp ( ${ }^{\circ} \mathrm{C}$ ) & 299 & 175 & 351 & 267 & 329 & 304 & 388 \\
\hline Cold layer temp $\left({ }^{\circ} \mathrm{C}\right)$ & 146 & 34 & 351 & 34 & 136 & 34 & 34 \\
\hline Wall temp $\left({ }^{\circ} \mathrm{C}\right)$ & - & 126 & 215 & - & - & - & - \\
\hline Heat loss to wall $(\mathrm{kw})$ & 600 & 231 & 682 & 327 & 629 & 640 & 640 \\
\hline Fire strength (kw) & 700 & 484 & 801 & 556 & 786 & 800 & 800 \\
\hline $\mathrm{O}_{2}(\% \mathrm{vol})$ & 6.5 & 7.6 & 1.0 & 10,8 & 7.9 & - & - \\
\hline $\mathrm{CO}_{7}$ (\% vol) & B.5 & 10.9 & - & 5.7 & 6.8 & - & - \\
\hline CO (\% yol) & 2.8 & 0.03 & - & 0.01 & 0.8 & - & - \\
\hline Flow reversal peak (g/cec) & -420 & -550 & -570 & -180 & -100 & 117 & - \\
\hline Ime of peak & $15 \mathrm{mec}$ & $2 m e$ & $20 \mathrm{sec}$ & $20 \mathrm{sec}$ & $11 \mathrm{sec}$ & 30 sec & - \\
\hline
\end{tabular}




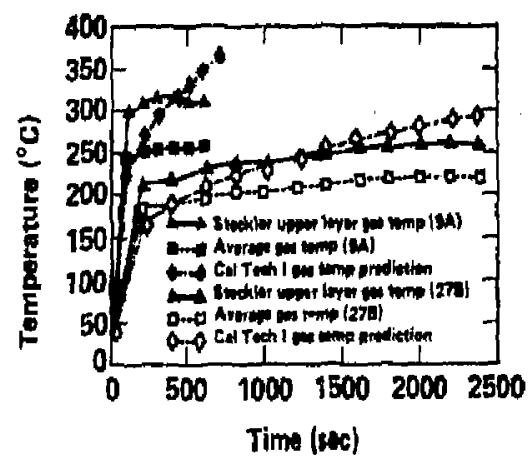

Figure 4. Comparison of Cal Tech I gas: temperature predictions for Teuis $9 \mathrm{~A}$ and $27 \mathrm{~B}$.

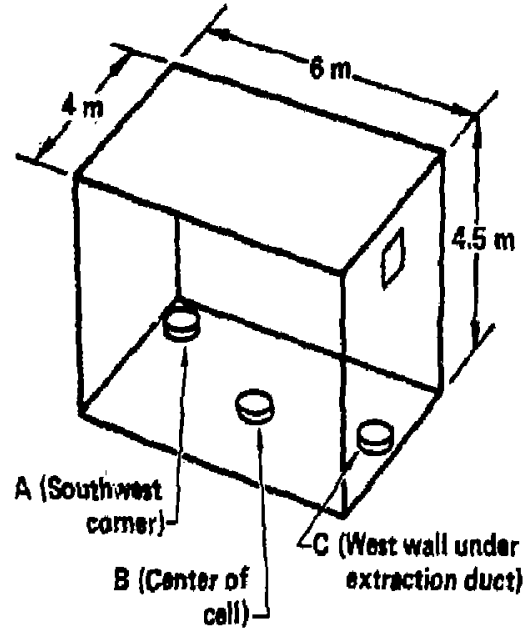

Figure 5. Closeup of fire-test-cell showing floor positions.
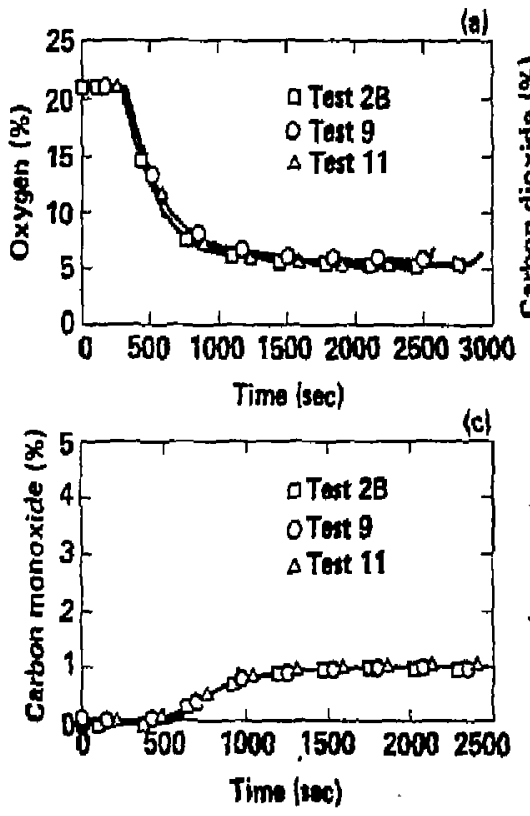

(b)

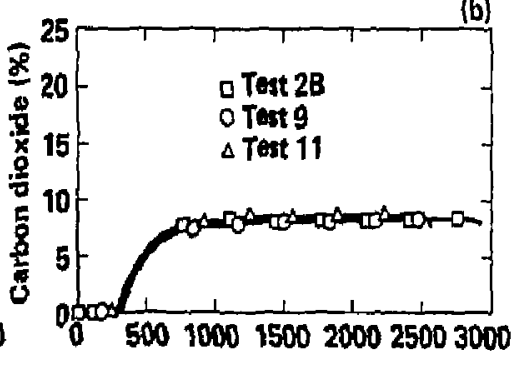

Time (sec)

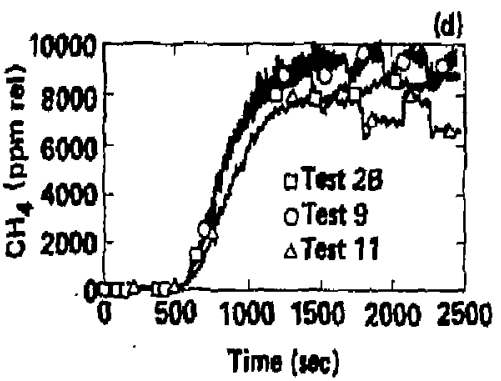

Figure 6. Teats 9, 2B, and 11 showing curves for (a) oxygen, (b) $\mathrm{CO}_{2}$, (c) $\mathrm{CO}$, and (d) $\mathrm{CH}_{4}$. 


\title{
Definition of the Concentration Gradient Above Flammable Liquids
}

\author{
Raficl Muroz-Candelario" and Norman J. Alvares
}

Areas where the potential for spill of flammable fluids is finite are defined as hazardous locations, and are subject to code restrictions regarding location anci protection from polential ignition sources. These locations require a specific separation distance between the potential spill plain and the ignition sources. This distance is universally accepled to be 18 inches for most U.S.A. codes. We found that acceptable separation distances have increased over the years, intuitively in the name of safety, although we found no data to support this. We surveyed the literature and performed experiments to find a quantitative basis for the increasing distances. The literature revealed a case for evaporating fluids with boundary conditions for the volatile vapor diffusing through a stagnant gas film. In containers with open tops, the calculated vapor-concentration gradjents are monotonic and directly proportional to the vapor pressure of the fluid. We confirmed the validity of these calculated values by performing experiments to determine the elevations at which flammable mixtures formed above the surfaces of low-volatility, high-vapor-density liquids.

\section{Introduction}

When the va 1 sity of flammable liquids or gases is greater the air density, released vapors tend to colle, at tight enclosures and in the depressions of honizontal surfaces. For spilled fluids, the concentration gradient above the liquid surface is driven by vapor pressure at the bulk fluid temperature. In a completely closed container, we expect that the partial pressure of flammable gas in air will come to equilibrium with the vapor pressuse at times long pasł the original spill (assuming enough fluid was spilled to provide this concentration). In open containers or in normal rooms with leaks, a concentration gradient is formed above the liquid surface. This gradient is dependent upon the rate of evaporation of the lig. uid and on the geometry and porosity of the container.

Current regulations require that appliances with ignition sources (open flame, sparking devices, glow coils, switches, etc.) be placed with the ignition source at least 18 inches above the potential spill surface.' In the past, this height varied from 61024 inches. We could find no documented reason for these choices of regulation heights. Therefore, to establish a technical basis for defin.

; University of Ruerto Rico at Mayaguez, Puerto Rlco. ing a "safe" height, we believed a quantitative investigation was necessary, including analytical and theoretical analysis of gradient formation.

A proper perspective of the wide range of practical situations requiring an adequate understanding of this problem can be gained from a brief review of the literature. Baum and Rockett ${ }^{2}$ developed equations to predict the vapor concentration of spilled volatile materials assumed to lie at the bottoms of container-ship holds. Wing did an equivalent study of accidental releases of toxic vapors in nuclear-reacior control tooms. ${ }^{3}$ Foerster et al. analyzed the formation of explosive gasoline-vapor clouds after major spills in road tunnels. Theoretical studies have also been made by Georgakis ${ }^{5}$ on the development and decay of liquid-fuel spills in large tankers, and by Zeman ${ }^{6}$ on the dynamics and modeling of heavier-than-air releases of cold gas. McKay and Matsugu measured wind-induced evaporation rates of liquid hydrocarbon spills on land and water, and developed equations to predict such rates.?

The most fundamental and comprehensive study on fuel and hydrocarbon vaporization was reported by Gauss in $1973^{8}$ Starting from the basic diffusional equations for steady. and unsteady-state vaporization, and using experimental data on evaporation from flat disks under low-velocity winds, Gauss developed a semiempirical expression to predict evaporation rates 
of pure liquid hydrocarbons over a wide range of conditions. Analyses of the flammable envelopes sursounding pools of pure hydrocarboss and otner fuels were also performed.

We found no experimental or theoretical study on the determination of the concentration of heavier-than-air vapors above the surfaces of lowvolatility liquids in the absence of convection currents. The work reported below was aimed at defining the fundamental mechanisms goveming such evaporation processes and at developing methods to estimate possible hazardous concentrations.

\section{Applicable Theory}

The rates at which pure liquids vaporize depend on factors such as air velocity across the liquid surface, air and liquid temperature, liquid vapor pressure and mass diffusivity, and geometry factors. If the air above the surface of the liquid is stagnant, evaporation occurs solely by mulecular diffusion. The driving force for this process is the difference between vapor concentration at the gas-liquid interface and at other points in the gas column in the direction of tiansport. Assuming an isothermal environment, conditions at the interface correspond to equilibrium. The partial pressure of the evaporating substance is therefore equal to its vapor pressure at the temperature involved. The equilibrium vapor concentration at the liquid surface is then a function only of temperature, since this in turn fixes the vapor pre:sure.

The diffusional equations have been solved for the simple case of a liquid in a container with an open top vaporiziıg into air. The liquid surface is totally bounded by the walls of the container, allowing diffusion to occur in only the vertical direction. The liquid level is maintained at constant temperakure and pressure, and we assume the vapor and air form an ideal-gas mixture.

Bird, Steward and Lighfoot discuss this specific evaporation problem and present solutions to the applicable diffusional equations for both unsteady- and steady-state conditions. ${ }^{9}$ For the case of steady-state diffusion in the system shown in $\mathrm{Fig}, 1$, concentration profiles in the gas phase are determined by solution of the molar flux equation:

$N_{A Z}=-C D_{A B} \frac{\partial X_{A}}{\partial Z}+X_{A}\left(N_{A Z}+N_{B Z}\right)$,

where $N_{A Z} N_{B Z}=$ molar fluxes with respect to fixed axis,

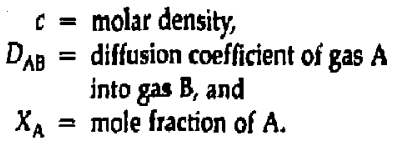

For $A$ vaporizing into $B, N_{B Z}=0$, and Eq. (1) reduces to

$N_{A Z}=-\frac{C D_{A B}}{1-X_{A}} \frac{\partial X_{A}}{\partial Z}$.

for the limit, $\Delta Z \rightarrow 0$, and sleady-state conditions,

$-\frac{d N_{A 2}}{d ?}=0$

Substituting Eq. (2) into (3) gives

$\frac{d}{d Z}\left(\frac{C D_{A B}}{1-X_{\Lambda}} \frac{d X_{\Lambda}}{d Z}\right)=0$.

For ideal gases at constant pressure and temperature, $c$ is constant and $D_{A B}$ is very close to constant, giving a second-order equation for concentration profiles in terms of $X_{A}$ :

$\frac{\mathrm{d}}{\mathrm{d} Z}\left(\frac{1}{1-\mathrm{X}_{A}} \frac{\mathrm{dX}}{\mathrm{d} Z}\right)=0$. file is

The solution of Eq, (5) for concentration pro-

$\frac{1-X_{A}}{1-X_{A 0}}=\left(\frac{1-X_{A 2}}{1-X_{A 0}}\right)^{Z-z_{0}} \frac{z_{2}-z_{01}}{1}$.

The subscripts 0 and 2 in Eq. (6) refer to the elevations at the surface of the liquid and the top of the enclosure, respectively. If the stagnant air colimn is assumed to be infinitely high, the value of $X_{A 2}$ is zero. Taking the datum plane for the elevations right at the liquid surface makes the value for $Z_{0}$ also zero, and the equation simplifies to the following form:

$\left(\frac{1-X_{A}}{1-X_{A 0}}\right)=\left(\frac{1}{1-X_{A 0}}\right)^{2 / Z_{2}}$

This pemits calculation of the gas-phase concentration as a function of fractional height above the liquid's surface for long enclosures of known height. The equilibrium gas-phase concentration for $\mathrm{Eq}$. (7) can be calculated from the vapor pressure of the liquid at the temperature of the system. 


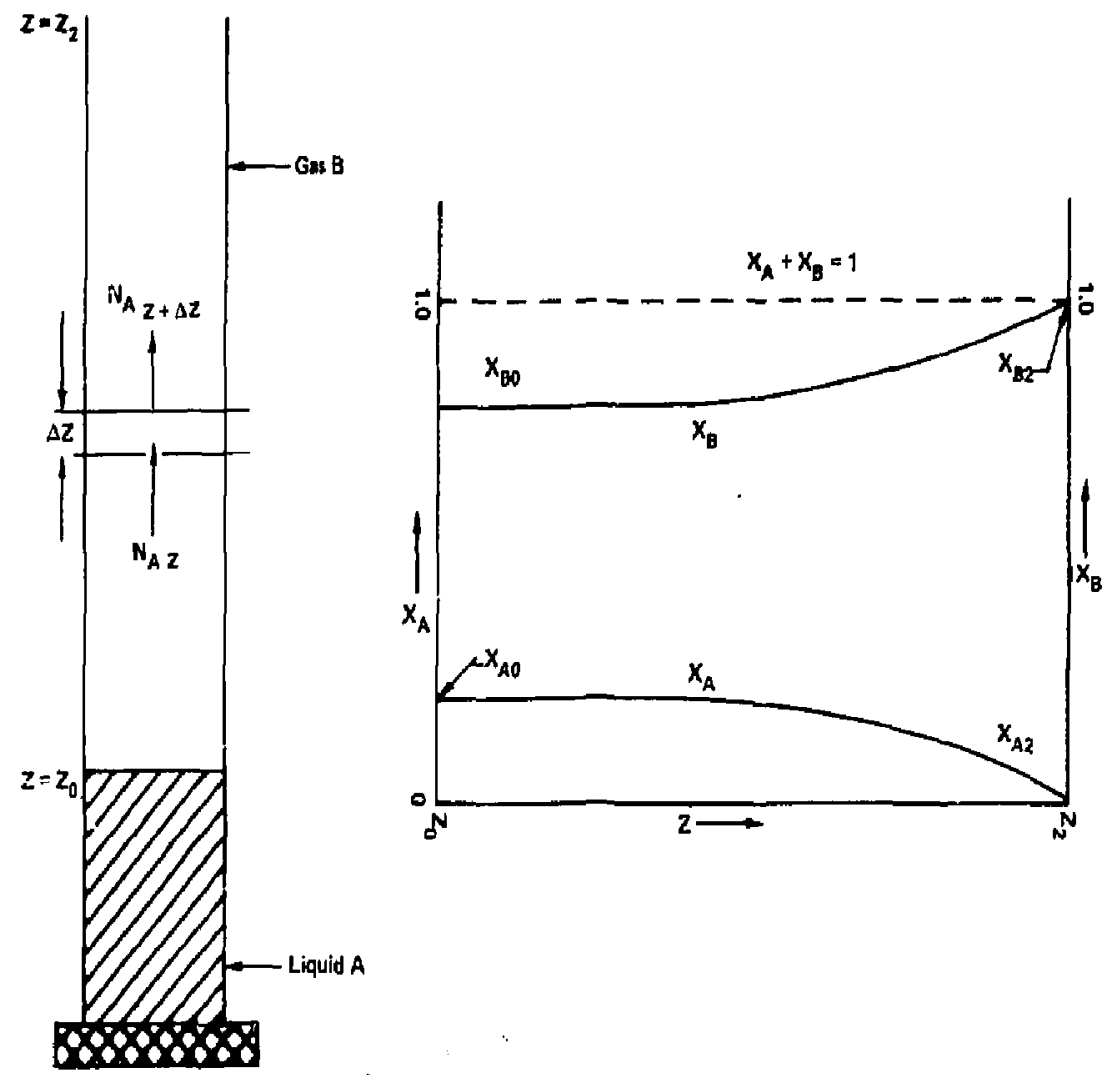

Figure 1. Diffusiun of $A$ through $B$ in steady state with B not in motion. Graph sl :ws how concentration profile for $B$ is distorred because of diffusion of $A$.

\section{Procedure and Results}

Our work was aimed at confirming the applicability of Eq. (3) for predicting the concentration of heavier-than-air vapors above the surfaces of low-volatility, flammable liquids. Rather than attempling to measure the concestrations at different heights, our approach was to determine only those heights corresponding to the lower Dammable limit (LFL) of the vapors. The values obtained in this wing were compared with the heights predicted by Eq. (3).
We used long, open-ended glass tubes of different diameters as enclosures, then immetsed the lower portions of the tubes in a vessel of water. The setup was placed in a large, closed chamber to eliminate convection currents and to provide serni-isothermal conditions.

The liquids tested were hydrocarbons immiscible with water. We then pipetted the hydrocarbons into the tubes to form a floating layer on the water surface. We calculated the time when the steady-state concentration gradient would be established in the tube. ${ }^{10}$ After the predetermined 
time had elapsed, we measured the LFL height using a very-small-capacitance spark probe inserted into the gas column from the top of the tube. Figure 2 shows this apparatus.

Table 1 lists experimental parameters for this series, In all experiments, the liquids were within 1 degree $C$ of the ambient air temperatures in the experinental chamber.

Table 2 summarizes our experimental data and results. Values of fractional height above the liquid suriace (corresponding to the LFL) are presented and compared with corresponding values predicted by theory. These were obtained from

Table 1. Experimental parameters.

\begin{tabular}{|c|c|}
\hline Parameter & \\
\hline Tube inner dizineters & $1.05,2.2$, and $10.3 \mathrm{~cm}$ \\
\hline $\begin{array}{l}\text { Tube lengths above the } \\
\text { liquid surface }\end{array}$ & 25 to $35.7 \mathrm{~cm}$ \\
\hline Hydrocarbans under tests & noragl heplane and octane \\
\hline Liquid temperatures & room $\left(20^{\circ} \mathrm{C}\right.$ to $\left.24^{\circ} \mathrm{C}\right)$ \\
\hline Diameter of the spark probe & $2 \mathrm{~mm}$ \\
\hline
\end{tabular}

Figs, 2 and 3 for n-heptane and n-octane, respectively.

\section{Conclusions}

Our results show that the concentration pro. files of low-volatility liquids vaporizing into stagnant atmospheres can be clasely approximated by the basic diffusional equation for steady-state vaporization. The data presented in Table 2 show good agreement between the observed and the calculated concentrations at LFL: within $4.4 \%$ in the $n$-heptane experiments, and within $10.7 \%$ in the n-octane experiment. This is remarkably good, considering that experimental deviations did not permit attaining true equilibrium at the gas-liquid interface. Small convection currents may have been generated by temperaturs variations between the gas and liquid.

Some of the tests described in Table 2 involved determining the position of the lower flammable concentrations near the walls of the large-diameter tube rather thar at its center. This was done to tstablish if radial concentration gradients occurred in addition to the expected vertical ones. The possibility of iduizl gradients arises because, at the wall, the rate of evaporation is zero,

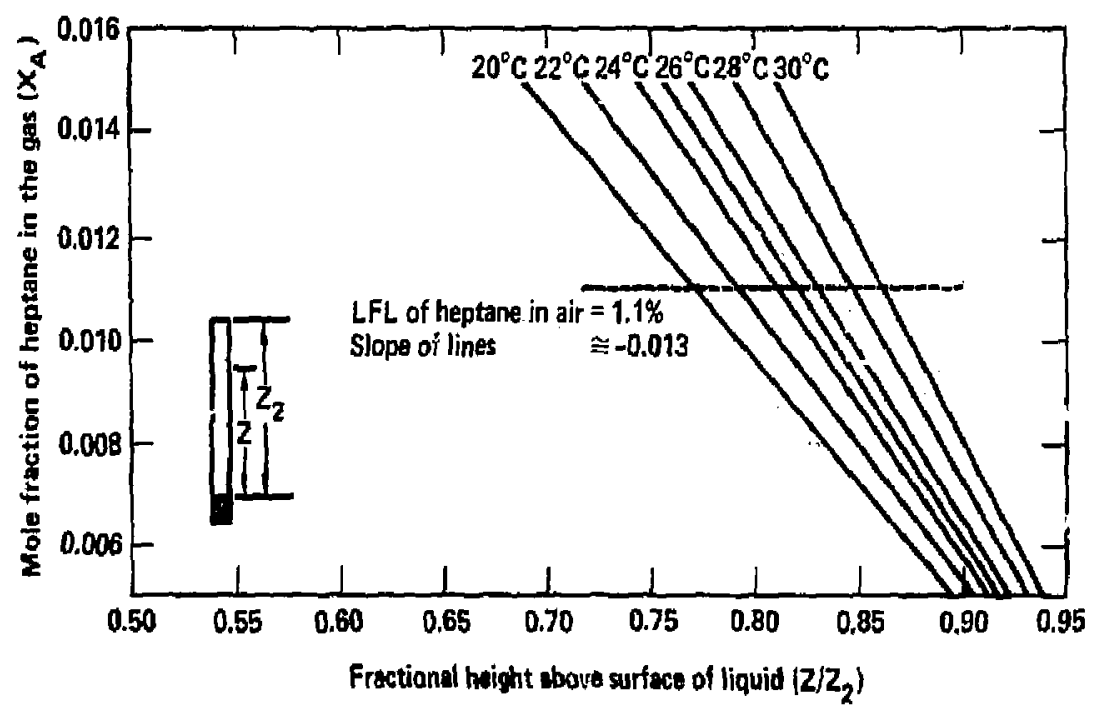

Figure 2. Change in concenteation of hegtane vapars with fractional height above surface of liquid. 
Table 2. Experimental data and results.

\begin{tabular}{|c|c|c|c|c|c|c|c|c|c|c|c|c|c|c|c|c|c|c|c|}
\hline Run & $\mathbf{1}$ & 2 & 3 & 4 & 5 & 6 & 7 & B & $=$ & 10 & 11 & 12 & 13 & 14 & 15 & 16 & 17 & 18 & $1 \%$ \\
\hline $\begin{array}{l}\text { Tube f.d. (em) } \\
\text { Hydro-carbon }\end{array}$ & $\begin{array}{l}1.05 \\
\text { normal } \\
\text { heplane } \\
\left(n C_{7}\right)\end{array}$ & $\begin{array}{l}1.05 \\
\mathrm{nC}_{7}\end{array}$ & $\begin{array}{l}1.05 \\
\pi C_{\pi}\end{array}$ & $\begin{array}{l}10.3 \\
\mathrm{nC}_{7}\end{array}$ & $\begin{array}{l}10.3 \\
\mathrm{nC}_{7}\end{array}$ & $\begin{array}{l}10.3 \\
n C_{7}\end{array}$ & $\begin{array}{l}10.3 \\
\mathrm{nC}_{7}\end{array}$ & $\begin{array}{l}10.3 \\
n C_{7}\end{array}$ & $\begin{array}{l}10.3 \\
\mathrm{nC}_{7}\end{array}$ & $\begin{array}{l}10.3 \\
n C_{7}\end{array}$ & $\begin{array}{l}10.3 \\
\mathrm{nC} \text {, }\end{array}$ & $\begin{array}{l}2.2 \\
\text { normal } \\
\text { octane } \\
\text { (nC) }\end{array}$ & $\begin{array}{l}1.05 \\
\mathrm{HC}_{8}\end{array}$ & $\begin{array}{l}22 \\
\mathrm{nC}_{\mathrm{n}}\end{array}$ & $\begin{array}{l}10.3 \\
\pi C_{8}\end{array}$ & $\begin{array}{l}10.3 \\
n C_{8}\end{array}$ & $\begin{array}{l}10.3 \\
\mathrm{nc}_{6}\end{array}$ & $\begin{array}{l}10.3 \\
n c_{0}\end{array}$ & $\begin{array}{l}1.05 \\
\mathrm{nc}_{\mathrm{b}}\end{array}$ \\
\hline${ }^{T}$ Liquid $\left({ }^{\circ} \mathrm{C}\right)$ & 21 & 22 & 20.5 & 21 & 21 & 20 & 19 & 19 & 20 & 20 & 20 & 22 & 22 & 21 & 21 & 21 & $2 x$ & 24 & 24 \\
\hline $\begin{array}{l}\text { Tyapor ('C) } \\
\text { Tube height } \\
\text { lbove Iiquild } \\
\text { surface cm } \\
\text { (Z2) }\end{array}$ & 35.4 & 22 & 21 & 21 & 23 & 21 & 21 & 21 & 21 & 22 & 22 & 22 & 22 & 22 & 21 & 14 & 27 & 24 & 24 \\
\hline $\begin{array}{l}\text { Height where } \\
\text { flaming } \\
\text { occurred (an) } \\
\text { (2) }\end{array}$ & & & & & & & & & & & & & & 87 & & & & & \\
\hline $\begin{array}{l}(2) \\
Z / Z_{2} \\
\text { (oberved) } \\
Z / Z_{2}\end{array}$ & 0.782 & 0.788 & $\begin{array}{l}27.1 \\
0.759\end{array}$ & $\begin{array}{l}18.4 \\
0.736\end{array}$ & $\begin{array}{l}18.8 \\
0.752\end{array}$ & $\begin{array}{l}18.6 \\
0.744\end{array}$ & 0.700 & $\begin{array}{l}17.7 \\
0.708\end{array}$ & $\begin{array}{l}18.3 \\
0.732\end{array}$ & $\begin{array}{l}17.8 \\
0.712\end{array}$ & $\begin{array}{l}18.1 \\
0.724\end{array}$ & 0.388 & $\begin{array}{l}8.3 \\
0.332\end{array}$ & $\begin{array}{l}8.7 \\
0.34 B\end{array}$ & $\begin{array}{l}8.2 \\
0.306\end{array}$ & $\begin{array}{l}8.2 \\
0.306\end{array}$ & $\begin{array}{l}8.5 \\
0.317\end{array}$ & $\begin{array}{l}11.2 \\
0.404\end{array}$ & $\begin{array}{l}9.0 \\
0.360\end{array}$ \\
\hline $\begin{array}{l}\text { (theoretical) } \\
\text { \% deviation } \\
\text { from theory }\end{array}$ & 0.782 & $\begin{array}{r}0.793 \\
-0.6\end{array}$ & $\begin{array}{l}0.776 \\
-22\end{array}$ & -5.9 & $\begin{array}{r}0.782 \\
-3.8\end{array}$ & $\begin{array}{l}0.770 \\
-3.4\end{array}$ & $\begin{array}{l}0.760 \\
-7.9\end{array}$ & $\begin{array}{l}0.760 \\
-6.8\end{array}$ & $\begin{array}{l}0.770 \\
-4.9\end{array}$ & $\begin{array}{l}0.770 \\
-7.5\end{array}$ & $\begin{array}{l}0.770 \\
-6.0\end{array}$ & 0.390 & $\begin{array}{l}0.390 \\
-14.9\end{array}$ & $\begin{array}{l}0.352 \\
-1.1\end{array}$ & $\begin{array}{l}0.352 \\
-13.0\end{array}$ & $\begin{array}{l}\mathbf{0 . 3 5 2} \\
-13.0\end{array}$ & $\begin{array}{r}0.352 \\
-9.9\end{array}$ & $\begin{array}{l}0.460 \\
-12.1\end{array}$ & $\begin{array}{l}0.460 \\
-21.8\end{array}$ \\
\hline $\begin{array}{l}\text { Sparker } \\
\text { posittion }\end{array}$ & & center o & of tube & & & 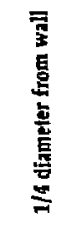 & 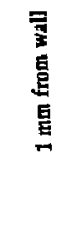 & 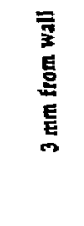 & 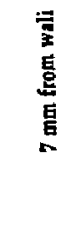 & $\begin{array}{l}\bar{Z} \\
\text { E } \\
\text { E } \\
\text { E }\end{array}$ & & & center o & of tube & & & 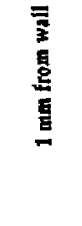 & center o & of tube \\
\hline
\end{tabular}




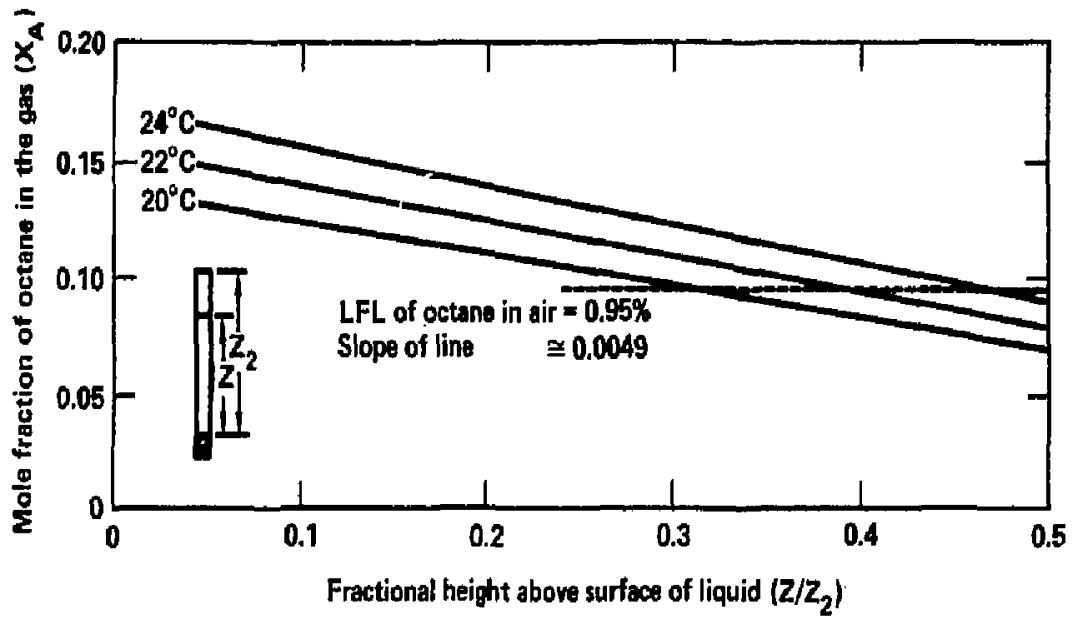

Figure 3. Change in concentration of octape vapors with fractional height above sarface of liquid.

and it increases toward the center. We were unable to provide conclusive evidence for either the presence or absence of radial gradients.

We note that the density gradient in the gas column above the surface of the liquids appears monotonic from bottom to top, as predicted by Eq. (6) and shown in Figs. 2 and 3. However, stratification, or gravity settling of the vapors heavier than air, may be indicated by the negative deviation between calculated and experimental data, especially apparent in the n-octane results.

\section{References}

1. National Electric Code, NFPA 70, Chapter 5, 1983.

2. Howard Baum and John Rockett, An Investigation of the Forced Ventilation in Containership Holds, U.S. Department of Commerce, NBSIR 83-2665 (1983).

3. James Wing, Toxic Vapor Concentrations in the Control Room Following a Postulated Accidental Release, U.S. Nuclear Regulatory Commission, Washington, D.C. (1979).

4. H. Foester, H. Kraemer, and G. Schoen "Dispersion of Gasoline in Road Tunnels Af- ter Release of Major Quantities," Heavy-Gas Risk Assessment Symposium Proceedings, edited by Hartwig Sylvius, Reidel, Neith. (1980).

5. C. Georgakis, J. Congalidis, and G. Williams, "Model for Non-Instantaneous LNG and Gasoline Spills," Fuel 58, 113 (1979).

6. Otto Zeman, "The Dynamics and Modeling of Heavier-Than-Air Cold Gas Releases," Atmospheric Environment 16, 741 (1982).

7. D. McKay, and R. S. Matsugu, "Evaporation Rates of Liquid Hydrocarbon Spills on Land and Water," The Canadian Jourral of Chemical Engineering 51, 434 (1973).

8. Arthur Gauss,"Fuel and Hydrocarbon Vaporization, U.S. Department of Defense, BRL Report No. 1661 (1982).

9. R. B. Bird, W. E. Steward, E. L. Lighfoot, Transport Phenomena, John Wiley \& Sons, New York (1960).

10. B. J. Zwolinski and R. C. Withoit, Handbook of Vapor Pressures and Heats of Vaporization of Hydrocarbons and Related Compounds, Publications in Science and Engineering, Texas A \& M University, Texas, API 44-TRC (1971). 


\section{Technical Notes}




\title{
INDUSTRIAL HYGIENE
}

\section{Impact and Vibration Testing of Firefighters' Self-Contained Breathing Apparatus}

\author{
J. Stengel
}

I conducted impact and vibration tests on two types of self-contained breathing apparatus (SCBA) used by Lawrence Livermore National Laboratory (LLNL) firefighters in an attempt to analyze the environmental effects of routine transport to and handling at the fire scene. The purpose of these tests was to evaluate the ruggedness and reliability of this life-support equipment. Although high-pressure fittings were found somewhat vulnerable to impacts, SCBA generally withstood testing at ambient temperatures. High- and lowtemperature extremes are likely to produce more severe damage.

\section{Introduction}

Impact tests are being proposed separately by the National Fire Protection Association (NFPA) and the National Institute of Occupational Safety and Heatth (NIOSH) to determine self-contained breathing apparatus' (SCBA) ability to withstand rough handling characteristic of their harsh use during firefighting. The proposed NIOSH test requires three 1-meter drops, once on each axis (Figs. 1 and 2). The proposed NFPA test procedure calls for pressurized SCBA to be functional following 12 l-meter drops and to have no catastrophic failure when dropped once from a 2-meter height.

\section{Impact}

\section{Experimental Description}

Our LLNL testing was performed using two types of compressed ais cylinders: a 4500 -psi, aluminum-fiber-wound composite cylinder (Survivair) and a heavier, 2200-psi, steel cylinder (Scott Air Pak Il)." Individual cylinders were dropped unpressurized once from a 2-meter height and twèlve times from a 1-meter height.

\footnotetext{
- The steel cylinder is representative of several older SCBA models. The Scolt model was prevlously used by LLNL and is currently used by the Fire Department of Livermore, California, and others in the Bay Area where LLNL. firefighters may be involved in "mutual-aid" responsts.
}

I used test stands to drop composite and steel SCBA cylinders. A regulator was dropped once from 2 meters. Another regulator was drop:? from 1 meter twelve times. A single facepiece was dropped once from 2 meters, then twelve times from 1 meter. Finally, a complete SCBA assembly was dropped a total of 36 times, 12 times per axis to study the effect of all drops on one axis as would be allowed by the NFPA test.

\section{Results}

Results of the impact testing are summarized in Table 1 and Fig. 3. The facepiece was tested for leakage and proper operation of the exhalation valve using test fixtures normally used for this purpose, and no serious damage was found. Regulators passed the machine test per NIOSH testing procedures and proper operation was observed. Cylinders passed hydrostatic testing per DOT sequirements and were serviceable. No visible cracks were observed in the threaded neck of the composite cylinders. Cylinder valves and gauges were damaged and rendered inoperable, but they did not fail in a way likely to release pressure. A high-pressure fitting was severed when the complete SCBA assembly was dropped by hand. This damage was found to be easily reproduced in a single attempt and was not the result of cumulative damage. 


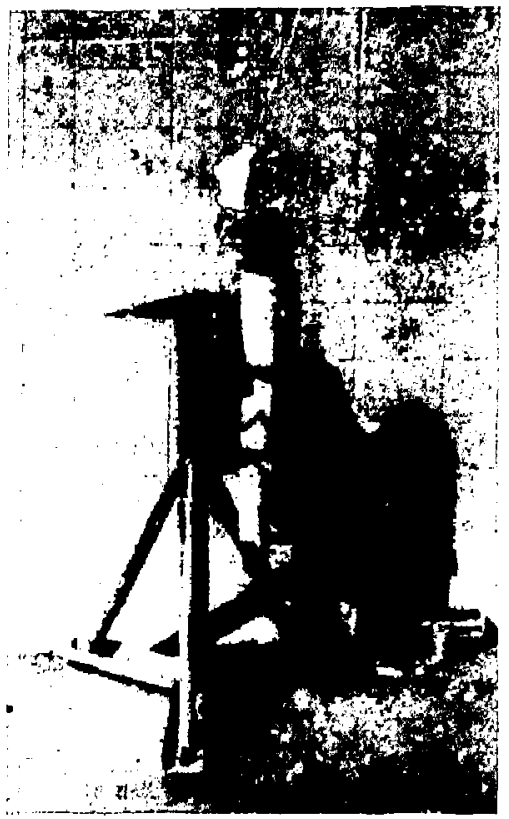

Figure 1. Stand for 1-meter dzop iest.

\section{Discussion}

Drop test stands are not as useful as "free drops" by hand in discovering SCBA weaknesses. Free drops represent a more realistic handling condition. Because of cumulative damage from repeated drops, the 1-meter drops are more severe than the 2-meter drops. Therefore, the 2-meter drop test is considered unnecessary.

I concluded that most NIOSH-approved SCBA would pass the 1-meter drop test except for weakness in the area of high-pressure connections to the SCBA cylinder and value assembly. Most other SCBA designs are similar in this respect and damage can be expected to be similar (or worse). A redesign to strengthen and protect this area of the SCBA will be required for most SCBA to pass, Since these tests were performed only at ambient temperatures, damage from highand low-temperature drop tests is likely to be more severe than noted. Nonetheless, I concluded the NFPA 1-meter drop should be adopted as the SCBA impact test.

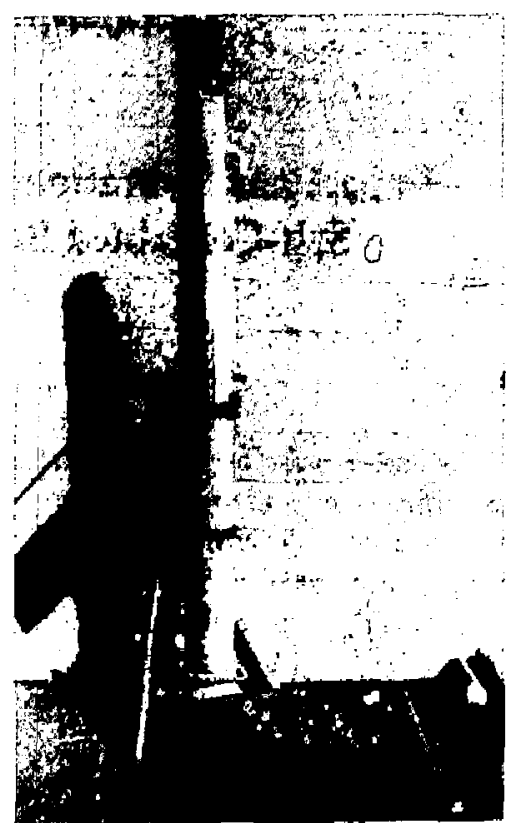

Figure 2. Stand for 2-meter drop test.

\section{Vibration}

The SCBA (Survivair Mk. I) currently in use at LLN/ was placed inside the protective case supplied by the manufacturer, and subjected to a Military Standard 810-C vibration test simulating ground tansportation by a rubber-tire vehicle. This vibration test is currently proposed by NIOSH and NFPA for SCBA testing.

Prior to installation on the vibration table, the SCBA was tested for proper function on a breathing machine similar to that used by the NIOSH in their certification testing of the apparatus. The protective case was placed inside a plywood box and secured to the vibration table with tie-downs.

Accelerometers were fixed to the vibration table, the SCBA container, and the SCBA to ensure that the required acceleration levels would be attained. The SCBA cylinder was fully charged with

\footnotetext{
${ }^{1}$ Military Standard 810-C, Method 514.2.
} 
Table 1. Results of unpreanurized impact teating.

\begin{tabular}{|c|c|c|c|c|}
\hline Test & $\begin{array}{l}\text { Totel } \\
\text { impuets }\end{array}$ & $\begin{array}{l}\text { Compontil } \\
\text { dropped }\end{array}$ & Nonts & Fonl \\
\hline \multicolumn{5}{|l|}{2 melens } \\
\hline & 1 & Fexepiere & $\begin{array}{l}\text { Functionul, } \\
\text { minor abreion }\end{array}$ & 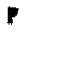 \\
\hline & 1 & Reģulutar & $\begin{array}{l}\text { Functionu, } \\
\text { ander abriten }\end{array}$ & $\mathbf{P}$ \\
\hline & 3 & $\begin{array}{l}\text { Sterd } \\
\text { Cylinder }\end{array}$ & $\begin{array}{l}2 \text { drop/axis, } \\
\text { enriouble. } \\
\text { pint abralded }\end{array}$ & $\mathbf{P}$ \\
\hline & 3 & $\begin{array}{l}\text { Conponite } \\
\text { Cylinder }\end{array}$ & $\begin{array}{l}1 \text { drop/axb, } \\
\text { enricenble, surfaces } \\
\text { ollghtly abraidad }\end{array}$ & $\mathbf{P}$ \\
\hline \multicolumn{5}{|l|}{1 mitter } \\
\hline & 12 & Facepiece & $\begin{array}{l}\text { 1 dropo/axil, } \\
\text { functiond, minor } \\
\text { abrasion, paned leak } \\
\text { fent }\end{array}$ & $P$ \\
\hline & 12 & Regulator & $\begin{array}{l}\text { functional, by-piws } \\
\text { valve opewed } 1 / 4 \text {, } \\
\text { refector valve bent }\end{array}$ & $\mathbf{P}$ \\
\hline & 36 & $\begin{array}{l}\text { Steal } \\
\text { Cylinder }\end{array}$ & $\begin{array}{l}12 \text { drops/axis, } \\
\text { serviceable, paead } \\
\text { DOT hydrobatic } \\
\text { teat, valve inoptrable }\end{array}$ & $P$ \\
\hline & 36 & $\begin{array}{l}\text { Complete SCBA } \\
\text { mosembly } \\
\text { (composite } \\
\text { cylinder) }\end{array}$ & $\begin{array}{l}12 \text { drope/axis, } \\
\text { wervireable, alarm } \\
\text { awembly uevered } \\
\text { from high-presure } \\
\text { line cuusing SCBA to } \\
\text { be inoperible }\end{array}$ & E \\
\hline
\end{tabular}

compressed air prior to the test. Testing was performed at ambient temperature.

Vibration was applied along each of three mutually perpendicular axes according to the plot in Fig, 4. The sine-wave sweep from 5 to 500 to $5 \mathrm{~Hz}$ yequires 15 minutes, and was done for one hour per axis. Prior to the test, a resonance search was done using a $\mathrm{lg}$ input, cycling from 7.5 to 2000 to $7.5 \mathrm{~Hz}$ in 15 minutes. No significant resonances were located.

\section{Results}

Visual inspection of the vibrated SCEA revealed a slight pressure loss (decrease from 4200 to 3900 psi), which, upon routine inspection by firelighters, would have resulted in the unit being semoved from service, It is likeiy that no leak actually occurred. 1 believe that the pressure gauge indication was changed by the vibration. Two areas of minor ubrasion were noted on the facepiece lens and high-pressure hose. Upon inspecting the fittings and hardware for tightness, the bypass valve and the locking sing on the mainline valve backed open. Significant air flow from the bypass should be detected and corrected as a well-trained wearer dons the SCBA.

\section{Discussion}

The facepiece assembly was successfully leak-tested. A post-vibration breathing machine test produced a tracing comparable to previbration testing, and I concluded that the vibration environment had no significant adverse affect on the SCBA's ability to function and protect if given a proper inspection before use. At ambient temperature this test is considered muld, but would be potentially severe if performed at high and low temperatures. This standard vibration test is considered appropriate for NIOSH and NFPA use in SCBA testing. 

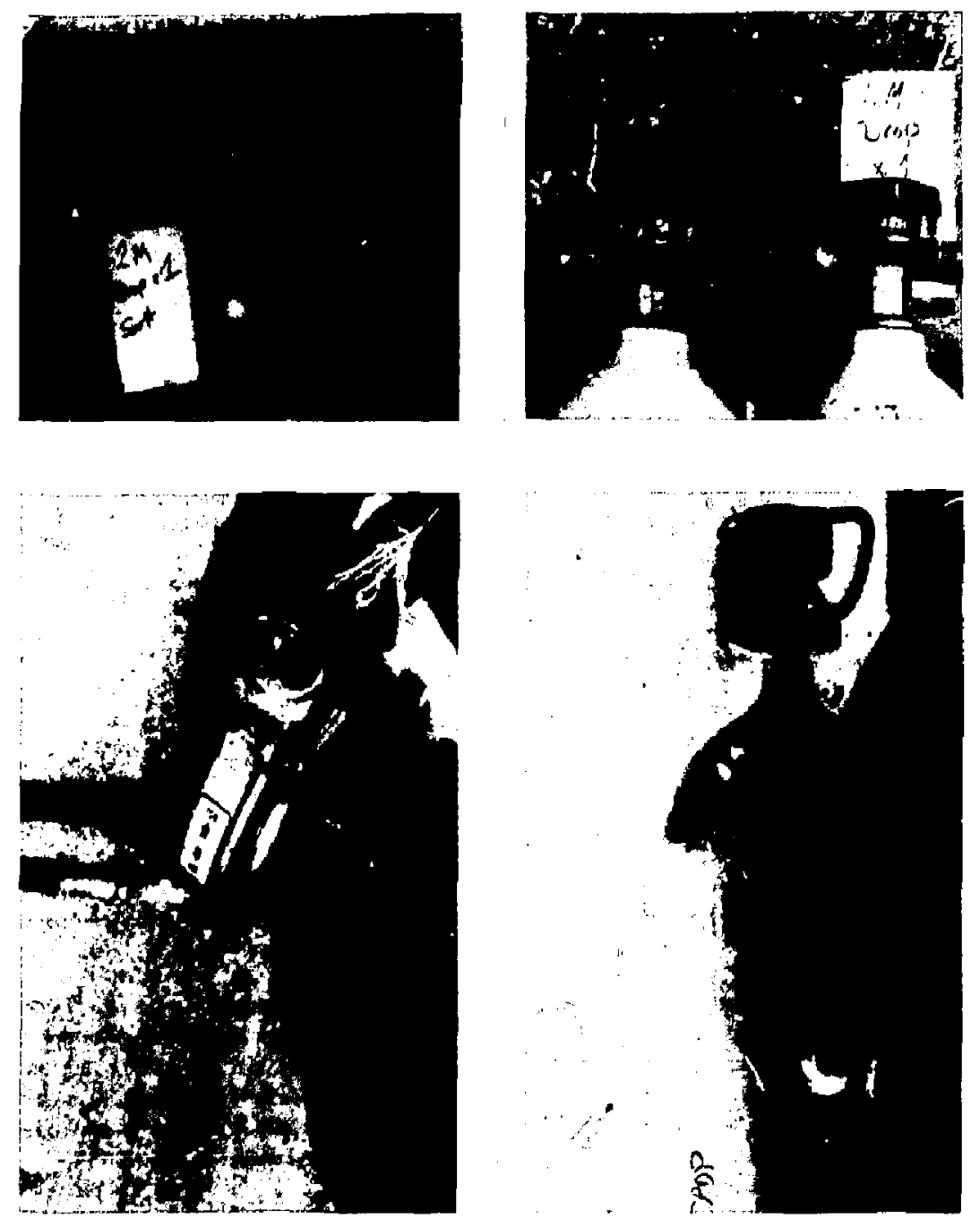

Figure 3. Selected damage pholos of test runs.

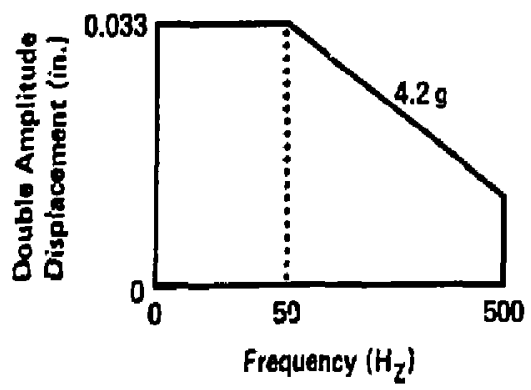

Figure 4. Profile of vibration test. 


\section{Measurement of Aerosol Concentration as a Function of Size and Charge}

\section{Arthut Biermann and Werner Bergman}

We have developed an aerosol diagnostic system that measures the number concentration of aerosols as a function of particle size and electronic charge. Size-charge analysis was accomplished by first fractionating the aerosol according to the electrical mobility of the particle, then determining the particle-size distribution of each mobility fraction using either a Climet optical counter or an ASASX-P laser spectrometer. By accumulating a particle-size distribution of each mobility fraction, we could determine by mathematical techniques the aerosol number concentration as a function of both particle charge and size. We are currently using this system to determine the aerosol number concentration as a function of particle size from 0.1 to $3.0 \mu \mathrm{m}$ in diameter and as a function of particle charge from -1000 to +1000 electronic charges.

\section{Introduction}

The behavior of charged aerosol particles can significantly affect particle deposition and coagulation. Applications of charged aerosols include aerosol capture involving such methods as filmation and electrostatic precipitation, and chargedspraying techniques. The change carried by aerosol particles has been measured by a variety of techniques including sirst- and second-order mobility spectrometers, aerosol electrometers, and variations on the Millikan oil-droplet apparatus. These previous methods have generally been applied to only the analysis of monodisperse aerosols, wheseas our charge measurement technique is valuable for heterodisperse aerosols. Modifivations to the mobility analyzer and computer data acquisition system will be discussed. We will also illustrate results for several types of latex aerosols.

\section{Instrumentation}

We show the instrumentation configuration, including our modifications, for particle-size and charge analysis in Fig. 1. The aerosol is first sampled by a Thermo Systems, Inc. electrostatic classifier (Model-3071). The Model 3071 is a differen- tial mobility analyzer (DMA), as opposed to the cumulative type or first-order, in that it extracts particles in a specific electric mobility range as determined by the electric fieid and air-flow rates. The instrument is commercially available with a negative high voltage appliad to the central cod of the cylindrical column, At a given voltage or electric field, charged particles experience a force tangential to their direction of flow due to the radially directed electric field. Negatively charged particles are repelled outward to be deposited on the outer cylinder. Positively charged particles are attracted to the center rod, Positively charged particles, in a certain mobility range, pass through the center-rod aerosol exit, forming the chargedparticle sample outlet, $q$.

The positively charged particles exiting in this airstream ate analyzed by a detector for size. In the case of monodisperse aerosols, the detection of particle size is not necessary. Howevet, in the case of heterodisperse aerosols, the size distribution and concentration of particles in the sample is determined by an optical particle counter. As the voltage is increased successively, the size distributions corresponding to lower and lower constant mobilities are measured until the entire mobility spectrum of the positively charged particles has been determined. 


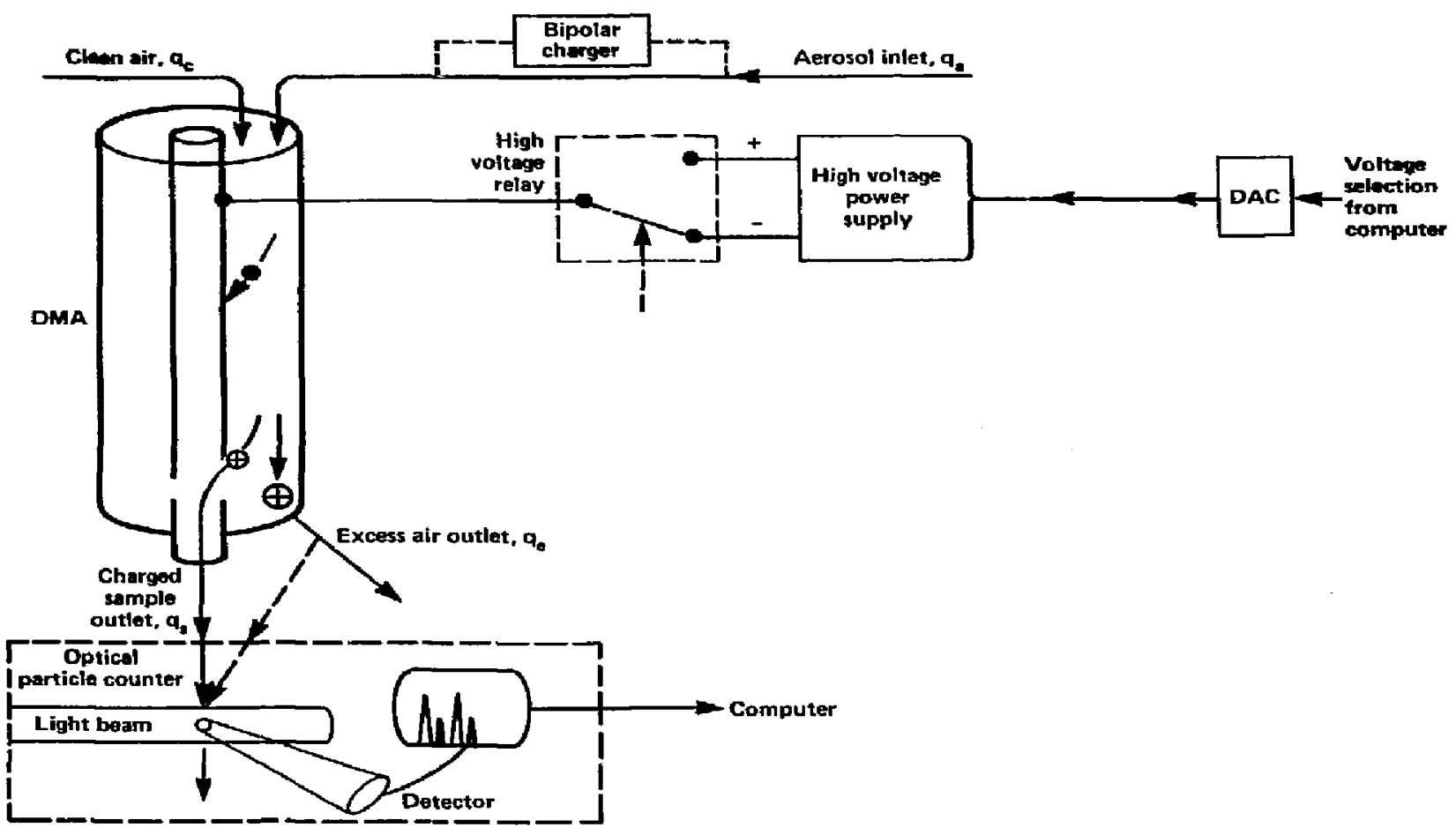

Figure 1. Instrumentation configuration for size-charge analysis. 
In order to also measure the mobility spectrum of particles carrying negative charges, we incorpotated a positive high-voltage power supply and high voltage relay into the DMA (Fig. 1). When the positive high voltage is applied to the center rod, negatively charged particles, nther than positively onzs, are collected through the mobility-fractionated sample outlet.

For a complete charge-distribution analysis, it is also necessary to determine the size distribution of particles without charge. For this, the optical counter sampling configuration was changed to sample a portion of the excess air. While in this mode, the greatest voltage is selected in an attempt to remove all charged particles from the excess air outlet.

We used either a Climet 208 particle analyzer or a Particle Measurement Systems ASASX-P laser spectrometer for the optical counter to determine particle size. With the Climet, the particlesize spectrum, ranging from 0.3 to $10 \mu \mathrm{m}$ in diameter, can be accumulated in 128 channels. The laser spectrometer, having a size range of 0.1 to $3.0 \mu \mathrm{m}$ in diameter over 32 chantinels, has the advantage of detecting a lower particle size thas the Climet.

Since 15 to 60 pre-selected mobility intervals might be necessary for a complete chargedistribution measurementi, a 30- to 50-channel size distribution is accumulated for each mobility interval, generating an inordinate amount of data to be processed. Because of this, we interfaced an LSI-11/23 computer with the instruments for control, data acquisition, data processing, storage, retrieval and three-dimensional graphical representations. The manner in which the instrumentation is interfaced to the computer has previously been reported. ${ }^{1}$ Using a FORTRAN program code, the experimenter is prompted for changes in default values for the DMA flow rates, optical-counter parameters, and sample time. The program proceeds to set a DMA voltage, wait for a certain equilibrium time period, and then accumulate a size spectrum with the specified optical particle counter. The mubility of particles sampled by the optical particle counter is determined according to Lit and Pui. ${ }^{2}$ Particle charge is given by the ratio of this mobility to the mobility ior a singlecharged particle. This process is repeated unili the entire range of pre-selected voltages, or mobilities, have been scanned.

\section{Results}

First, we obtuined results of aerosol concentration as a function of both particle size and charge for only particles carrying positive charges. And, to fusther simplify the distribution, we used only monodisperse aerosols. Figure 2 is a threedimensional representation of the size-charge distribution for the $0.797-\mu \mathrm{m}$ latex aerosol. Grid lines for both the charge and diameter axes are positioned at equal-logarithmic spacings. Vipwing the peak from the diameter axis, the peak is extremely narrow because of the monodisperse latex. But, viewing the peak from the charge axis, the peak is much broader, with some particles having as many as 1000 charge units. The highest particle concentration occurs at 14 charge units. The peak in the center rear of the graph is the background particles occurring from the evaporation of water droplets without a latex particle in them. Note that most of these smaller particles have little charge. The distribution sparing seems rather coarse with respect to charge because only 14 mobility intervals were scanned.

The combined positive- and negative-charge distribution for the 0,797- $\mu \mathrm{m}$ latex atomized at 25 psi is shown in Fig. 3. Equal-log intervals wete still being used along both axes, however, on the charge axis, the "zero" grid line was added between the negative and positive distributions using the same spacing. Herz, we have two peaks for the $0.797-\mu \mathrm{m}$ latex corresponding to particles carrying negative and positive charges. Peak counts occur at \pm 12 charge units. A greater concentration of particles carry positive charges. For the background aerosol particles at $0.2 \mu \mathrm{m}$ diameter, the majority of particles are uncharged.

To further test the overall behavior of the size and charge distribution analysis, the $0.797-\mu \mathrm{m}$ atomized latex aerosol was passed through a unipolar charger prior to sampling by the DMA and laser spectrometer. Ideally, this unipolar charger should place equal positive charges on particles of the same size by diffusion charging. The result, shown in Fig. 4 , was a very narrow concentration distribution with respect to both the size and charge. A very small peak next to the major peak cortesponds to doublets. The geometric mean charge for the $0.797-\mu \mathrm{m}$ latex particles is +33 units with a corresponding geometric standard deviation of 1.45. The relative standard deviation, or 


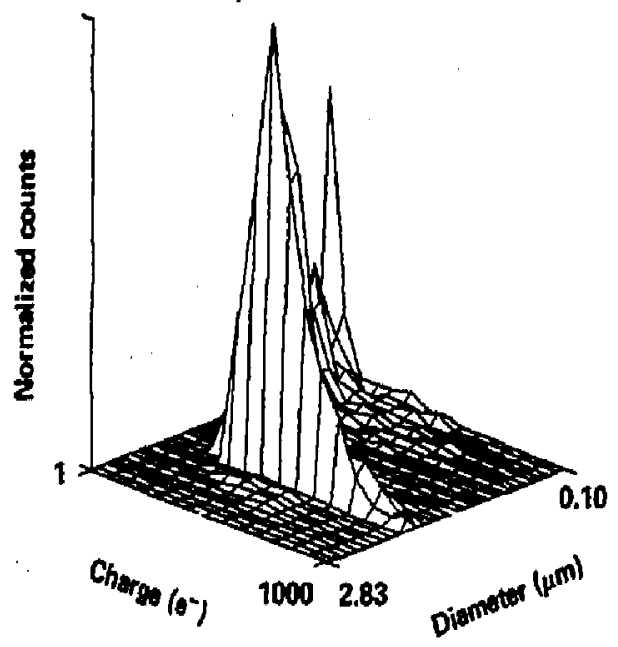

Figure 2. Three-dimensional surface representation for the atomized $0.797-\mu \mathrm{m}$ latex, positive portion only.

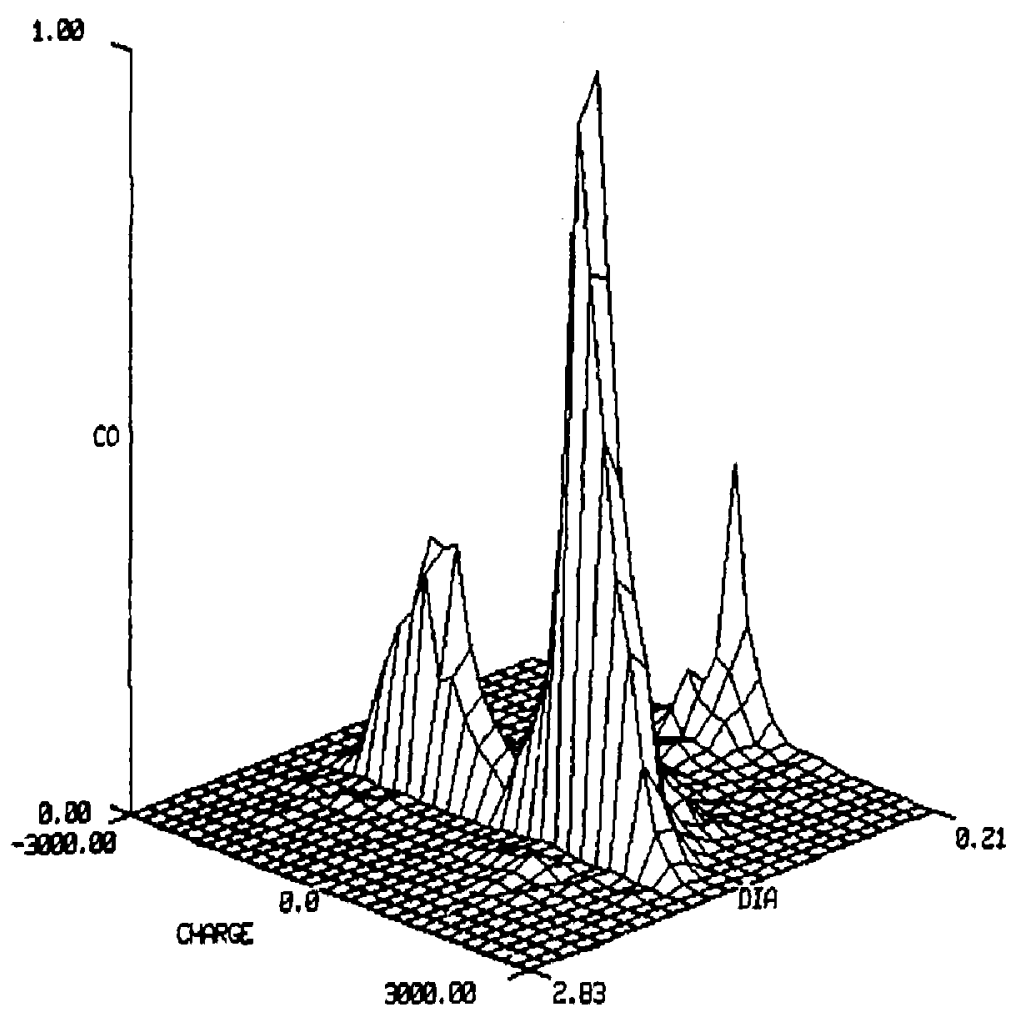

Figure 3. Normalized countu for the combined positive, zero, and negative size-change surface representation for the atomized $0.797-\mu \mathrm{m}$ latex aerosol. 


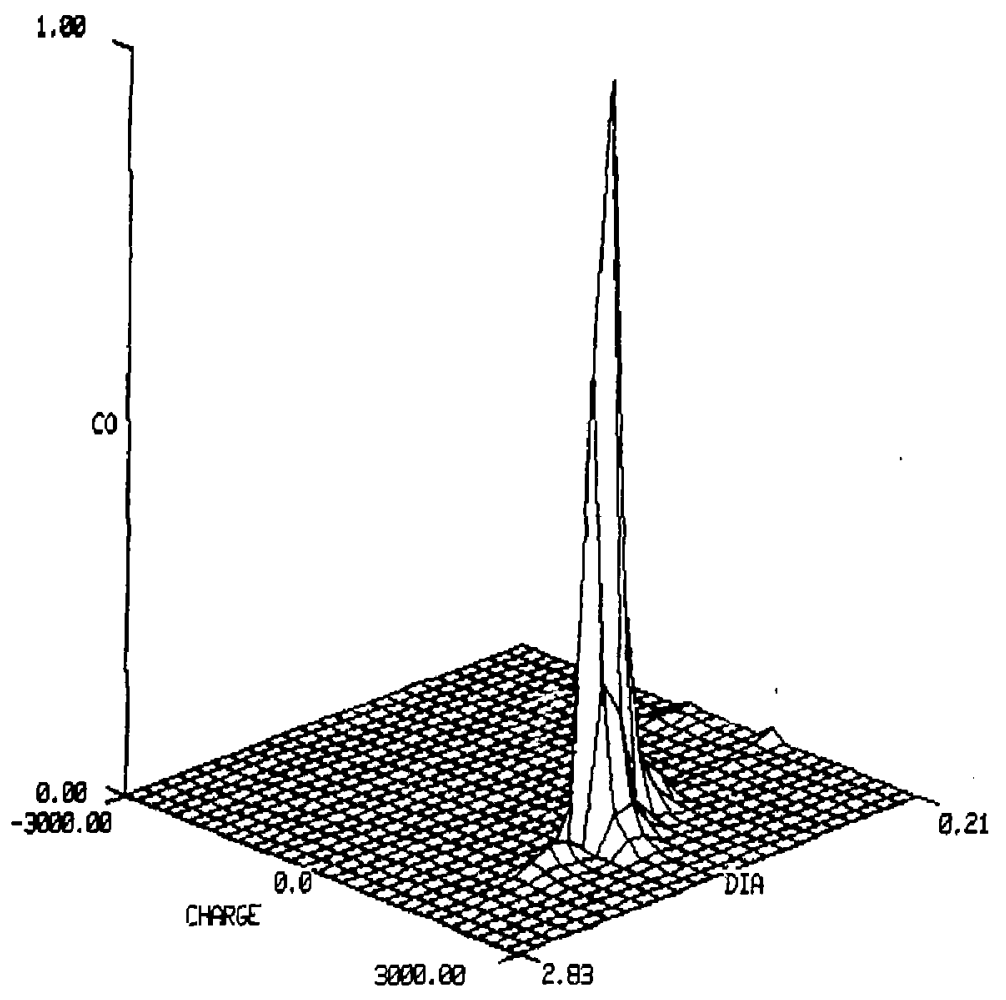

Figure 4. The size-charge distribution for the unipolar charge $0.797-\mu \mathrm{m}$ latex aerosol.

the arithmetic standard deviation/mean charge, is $25.8 \%$. Both the mean and standard deviation agree with what other investigators have found for the mobility spectrum from this unipolar charger. ${ }^{3}$

The final test case using a monodisperse aerosol involyed passing the aerosol through a ncutralizer prior to sampling. Theoretically, the neutralizer reduces the aerosol charge to the Boltzman equilibrium charge distribution. The result, illustrated in Fig. 5, indicated the maximum particle concentration occurred at about "zero" charge. Comparing the atomized-only case in Fig, 3, the positive and negative charge peaks have been eliminated and merged toward zero charge. The peak concentration for the latex actually occurred at slightly less than zero charge at -3 units.

Summarizing the various treatments for the latex aerosols, Fig. 6 compares the corresponding contour graphical representations for the atomized only, unipolar-charged, and neutralized cases previously shown in Figs. 3, 4, and 5. The contour tines corresponding to equal-normalized concentrations are $0.05,0.1,0.2,0.3,0.4,0.5,0.6,0.7$, 0.8 , and 0.9 . This provided a more quantitative presentation of the data than the threedimensional surface figures.

\section{Conclusions}

The aerosol diagnostic system we described can measure the number concentration of particles as a function of both size and electronic charge. instrumental to our system is an LSI-11/23 computer that controls, accepts, and processes large quantities of information. Accumulation of a complete size-charge distribution requires 30 to 90 minutes depending upon the desired charge resolution and the optical-counter sampling time. In any case, the sampling time necessitates a constant aerosol for a significant period of time. 


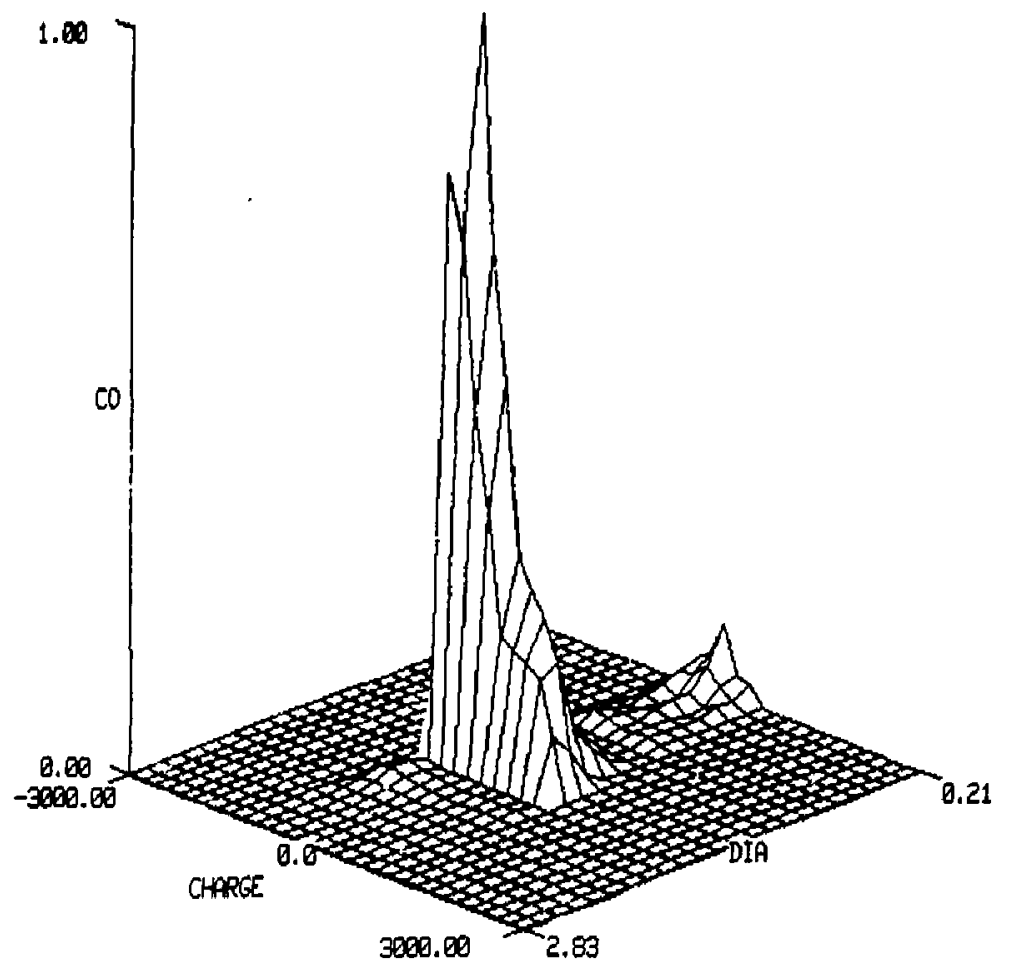

Figure 5. The combinc 4 size-charge üistribution for the neutralized $0.797-\mu \mathrm{m}$ latex aerosol. 


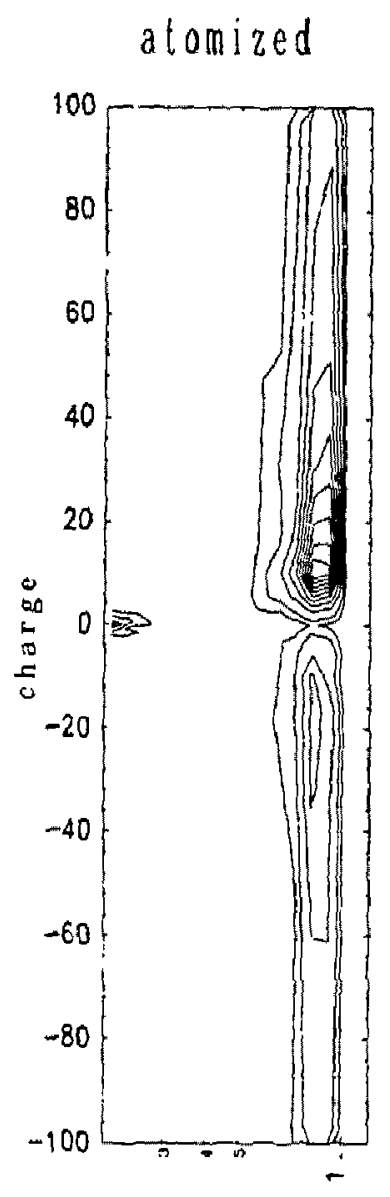

unipolar

neulralized
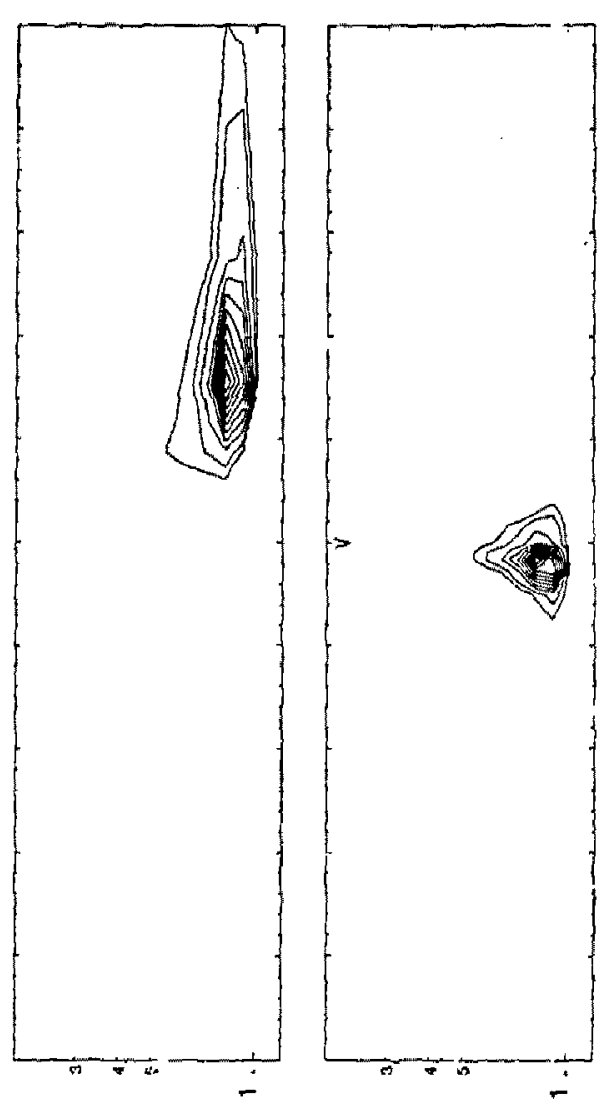

diameler

Figy"e 6. Three-dimensional contout representations for the $8.797 \times 4 \mathrm{~m}$ latex aerosol-atomized only, unipolar-sha ;ed, and reutralized.

\section{References}

1. A. Biermann and W. Bergman, Measurement of Aerosol Concentration as a Function of Size and Charge, Lawrence Livermore Nationa! Laboratory, Livermore, CA, UCRL-88417 (1983).

2. B. Y. H. Liu and D. Y. H. Pui, "A Submicton Aerosol Standard and the Primary Absolute
Calibration of the Condensation Nuclei Counter," ]. of Colloid and Interf. Sci, 47, 155171 (1974),

3. B. Y. H. Liu, K. T. Whitby, and D.Y. H. Pui, "A Possible Elentrical Analyzer for SiztDistribution Measurement of Submicron Aerosols," APCA fournal 24, 1067-1072 (1974). 


\title{
RADIATION PROTECTION
}

\section{Comparison of Calculated Neutron Spectrum and Dose Equivalent from NBS and LLNL 15-cm $\mathrm{D}_{2} \mathrm{O}$ Spheres}

\author{
Charles T. Erevo
}

We compared calculated neutron spectra and dose-equivalent for National Bureau of Standards (NBS) and Lawrence Livermore National Laboratory (LLNL) 15-cm $\mathrm{D}_{2} \mathrm{O}$ spheres. First, MORSE calculations of the NBS sphere were compared to O5R calculations. Second, MORSE calculations of the LLNL sphere were compared to MORSE calculations of the NBS sphere.

\section{Introduction}

Unless the shape of the neutron spectrum of the source being measured is the same as that used for calibration, there will be some error in the measurement of the neutron dose rate with any instrumont or dosimeter. To minimize these errors due to spectral differences, the experimenter must have a variety of neutron spectra when calibrating or evaluating instruments or dosimeters. This allows the experimenter to select a spectrum that most nearly represents the desired measurement.

Since neutron spectra at power reactors are much softer (low average energy) than those from the fasi neutron sources ( ${ }^{252} \mathrm{Cf}$, PuBe, etc.) normally used for calibration, the National Bureau of Standards (NBS) designed a moderated ${ }^{252} \mathrm{Cf}$ calibration source using a $D_{2} O$-filled sphere with a radius of $15 \mathrm{~cm}$. The sphere is covered with a 0.05 $\mathrm{cm}$ thick cadmium shell. This sphere is based on a similar sphere developed at the Lawrence Livermore National Laboratory (LLNL). 'Although the neutron spectrum does not duplicate reactor spectra, it is much closer than that from fast neutron sources.

\section{Experimental Description}

The $15 . \mathrm{cm} \mathrm{D}_{2} \mathrm{O}$ sphere and source encapsulation used by LLNL is significantly different from that used at NBS. In order to make a comparison of the two spheres, we first performed calculations using the N3S geometry to see how well our results compared with those done for the NBS.
Ing and Cross used the radiation-transport code OSR to perform the calculations on the NBS sphere in free space without cadmium. ${ }^{2}$ They also investigated the significance of various parameters such as the encapsulation and the material in the tube used for inserting the source into the sphere. They concluded that most of these had an insignificant effect on dose equivalent and came up with the simplified model shown in Fig. 1. The results for this model are given in Table $1^{2}$ The fluence given at an energy, $E_{\mathrm{i}}$, represents the quanticy $4 \pi R^{2} E_{i} \phi(E)$ for the histogram interval deSined by $E_{i}$ and $E_{i+1}$. This convention follows that used by lng and Makra. ${ }^{3}$ These spectra are in the form of $4 \pi R^{2}$ times the fluence per unit lethargy (i.e., $\Delta N / \Delta l n E$ ). The values in Table 1 were for 256,000 neutrons and have not been normalized. The 1-meter fuence in the third column was obtained by dividing the second column by $4 \pi R^{2}$, multiplying by $\ln \left(E_{i} / E_{i+1}\right)$, and dividing by $\left(E_{i}-\right.$ $\left.E_{j+1}\right) \times 256,000$.

\section{Calculation Basis}

We used the LLNL version of the radiationtransport code, MORSE, for all our calculations. The first model we used was the one from Ing and Cross. The second was a much more detailed model of the description given by Schwart and Eisenhaur. Both models gave $2.37 \times 10^{-7}$ and $2.42 \times 10^{-7}$ (urrem/hr) $/(\mathrm{n} / \mathrm{sec}$ ), respectively, at 1 meter from the center of the sphere. Both of 


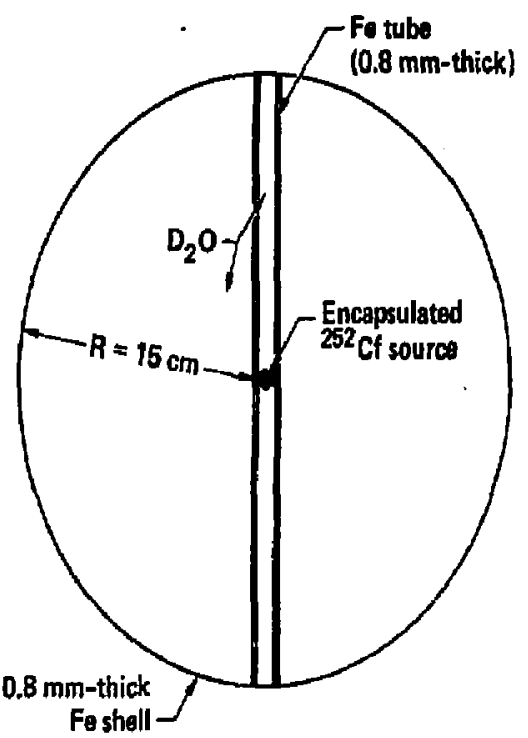

Figure 1. Ing and Cross model of NBS 15-cm $\mathrm{D}_{2} \mathrm{O}$ sphere.

these calculations used a modified Maxwellian fission spectrum, with a temperature of $1,42 \mathrm{MeV}$ as an input spectrum. The spectrum for the detailed model is given in Table 2.

The NBS 15-cm sphere is wrapped with cadmium, so Schwartz used Ing and Cross' free-space spectrum, cadmium cross sections, and ICRP fluence-to-dose-equivalent conversion factors, and arrived at $2.29 \times 10^{-7}(\mathrm{mrrem} / \mathrm{hr}) /(\mathrm{n} / \mathrm{sec})$ at 1 meter from the center of the sphere, ${ }^{5}$ For the MORSE calculation, we included cadmium in the model and repeated the calculation. The result was $2.33 \times 10^{-7}(\mathrm{mrem} / \mathrm{hr}) /(\mathrm{n} / \mathrm{sec})$. Despite this excellent agreement in the dose equivalent rate, Fig. 2 shows the differences in the spectra.

Since the O5R and MORSE codes produced results that agreed with the NBS $15-\mathrm{cm}$ sphere results, we chose MORSE for the LLNL-sphere calculations. The source-insertion hole in the LLNL sphere is much larger in diameter than that in the NBS sphere $(3.387 \mathrm{~cm}$ vs $0.64 \mathrm{~cm})$. As a result, the outer radius of the $\mathrm{D}_{2} \mathrm{O}$ is also larger $(18.364 \mathrm{~cm})$. Moreover, the encapsulation of the LLNL ${ }^{252} \mathrm{Cf}$ source is different than that of the NBS ${ }^{252} \mathrm{Cr}$ source. The model used for the calculation is shown in Figs. 3 and 4 . The calculated spectrum for the LLNL sphere is given in Table 3 and is compared with the NBS sphere in Fig. 5. The dose
Table 1. Leakage opectrum trom NBS $\mathrm{D}_{2} \mathrm{O}$. moderated ${ }^{232} \mathrm{Cf}$ source at 1 ineter $(256,000$ neutrons).

\begin{tabular}{|c|c|c|}
\hline $\begin{array}{l}\text { Energy } \\
\text { (MeV) }\end{array}$ & ${ }^{4 \pi} R^{2} E_{j} \backsim E Y^{\prime}$ & $\begin{array}{l}\mathrm{n} / \mathrm{cm}^{2} \\
(\mathrm{MeV})\end{array}$ \\
\hline $1,00 E-05$ & $7,02 \mathrm{E}+03$ & $5.56 \mathrm{E}-02$ \\
\hline $5.00 E-05$ & $9.59 E+03$ & $1.20 E-02$ \\
\hline 1.0OE-M & t.17E+04 & $5.04 E-03$ \\
\hline $200 \mathrm{E}-04$ & $1.26 E+04$ & $271 \mathrm{E}-03$ \\
\hline $4.00 t-04$ & $1.41 \mathrm{E}+04$ & $1.52 \mathrm{E}-03$ \\
\hline $7.00 \mathrm{E}-04$ & $1.50 E+04$ & $8.70 \mathrm{E}-04$ \\
\hline $1.00 E-03$ & t.61E +04 & 5.95E-04 \\
\hline $3.00 E-03$ & $1.76 \mathrm{E}+04$ & $3.01 E-\operatorname{mos}$ \\
\hline $6.00 E-03$ & $1.69 E+04$ & 1.35E-OA \\
\hline $1.00 \mathrm{E}-02$ & $1.90 E+04$ & 7.5AE-05 \\
\hline $200 \mathrm{E}-02$ & $202 \mathrm{E}+04$ & 4.35E-05 \\
\hline $4.00 E-02$ & $1.89 \mathrm{E}+04$ & 204E-05 \\
\hline $6.00 \mathrm{E}-02$ & $1.87 E+04$ & 1.18E-05 \\
\hline $8.00 \mathrm{E}-02$ & :.7AE+04 & $7.96 \mathrm{E}-06$ \\
\hline $1,00 \mathrm{E}-01$ & $1.67 \mathrm{E}+04$ & 5.79E-06 \\
\hline $1.50 E-01$ & $1,36 \mathrm{E}+04$ & $339 \mathrm{E} \rightarrow 06$ \\
\hline $2,00 E-01$ & $1.42 \mathrm{E}+04$ & 254E-06 \\
\hline $2.50 \mathrm{E}-01$ & $1.31 E+04$ & 1.82E-06 \\
\hline $3.00 E-01$ & $1.25 E+04$ & $1.42 E-06$ \\
\hline $3.50 \mathrm{E}-01$ & $1.09 \mathrm{E}+04$ & $1.04 E-06$ \\
\hline $4,00 E-01$ & 9.37E+03 & $T .78 \mathrm{E}-0 T$ \\
\hline $4.50 E-01$ & $5.77 E+03$ & $4.23 \mathrm{E}-07$ \\
\hline $5.00 E-01$ & $7.62 E+03$ & $499 E-07$ \\
\hline $5.50 \mathrm{E}-01$ & $1.13 E+04$ & $6.70 E-07$ \\
\hline $6.00 \mathrm{E}-01$ & $1.21 E+04$ & $6.55 E-07$ \\
\hline $7,00 E-01$ & $1,30 E+04$ & $6.23 \mathrm{E}-07$ \\
\hline $8.00 \mathrm{E}-0 \mathrm{t}$ & $1.30 E+04$ & $5.40 \mathrm{E}-07$ \\
\hline $9.00 \mathrm{E}-01$ & $1.25 \mathrm{E}+0 \mathrm{~s}$ & $4.59 \mathrm{E}-07$ \\
\hline $1.00 \mathrm{E}+00$ & $8.67 E+03$ & 2.84E-07 \\
\hline $1.20 E+00$ & $1.05 \mathrm{E}+0.4$ & $298 \mathrm{E}-07$ \\
\hline $1.40 E+00$ & $1.40 \mathrm{E}+06$ & $335 \mathrm{E}-07$ \\
\hline $1.60 \mathrm{E}+00$ & $1.75 \mathrm{E}+04$ & $3.63 \mathrm{E}-0.7$ \\
\hline $1.80 \mathrm{E}+00$ & $7.66 \mathrm{E}+04$ & $3,40 E-07$ \\
\hline $200 E+00$ & 1.96E + OS & 3.21E-07 \\
\hline $230 E+80$ & $245 E+04$ & $3.55 E-6 r$ \\
\hline $260 E+00$ & $3.02 \mathrm{E}+04$ & $384 \mathrm{E}-07$ \\
\hline $3.00 \mathrm{~F}+00$ & $267 E+04$ & $297 \mathrm{E}-07$ \\
\hline $3.50 E+D 0$ & $205 E+00$ & $1.95 \mathrm{E}-07$ \\
\hline $4.00 E+00$ & $1,57 \mathrm{t}+04$ & $1.30 E-07$ \\
\hline $4.50 E+00$ & $1.76 E+04$ & $1.29 \mathrm{E}-07$ \\
\hline $5.00 \mathrm{E}+00$ & $1.59 \mathrm{E}+04$ & 1.04E-07 \\
\hline $6.00 \mathrm{E}+00$ & $122 \mathrm{E}+04$ & $6.91 E-0.08$ \\
\hline $7.00 \mathrm{E}+00$ & 8. $0 E+03$ & $3,93 \mathrm{E}-68$ \\
\hline $8.00 E+00$ & $6.61 \mathrm{E}+03$ & $3.93 \mathrm{E}-08$ \\
\hline $9.00 E+\infty$ & $2.82 \mathrm{E}+03$ & $1.03 \mathrm{E}-06$ \\
\hline $100 E+01$ & LBSE+03 & $6.09 t-09$ \\
\hline $1.10 E+01$ & $1,19 E+03$ & $3.53 \mathrm{E}-0.9$ \\
\hline $1.20 E+01$ & $4.76 \mathrm{E}+02$ & $1.29 E-09$ \\
\hline $1.30 E+01$ & $3.97 \mathrm{E}+02$ & $9.88 \mathrm{E}-10$ \\
\hline $1.40 E+01$ & $206 \mathrm{E}+02$ & $4.75 E-10$ \\
\hline $1.50 \mathrm{E}+01$ & $1,06 \mathrm{E}+02$ & $2.27 E-10$ \\
\hline
\end{tabular}

' From Ing and Crow. 
Table 2. LLNL-caleulated differential leakage spectrum from NBS $\mathrm{D}_{2} \mathrm{O}$-moderated ${ }^{252} \mathrm{CF}$ source at 1 meter.

\begin{tabular}{|c|c|}
\hline $\begin{array}{l}\text { Energy } \\
\text { (MeVl }\end{array}$ & $\begin{array}{l}n / \mathrm{cm}^{2} \\
\text { (MeV) }\end{array}$ \\
\hline $1.000 E-10$ & $2005 E+00$ \\
\hline $4.000 E-07$ & $1.398 \mathrm{E}-01$ \\
\hline $3.180 E-06$ & $2.392 \mathrm{E}-02$ \\
\hline $2.520 \mathrm{E}-05$ & $4,194 E-03$ \\
\hline $2,000 \mathrm{E}-04$ & $5.799 E-04$ \\
\hline $1.590 \mathrm{E}-03$ & $9.364 E-05$ \\
\hline $1.261 E-02$ & 1. $\stackrel{x}{*}-05$ \\
\hline $1.000 \mathrm{E}-01$ & $3.146 \mathrm{E}-06$ \\
\hline $2.236 E-01$ & $9.142 \mathrm{E}-07$ \\
\hline $5.000 \mathrm{E}-01$ & $7.264 \mathrm{E}-07$ \\
\hline $5.946 \mathrm{E}-01$ & $6.103 E-07$ \\
\hline $7.071 \mathrm{E}-01$ & $5.405 \mathrm{E}-0 \mathrm{t}$ \\
\hline $8.409 E-01$ & $3.438 \mathrm{E}-07$ \\
\hline $1.000 E+00$ & $2,801 E-07$ \\
\hline $1.257 \mathrm{E}+00$ & $3.482 \mathrm{E}-07$ \\
\hline $1.581 E+00$ & $3.626 E-07$ \\
\hline $1.988 \mathrm{E}+00$ & $3.821 E-07$ \\
\hline $2.500 \mathrm{E}+00$ & $3.066 \bar{E}-07$ \\
\hline $2.973 E+\infty 0$ & $2,129 \mathrm{E}-07$ \\
\hline $3.535 \mathrm{E}+\infty 0$ & $1,547 \mathrm{E}-07$ \\
\hline 4.204E+60 & 1.084E-07 \\
\hline $5.000 E+\$ 0$ & $7,132 \mathrm{E}-0 \mathrm{~B}$ \\
\hline $5.765 E+00$ & $4.09 E-08$ \\
\hline $6.646 E+00$ & $2297 \mathrm{E}-0$ \\
\hline $7.663 E+00$ & $1.116 E-0$ \\
\hline B.835E + DO & $5.714 E-09$ \\
\hline $1.019 \mathrm{E}+01$ & $2055 E-09$ \\
\hline $1.174 \mathrm{E}+01$ & $6.700 \mathrm{E}-10$ \\
\hline $1.354 E+01$ & $1.790 \mathrm{E}-10$ \\
\hline $1.561 E+01$ & 4.7मE-11 \\
\hline $1.800 E+00$ & \\
\hline
\end{tabular}

equivalent at 1 meter is $2.02 \times 10^{-7}$ (mrem/hr)/ $(\mathrm{n} / \mathrm{sec})$. This is $11.8 \%$ lower than that for the NBS sphere. Next, the walls, floor, and air were included in the model to determine the effects of scatter. The spectrum is given in Table 3 . The scatter raised the dose-equivalent rate to $2.16 \times 10^{-7}$ $($ (ntem $/ \mathrm{hr}) /(\mathrm{n} / \mathrm{sec})$ at 1 meter.
Table 3. LLNL-calculated differential leakage spectrum from LLNL $\mathrm{D}_{2} \mathrm{O}$-moderated ${ }^{252} \mathrm{Cf}$ source at 1 meter.

\begin{tabular}{|c|c|c|}
\hline $\begin{array}{l}\text { Energy } \\
\text { (MeV) }\end{array}$ & $\frac{\mathrm{n} / \mathrm{cm}^{2}}{\mathrm{MeV}}$ & $\frac{\mathrm{n} / \mathrm{cm}^{\mathrm{d}}}{\mathrm{Me \textrm {V } ^ { b }}}$ \\
\hline $1.000 E-10$ & $8.960 \mathrm{E}-04$ & $1.778 E+01$ \\
\hline $1.000 \mathrm{E}-09$ & $1.257 \mathrm{E}-01$ & $2042 E-01$ \\
\hline $3.180 E-06$ & $2.612 E-02$ & $3.250 E-02$ \\
\hline $2520 \mathrm{E}-05$ & $4.200 E-03$ & $5.107 E-03$ \\
\hline $2.000 E-01$ & $4,911 \mathrm{E}-04$ & $5.956 \mathrm{E}-04$ \\
\hline $1.590 \mathrm{E}-03$ & $7.909 E-05$ & $9.371 E-05$ \\
\hline $1.261 \mathrm{E}-02$ & $1.150 \mathrm{E}-05$ & $1.379 E-05$ \\
\hline $1,000 E-01$ & $2741 E-06$ & $3.191 E-06$ \\
\hline $2.236 E-01$ & $7.949 \mathrm{E}-07$ & $9.476 \mathrm{E}-07$ \\
\hline $5.000 \mathrm{E}-07$ & $8.512 E-03$ & $7.404 \mathrm{E}-07$ \\
\hline $5.946 \mathrm{E}-01$ & $5.027 E-07$ & $6.009 E-07$ \\
\hline $7.071 E-01$ & 4.510E-07 & $5.580 \mathrm{E}-07$ \\
\hline $8.409 \mathrm{E}-01$ & $3.053 E-07$ & $3.618 \mathrm{E}-07$ \\
\hline $1.000 E+00$ & $2157 \mathrm{E}-07$ & $2769 \mathrm{E}-07$ \\
\hline $1.257 \mathrm{E}+00$ & $2562 E-07$ & $3.116 \mathrm{E}-07$ \\
\hline $1.541 \mathrm{E}+\infty 0$ & $2.504 E-07$ & $2752 \mathrm{E}-07$ \\
\hline $1.988 E+\infty 0$ & $3347 \mathrm{E}-07$ & $3.374 E-07$ \\
\hline $2.500 E+60$ & 2B19E-07 & 2BO4E-07 \\
\hline $2.973 E+00$ & $1.672 E-07$ & $1.624 \mathrm{E}-07$ \\
\hline $3,535 \mathrm{E}+00$ & $1.259 E-07$ & $1,092 \mathrm{E}-07$ \\
\hline $4.204 E+00$ & $9.863 \mathrm{E}-0 \mathrm{~B}$ & $8.267 \mathrm{E}-00$ \\
\hline $5.000 E+00$ & $6.182 E \sim 08$ & $5.933 \mathrm{E}-08$ \\
\hline $5.765 E+00$ & $3.926 \mathrm{E}-08$ & 3.897E-08 \\
\hline $6.646 E+00$ & $2057 E-08$ & $1.966 \mathrm{E}-08$ \\
\hline $7.663 \mathrm{E}+00$ & $1.030 \mathrm{E}-08$ & $9.895 E-09$ \\
\hline $8.835 E+00$ & $4873 \mathrm{E}-09$ & $4.025 \mathrm{E}-09$ \\
\hline $1.019 E+01$ & $1.779 \mathrm{E}-09$ & $1.755 \mathrm{E}-09$ \\
\hline $1.174 \mathrm{E}+01$ & $6.478 \mathrm{E}-10$ & $5.241 \mathrm{E}-10$ \\
\hline $1.354 E+01$ & $1.572 \mathrm{E}-10$ & $1.613 \mathrm{E}-10$ \\
\hline $1.561 E+01$ & $4.461 E-11$ & $4,001 \mathrm{E}-11$ \\
\hline $1.800 E+00$ & & \\
\hline
\end{tabular}

“Without walls, floor, and air.

Wilh walls, tloor, and air.

In the near future, we will make a comparison between the MORSE results and that from the radiation-transport code, TART. Also, we will try to resolve the spectra differences in the codes O5R and MORSE. 


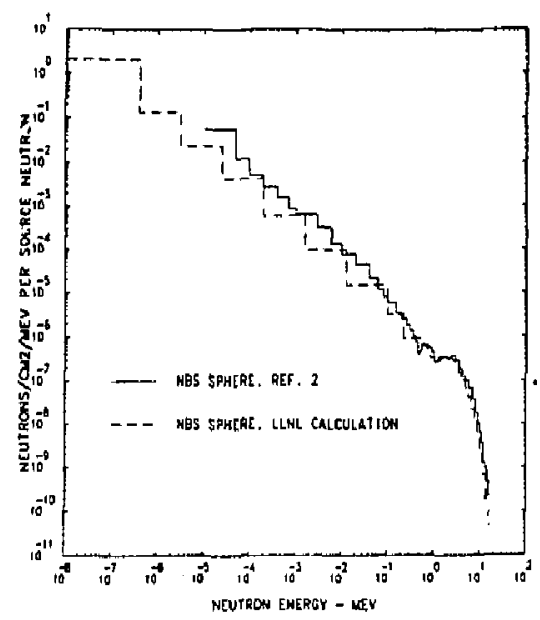

Figure 2. NBS sphere vs NBS sphere with LLNL calculation.

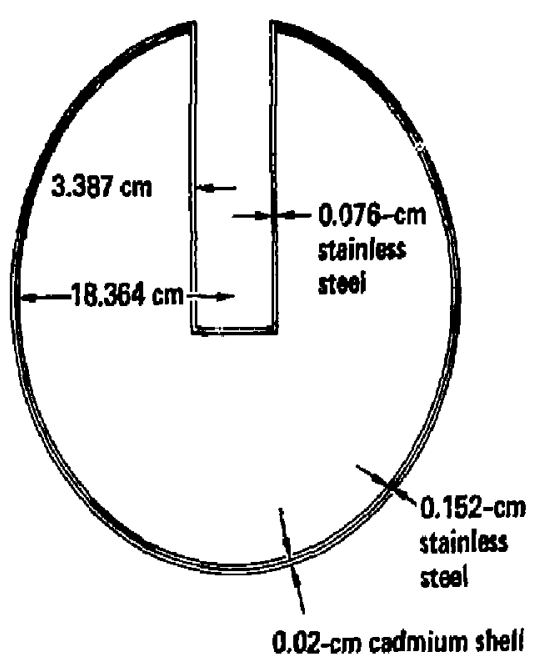

Figure 3. Model of LLNL $15-\mathrm{cm} \mathrm{D}_{2} \mathrm{O}$ sphere.

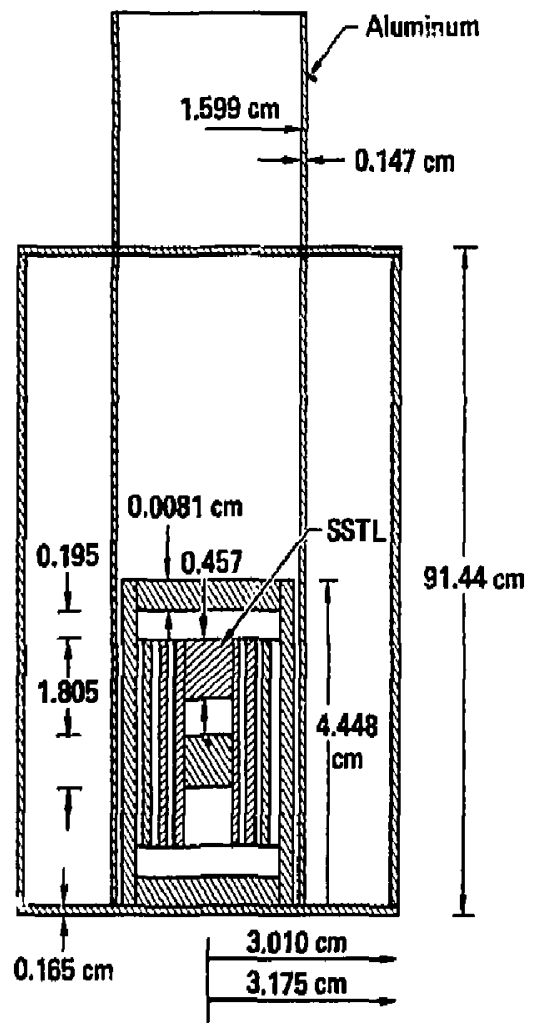

Figure 4. Source encapsulation and rabbit for LLNL model. 


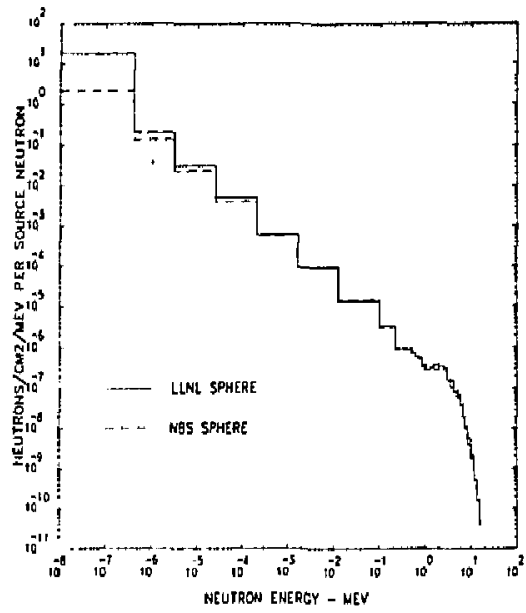

Figure 5. LLNL sphere vs NBS sphere calculation.

\section{References}

1. R. V. Griffith, D.R. Slaughter, H.W. Patterson, J. L. Beach, E. C. Frank, D. W. Rueppel, and J.C. Fisher, "Multi-Technique Characterization of Neutron Fields from Moderated ${ }^{252} \mathrm{Cl}$ and ${ }^{238} \mathrm{PuBe}$ Sources," Proc. National and International Standardization of Radiation Dosimetry, Atlanta, GA, Vol. II, p. 167 (Dec, 5-9, 1977).

2. H. Ing and W. G. Cross, "Spectral and Dosimetric Characteristics of a $\mathrm{D}_{2} \mathrm{O}$-Moderated ${ }^{252} \mathrm{Cl}$ Calibration Facility," Health Physics 46, 1 (1984).
3. H. Ing and S. Makra, JAEA Compendium of Neutron Spectra in Crittcality Accident Dosimetry, International Atomic Energy Agency, Vienna, Austria, Technical Report Series No. 180 (1978).

4. R. B. Schwartz and C. M. Eisenhaur, The Design and Construction of a $\mathrm{D}_{2} \mathrm{O}$-Moderated ${ }^{252} \mathrm{Cf}$ Source for Calibrating Neufron Personnel Dosimeters Used at Nuclear Potwer Reactors, National Bureau of Standards, Gaithersburg, MD, NUREG/CR-1204 (1980).

5. R. B. Schwartz, private communication, National Bureau of Standards, Gaithersburg, MD (August 1983). 


\title{
Programs for Calculating Beta Spectra
}

\author{
Charles T. Prevo
}

Several programs have been written to calculate beta spectra given the atomic number of the daughter and the transition energy. We discuss and compare two methods of obtaining Fermi function values.

\section{Introduction}

With the recent increased interest in beta dosimetry by the nuclear industry, a need exists to have beta spectra available for theoretical analyses such as radiation transport. The calculation of detecter response functions requires the use of a gamma, $\Gamma$, function with a complex argument. This function cannot be readily evaluated, but it has been tabulated; Wilkinson has developed analytical approximations. ${ }^{1,2}$ Mantel has reported beta spectra ${ }^{3}$; unfortunately, he does not include tables of intensity versus energy, so the data is difficult to use. So, we wrote several codes Ior the HP.85 which will calculate any beta spectrum of interest.

\section{Fermi Function}

Beta particles of either sign (positive or negative electrons) may be ejected in the course of spontaneous transformation of atomic nuclei. The statistical distribution of the electrons ejected covets all energies from zero up to a maximum energy, $E_{0}$, characteristic of the transformation. This distribution of electron energies reflect the relative probability of the various possible ways in which the lotal energy, $E_{0,}$ released by a nucleus, can be shared between an electron and a neutrino.

The probability of emission of an electron is proportional to the Fermi function, which is tefined as the ratio of the electron density at the. daughter nucleus to the density at infinity (outside the atom):

$$
\begin{aligned}
f(Z, E)=f(Z, \eta)= & =\frac{|\phi e(0)|}{\delta e(\infty)_{2}} \\
& =\pi^{2 s} e^{-\pi \delta}(1+s+i 6),
\end{aligned}
$$

where

$\Gamma(z)=$ complex gamma function $\mathrm{Z}=$ atomic number of daughter

$$
\begin{aligned}
& \eta=\text { momentum of electron after its } \\
& m_{0}=\text { mass of the electron, } \\
& c=2.99776 \times 10^{8} \mathrm{~m} / \mathrm{sec} \text {, } \\
& v=\text { velocity of electron }(\mathrm{m} / \mathrm{sec}) \text {, } \\
& \beta=v / c=\eta / \sqrt{1+\eta^{2}}, \\
& \varepsilon=w=\sqrt{1+\eta^{2}}=\text { total energy of } \\
& \text { electron (in units of } \mathrm{mc}^{2} \text { ) } \\
& T=m^{2}(w-1)=\text { kinetic energy of } \\
& \text { electron (in units of } \mathrm{mc}^{2} \text { ) } \\
& \gamma=Z / 137 \text {, } \\
& s=\sqrt{1-\gamma^{2}}-1 \text {, } \\
& \delta=\gamma / \beta=Z \sqrt{1+\eta^{2}} / 137 \eta \text {, } \\
& =(4 \pi \mathrm{mc} R / h)^{2 s}[\Gamma(3) / \Gamma(3+2 s)]^{2} \\
& (1+5 / 2) \text {. } \\
& R=\text { nuclear radius }=1.37 \mathrm{~A}^{1 / 3} 10^{-15}(\mathrm{~m}) \text {, } \\
& h=6.62 \times 10^{-34} \mathrm{~J}-\mathrm{s} \text {, and } \\
& A=\text { atomic weight. }
\end{aligned}
$$

The Fermi function depends on the atomic number of the daughter and electron energy, but not of the maximum energy.

\section{Beta Spectrum}

The beta spectrum is related to the Fermi function by the relation

$$
\begin{aligned}
N(E)= & f_{c}(Z, E)\left(E_{0}-E\right)^{2} \\
& \quad \times(E+1)\left(E^{2}+2 E\right)^{-1 / 2},
\end{aligned}
$$

where $E$ is in units of $m_{0} c^{2}$, and $f_{r}$ is the Fermi function multiplied by a screening correction and a shape factor. Since the screening correction rarely has more than a 2-3\% effect, it was ignored for thest calculations,

Shape Factor. The transition probability is proportional to the product of the electron and neutrino wave functions. Consecutive terms in the expansion for these wave functions decrease rapidly. The first term in the expansion generates the 
allowed transition, and successive terms refer to the forbidden iransitions of increasing order. These forbidden transitions have diminishing, but nonvanishing probability.

Allowed transitions are characterized by the absence of a change in nuclear spin and parity $(\Delta)=0, \Delta x=n o$ ). Forbidden transitions are hindered by the involvement of a change in nuclear spin and parity $(\Delta)=1, \Delta x=$ yes $)$. Unique transitions are associated with those forbidden transitions governed by a single moment, as against parity-forbidden trar itions which are govemed by a combination r eral beta moments. Presently, it is impossib. o calculate the shape for non-unique forbidden spectra. However, it has been shown empirically that the non-unique, first-forbidden spectra have a shape similar to unique, allowed transitions, ${ }^{4}$ and the non-unique, second-forbidden spectra have a shape similar to unique, first-forbidden transitions. ${ }^{5}$ Table 1 shows the shape-comection type for various transition classifications. The type of transition is given by Mantel for a large number of transitions. ${ }^{3}$ The shape-correction factor for unique spectra is given by

$$
S_{n}=\sum_{n=0}^{n} \frac{(2 \nu+1) !}{4^{n}(\nu !)^{2}(2 n-2 \nu+1) !} !^{2(n-n)} L_{\nu},
$$

where

$$
\begin{aligned}
& n=\text { degree of forbiddenness, } \\
& \eta=\text { neutrino momentum in units of } m_{0} c, \\
& \text { and } \\
& L=\text { tabulated function. }{ }^{5.6}
\end{aligned}
$$

For unique, forbidden spectra, the correction factor, $S_{n^{\prime}}$ simplifies to

$$
\begin{aligned}
S_{1}= & \left(w^{2}-1\right)+\left(w_{0}-w\right)^{2} \\
S_{2}= & \left(w^{2}-1\right)^{2}+\left(w_{0}-w\right)^{4} \\
& +10 / 3\left(w^{2}-1\right)\left(w_{0}-w\right)^{2}
\end{aligned}
$$

$$
\begin{aligned}
S_{3}= & \left(w^{2}-1\right)^{3}+\left(w_{0}-w\right)^{6}+ \\
& 7\left(w^{2}-1\right)\left(w_{0}-w\right)^{2}\left[\left(w^{2}-1\right)\right. \\
& \left.+\left(w_{0}-w\right)^{2}\right] .
\end{aligned}
$$

Since we are really interested in the shape and not the magnitude of these corrections, the comection factors were all nomalized to their value at zero kinetic energy $(w=1)$. Thus, $S_{1}$ was divided by $S_{1}(1)=\left(w_{0}-1\right)^{2} ; S_{2}$ by $S_{2}(1)=\left(w_{0}-\right.$ $1)^{4} ; S_{3}$ by $S_{3}(1)=\left(w_{0}-1\right)^{6}$. The shape-correction factor for allowed spectra is 1 .

\section{Evaluating the Fermi Function}

There are two ways of obtaining values of the Fermi function. The first is to interpolate between values tabulated in the NBS tables, and the second is to use Wilkinson's approximation for the complex gamma function to derive an analytical expression for the Fermi function.

The program NBSTAB was written to take 80 pairs of energy and Fermi function values from the NBS tables and create a data file which can be read by the program that then calculates the beta spectrum (called BETAS). This was done so that the table values would only have to be entered once. They are then saved in a data file for subsequent use. BETAS reads the energy and Fermi function data from the file created by NBSTAB and interpolates to obtain Fermi function values at energies of interest, which are integer multiples of $E_{0} / 20$. For energies greater than $3.1018 \mathrm{MeV}$ $(\eta=7)$, the following expression is used:

$f(Z, \eta)=\eta^{2} F(Z, \eta)=\eta^{2+2 s}\left(A+B / \eta+C / \eta^{2}\right)$

\begin{tabular}{|c|c|c|c|c|}
\hline $\begin{array}{l}\text { Mantel } \\
\text { type }\end{array}$ & CIstifieation & $\begin{array}{l}\text { Nuclear spin } \\
\text { change }\end{array}$ & $\begin{array}{c}\text { Noclear parity } \\
\text { change }\end{array}$ & Shape type \\
\hline 0 & Allowed & $0, \pm 1(n \times t 0-0)$ & No & 0 \\
\hline $1^{\prime}$ & Nen +un ique, fint-forbladen & $0, \pm 1$ & Yes & 0 \\
\hline 1 & Unique, fint-forbldden & \pm 2 & Yes & 1 \\
\hline$z^{\prime}$ & Non-unique, forbidden & \pm 2 & No & 1 \\
\hline 2 & Unique, mecond-forbidden & \pm 3 & No & 2 \\
\hline
\end{tabular}

The values of $A, B$, and $C$ are tabulated in the NBS tables for each 2 . This program also calculates the spectral correction factors which vary for allowed and forbidden transitions. The corrected spectrum is written out on the printer as a function of energy, and is written to a data file that can be plotted with the program DPLOTM, which is a modified version of HP's DPLOT.

Table 1. Shape-correction type for various transition classifications. 
The code WLKFF uses a Wilkinson approximation for the complex gamma function to calculate the Fermi function and create a data file which an be read by BETAS. For this case,

$$
\begin{gathered}
F(Z, w)=2(1+\gamma)(2 p R)^{2(\gamma-1)} \mathrm{e}^{\frac{-x \alpha 2 w}{p}} \\
\quad \times[\Gamma(2 \gamma+1)]^{-2}\langle\Gamma(\gamma+i \alpha Z z w / p))^{2},
\end{gathered}
$$

where

$$
\begin{aligned}
\ln [(z)= & (z-1 / 2) \ln z-z+1 / 2 \ln (2 \pi) \\
& +1 / 12 z+\ldots \\
\ln (x+i y)= & (x-1 / 2) \ln \left(x^{2}+y^{2}\right) \\
& -2 y \text { Arctan }(y / x)-2 x \\
& +\ln (2 \pi)+x /\left[6\left(x^{2}+y^{2}\right)\right]+\ldots . \\
w= & \text { total electon energy in } m_{0} c^{2} \text { units, } \\
p= & {\left[w^{2}-1\right]^{1 / 2}, } \\
s= & (E-2) /(E+2), \\
= & e^{2} / \operatorname{hc}=1 / 137, \text { and } \\
= & {\left[1-(x Z)^{2}\right]^{1 / 2} . }
\end{aligned}
$$

The function, $\Gamma(2 \gamma+1)$, depends on $Z$, and since it has no effect on the shape, it does not need to be included in the calculation.

Figure 1 , a flow chart illustrating the use of the codes, shows two methods of obtaining the spectra. The first involves the use of NBSTAB, BETAS, and DPLOTM. After the initial use of NBSTAB for a given $Z$, only BETAS and DPLOTM are required for subsequent calculations for that $Z$. The second method requires only WLKFF and DPLOTM.

\section{Results}

Both BETAS and WLKFE were used to calculate spectra for ${ }^{11^{7}} \mathrm{Pm},{ }^{214} \mathrm{Tl}$, and ${ }^{90} \mathrm{~S}$. Although different in magnitude, the shape determined by the two methods are within $1 \%$ at all energies and within a tenth of a percent, except near the ends of the spectra. Thus, the Wilkinson approximation is more than adequate and is easier to use than entering the NBS values from tables. Our results are given in Tables 2,3, and 4, and also shown in Figs. 2, 3, and 4. Both uncorrected and comrected spectra are shown to illustrate the effect of the shape-correction factor.

\section{References}

1. U.S. Department of Commerce, Tables for the Analysis of Beta Spectra, National Burreau of Standards, Applied Mathematics Series 13.

2. D. H. Wilkinson, "Evaluation of the Fermi Function," Nuclear Instruments and Methods 82, 122-124 (1970).

3. J. Mantel, "The Beta Ray Spectrum and the Average Beta Energy of Several Isotopes of Interest," Jourmal of Applied Radiation and Isotopes 23, 407-413 (1972).

4. L. T. Dillman, "Radionuclide Decay Schemes and Nuclear Parameters for Use in Radiation-Dose Estimation," I. Nucl. Med. 10, Suppl. 2 (1969).

5. K. Siegbahn, Beta- and Gamma-Ray Spectroscopy (North-Holland Publishing Co.r Amsterdam 1955), p. 328.

6. M. E. Rose, Tables for the Anolysis of Allowed and Forbidden Bela Transitions, Oak Ridge National Laboratory, Oak Ridge, TN, ORNL. 1459 (1953). 


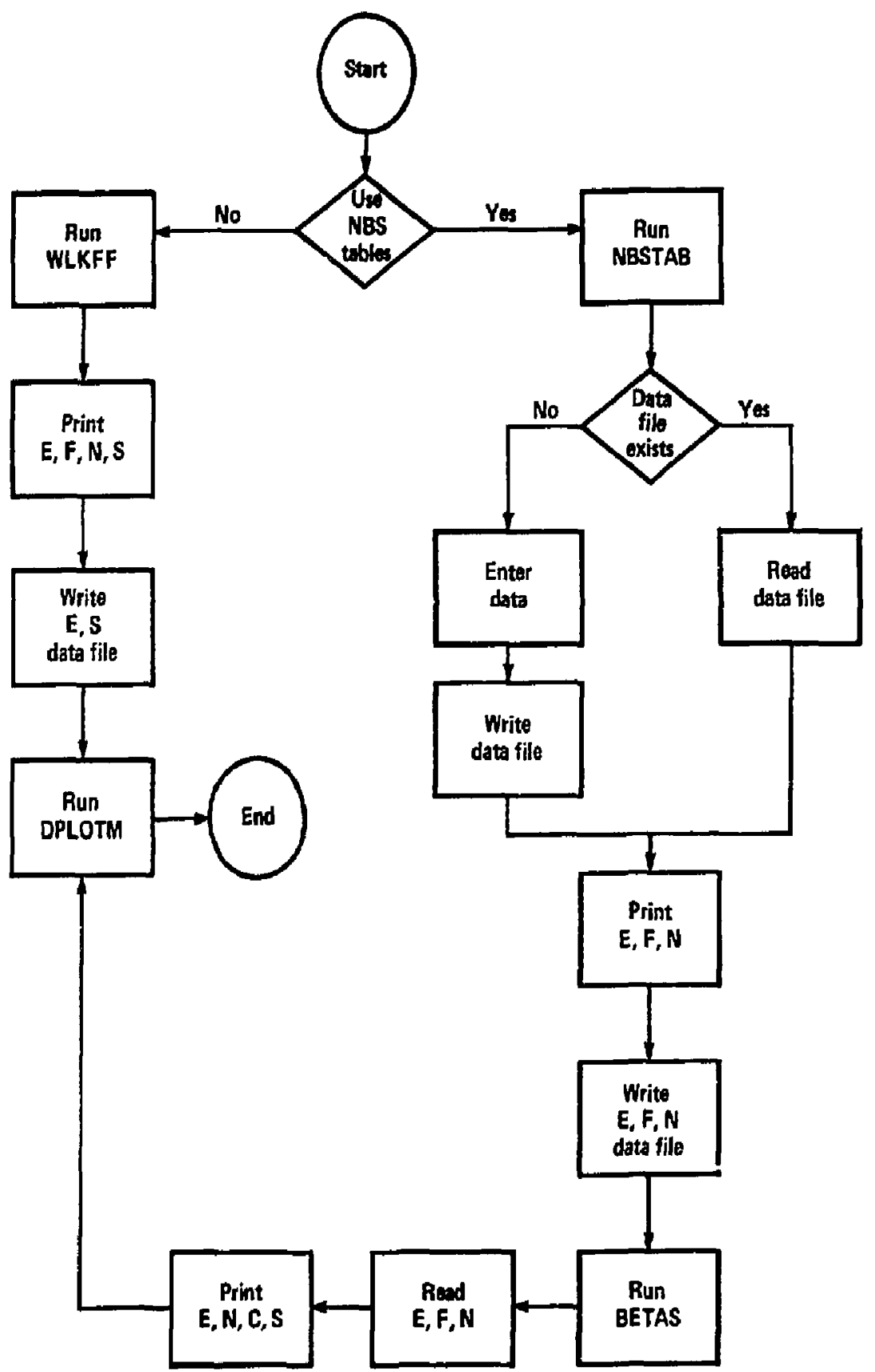

Figure 1. Flowchart for calculation of the beta spectrum. 
Table $2{ }^{14} \mathrm{Pm}$ bela spectrum.

\begin{tabular}{cccc}
\hline$E(\mathrm{MeV})$ & $N(E)$ & $C$ & $\$(E)$ \\
\hline 0.0016 & 0.650 & 1.000 & 0.650 \\
0.0112 & 0.607 & 1.000 & 0.606 \\
0.0225 & 0.567 & 1.000 & 0.567 \\
0.0337 & 0.523 & 1.000 & 0.523 \\
0.0149 & 0.479 & 1.000 & 0.479 \\
0.0561 & 0.436 & 1.000 & 0.456 \\
0.0674 & 0.393 & 1.000 & 0.342 \\
0.0786 & 0.350 & 1.000 & 0.350 \\
0.0996 & 0.306 & 1.000 & 0.306 \\
0.1010 & 0.267 & 1.000 & 0.267 \\
0.1123 & 0.228 & 1.000 & 0.228 \\
0.1235 & 0.190 & 1.000 & 0.190 \\
0.1347 & 0.155 & 1.000 & 0.155 \\
0.1459 & 0.122 & 3.000 & 0.122 \\
0.1572 & 0.093 & 1.000 & 0.093 \\
0.1684 & 0.066 & 1.000 & 0.066 \\
0.1796 & 0.044 & 1.000 & 0.044 \\
0.1908 & 0.025 & 1.000 & 0.025 \\
0.2021 & 0.012 & 1.000 & 0.012 \\
0.2193 & 0.003 & 1.000 & 0.003 \\
0.2245 & 0.000 & 1.000 & 0.000 \\
\hline & & &
\end{tabular}

Table 3. ${ }^{204} \mathrm{Tl}$ bela spectrum.

\begin{tabular}{|c|c|c|c|}
\hline$E(M e V)$ & $N(E)$ & $C$ & $S(E)$ \\
\hline 0.0006 & 10.31 & 0.999 & 10.31 \\
\hline 0.0382 & 10.36 & 0.972 & 10.07 \\
\hline 0.0764 & 10.30 & 0.954 & 9.82 \\
\hline 0.1145 & 10.12 & 0.946 & 9.57 \\
\hline 0.1527 & 9.81 & 0.948 & 9.30 \\
\hline 0.1909 & 9.40 & 0.960 & 9.02 \\
\hline 0.2291 & 8.89 & 0.962 & 8.73 \\
\hline 0,2672 & 8.29 & 1.013 & 8.40 \\
\hline 0.3056 & 7.61 & 1.055 & 8.03 \\
\hline 0.3436 & 6.87 & 1.107 & 7.61 \\
\hline 0.3818 & 6.08 & 1,161 & 7.11 \\
\hline 0.4199 & 5.26 & 1.261 & 6,53 \\
\hline 0.4581 & 403 & 13323 & 5.86 \\
\hline $0,4 \% 63$ & 3,61 & 1.415 & 5.10 \\
\hline 0.5315 & 281 & 1.517 & 4.26 \\
\hline 0.5726 & 207 & 1.624 & 3,37 \\
\hline 0.6108 & 1.6 & 1.731 & 2,45 \\
\hline 0.6490 & 0.83 & 1.113 & 1.56 \\
\hline 0.6072 & 0.39 & 2025 & $0.7 \mathrm{~A}$ \\
\hline 0.7253 & 0.10 & 2176 & 0.22 \\
\hline 0.7635 & 0.00 & 2.334 & 0,00 \\
\hline
\end{tabular}

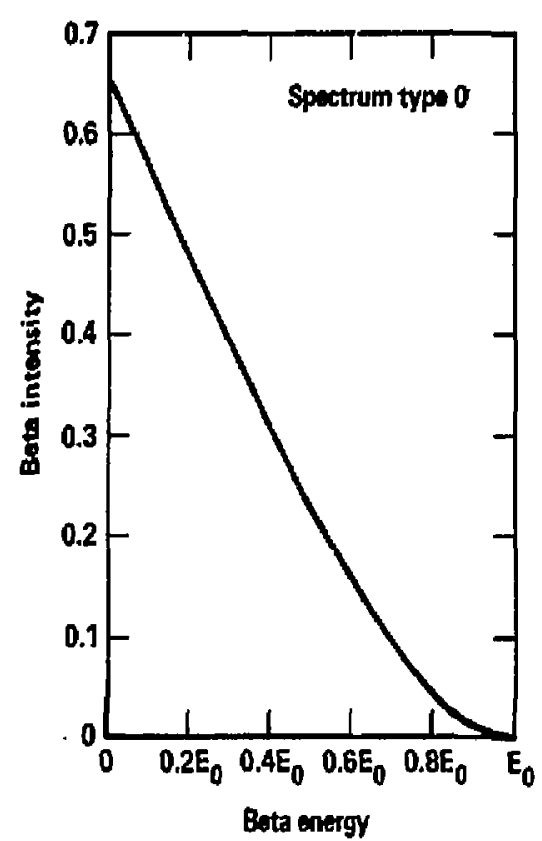

Figure 2. ${ }^{147} \mathrm{Pm}$ bela specirum.

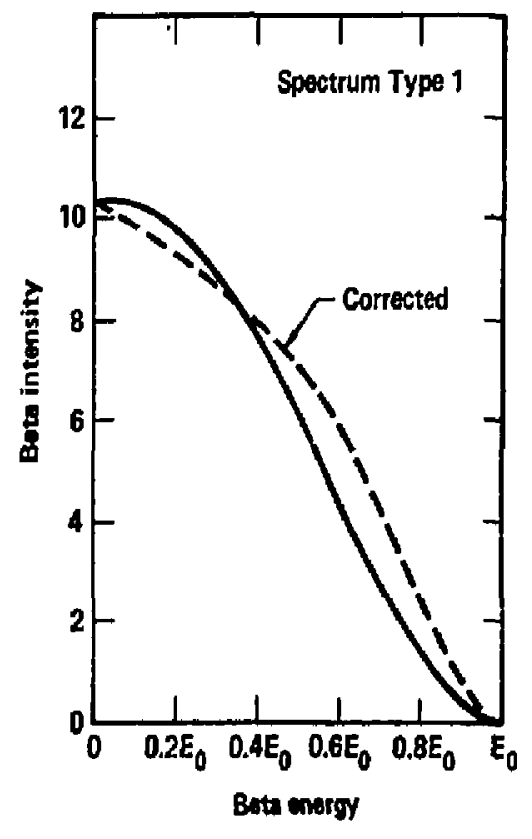

Figure 3. Tl bela spectrum. 
Table 4. "Sr beta spectrum.

\begin{tabular}{|c|c|c|c|}
\hline E(MeV) & $N(E)$ & c & SE) \\
\hline 0,0006 & 40.7 & 1.000 & 40.7 \\
\hline 0.1135 & 54.1 & 0.926 & 50,2 \\
\hline 1.22570 & 68.8 & 0.865 & 59.5 \\
\hline 0.3405 & 321 & 0.813 & 66.7 \\
\hline 0.4540 & 93.5 & 0.770 & 720 \\
\hline 0.5675 & 1025 & 0,738 & 75.6 \\
\hline 0.6810 & 100.8 & 0.715 & 77.8 \\
\hline 0.7945 & 112.1 & 0.703 & 76.8 \\
\hline 0.9000 & 1124 & 0.700 & 78.7 \\
\hline 1.0215 & 109.7 & 0,708 & 7.6 \\
\hline t.1350 & 104.2 & 0.725 & 75.5 \\
\hline 1.245 & 96.0 & 0.753 & 723 \\
\hline 1,3620 & 85.6 & 0.790 & 67.7 \\
\hline 1,4755 & 73.5 & 0,838 & 61.5 \\
\hline 1.5890 & 60.1 & 0.895 & 53.8 \\
\hline 1.7025 & 46.2 & 0.963 & 4.5 \\
\hline 1.8160 & 325 & 1.090 & 33.8 \\
\hline 9.9295 & 20.1 & 1,128 & 22.6 \\
\hline 2.0430 & 9.7 & 1.123 & 11.9 \\
\hline 2.1565 & 26 & 1.333 & 3.5 \\
\hline 2.2700 & 0.0 & 1.450 & 0.0 \\
\hline
\end{tabular}

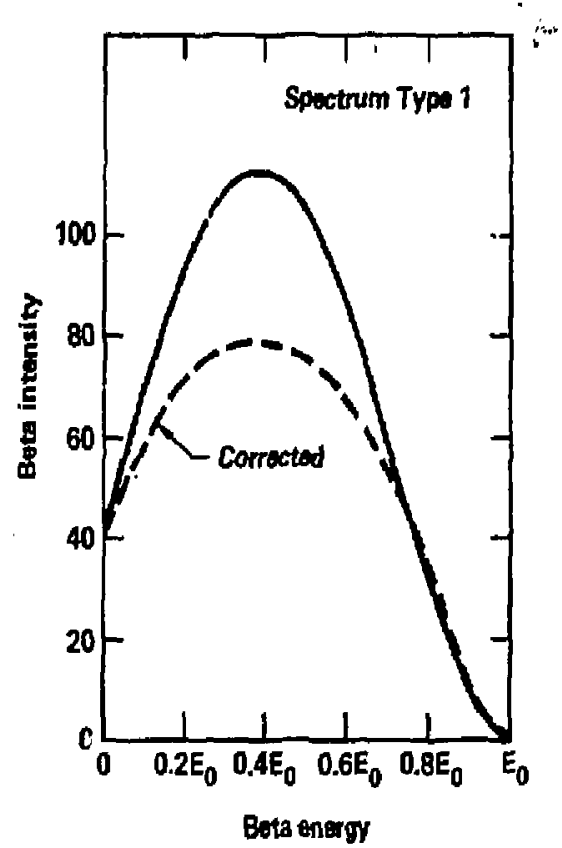

Figure 4, ${ }^{90} \mathrm{Sr}$ beta spectrum. 


\title{
CAM Particle Deposition Evaluation
}

\author{
Arthur Biermann and Steve Velen
}

We assessed particle deposition and loss occurring in an Eberline Alpha-3 Continuous Air Monitor (CAM) using monodisperse test aerosols. Our study also included the investigation of detection loss due to deposition of nonuniform particles on the collection filter. Results indicate that particle losses were is strong function of aerosol size, with a $44 \%$ loss occurring for $6-\mu \mathrm{m}$ diameter aerosols and a $0.3 \%$ loss for the $0.6-\mu \mathrm{m}$ diameter aerosols.

\section{Introduction}

We investigated the deposition and loss of laboratory-generated aerosols in an Eberline Alpha-3 Continuous Air Monitor (CAM). CAMs are used at LLNL in radiation alarm systems; they contain 47-mm-diameter particulate collection filters and $25 \cdot \mathrm{mm}$ alpha detectors. We determined the distribution of dilferent aerosol sizes on the particulate-collection filter in order to investigate the effectiveness of the CAM's sampling and detector configuration. We also assessed the dependence of aetosol losses in the sampling inlet, filter housing and other locations it the CAM detector and filter chamber as a function of particle sice. This information, along with a spatial calibration of the alpha detector, result in a more quantitative determination of alarm points for the CAM.

\section{Experimental Procedure}

Monodisperse aerosols of dioctylsebacate (DOS) and methylene blue (MB) were generated using a Berlund-Liu aerosol generator. ${ }^{1}$ This generator uses a vibrating arifice to produce uniformly sized droplets from a pressurized liquid solution. We added dispersion air to the particles, and added additional air to evaporate the droplets leaving the solute as either a solid or nonvolatile liquid particle. The concentration of the solution and the size of the orifice desermined the final aerosol particle size. We generated three different sized aprosols. A solution of $0.01 \% \mathrm{MB}$ in isopropanol resalted in a $056 \cdot \mu \mathrm{m}$-diameter solid

\footnotetext{
'R. N. Berglund and B. Y. H. Lit, "Cenention of Monodisperse Aetosol Sundards," Lnv. Sri. and Teth, 7 147-352 (1973).
}

aerosol, Solutions of 0.01 and $0.1 \%$ DOS pro-

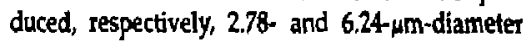
liquid aerosols. Trace amounts of MB were also added to the DOS solutions for subsequent spectrophotometric antalysis. After generation, the aerosol particles were passed vertically upwand through a ${ }^{85} \mathrm{Kr}$ ionizing aerosol neutralizer, and then eirected downward toward the CAM inlet sample port.

The size distributions of the aerosols were monitored using a Climet 208 optical-particle analyzer. The Climet had been calibrated for particle sizes from $0.3-$ to $10.0-\mu \mathrm{m}$ in diameter using aerosols of uniform latex spheres. Before each CAMsampling period, we used the optical counter to verify the uniformity of the aerosol distribution. If any doublet or triplet particles appeared, the aerosol generator was readjusted to eliminate them. Fot each test aerosol, several Climet size distributions were taken during the CAM-sampling periods. The size values we report are the average of the geometric mean diameters from the Climet distributions.

The CAM contained a 47-mm diameter, cellulose membrane filter with a pore diameter of $5.0 \mu \mathrm{m}$. The sampling flow rate for the three aerosol tests was $11 \mathrm{lpm}$ (or $30 \mathrm{lpm}$ as measured by the CAM rotometer). We used sampling times from 60 to $90 \mathrm{~min}$ depending on the particular aerosol size.

Aerosol particles that wese deposited on the surfaces of the CAM sample chamber walls or inlet probe were removed by repeated swipes using Q-tips soaked in acetone. Each swipe was rinsed in 5 or $10 \mathrm{cc}$ of acetone. Aerosel particles collected by the filter were removed by dissolving portions of the filter in acetone. A DK-11 spectrophotometer was used to measure the absorbanc. If $M B$ in the solutions. 


\section{Results}

We measured the amsunt of particle deposition for eight different portions of the CAM chamber, including the collectior, filter A schematic depicting the loxation of thes. areas is shown in Fig. 1 . The deposition occurritg in these areas is listed in Table 1 for the three test aerosols. Diameters of the test aerosols are reported as the optical particle diameters and calculated aerodynamic diameters. Deposition values are given as percentages relative to the total mass of MB retrieved from all CAM surfaces and the filter. The fitter was the major collection area for the smaller particle sizes, with 96.0 and $99.7 \%$ of the particle de-

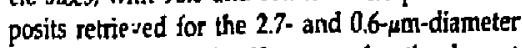
aerosols, respectively. However, for the largest
Table 1. CAM serosol deposition at 30 lpm (CAM rotameter) for three monodisperse aerosols.

\begin{tabular}{lccc}
\hline & 1 & 2 & 3 \\
Optical dianeler (Mni & 6.23 & 276 & 0.54 \\
Aerodynamic diameter (m) & 5.95 & 265 & 0.64
\end{tabular}

\begin{tabular}{|c|c|c|c|}
\hline Location & \multicolumn{3}{|c|}{ Iof total deponts } \\
\hline inlet tube & 0.61 & 0.42 & 0.055 \\
\hline Inlet tobe, boltow & 206 & 14 & 0.071 \\
\hline Ares above delector & 4.0 & D.AB & 0.05 \\
\hline Ret of ures aroused detector & 1,90 & 0.11 & 0.036 \\
\hline Rent of chamber, back, outide & 4.67 & 0.35 & 0.04 \\
\hline Filtet holder tidag & 0.50 & 0.46 & 0.022 \\
\hline Detector & 0.05 & 0,11 & 0.02 \\
\hline Filler & 46.2 & 9.0 & 99.7 \\
\hline
\end{tabular}

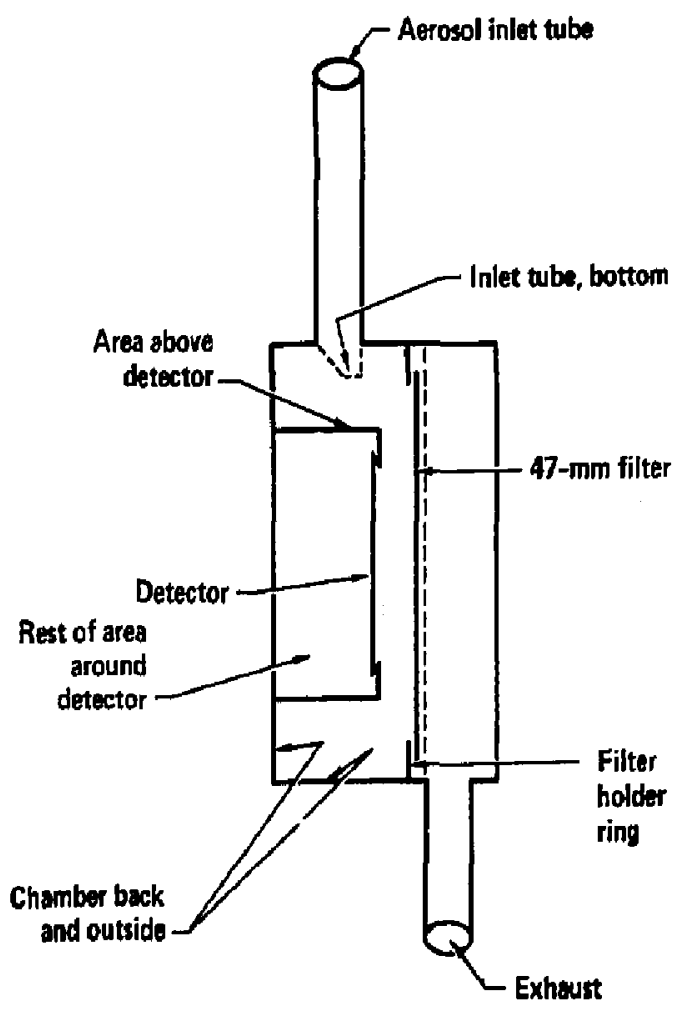

Figure 1. CAM chamber and collection areas. 


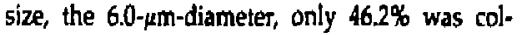
lected by the filter. Areas of significant collection occured in serosol inlet regions of the CAM. In the case of the $6.0-\mu \mathrm{m}$ aerosol, the area above the detector and opposite the inlet collected $44 \%$ of the particles, neariy as much as the filter itself. Obviously, the larges particles deviate from the air streamlines as they approach the filter and hit this localized area above the detector.

Secondary collection areas for the largersized particles are the outside edge and back of the chamber and the inlet tube itself. C.smbined, these areas captured $7.2 \%$ of the $6.0-\mu \mathrm{m}$ particles, but only $1.1 \%$ of the $2.6-\mu \mathrm{m}$ particles.

The deposition patterns of the particles captured on the filter surface are illustrated in Fig, 2 for the 0.6-, 2.7-, and 6.0- $\mu \mathrm{m}$-diameter cases. The most uniform collection is that for the $0.6-\mu \mathrm{m}$ diameter particles, while the 2.7- and 6. $\mathrm{C}$-um diameter particles silow marked high concentrations in an area of the filter which is opposite the chamber from the inlet. With these pattems in inind, filters from actual tests were divided into four concentric areas. The subdivided area boundaries are illustrated on the clean filter in Fig. 2. The percentage of particle deposition in the subdi ided areas trlative to the total collected on the filter is presented in Table 2 . The values confirm quantilatively that particle collection is extremely nununiform on the filter surface. For all test aerosols, deposition decreases toward the center of the filter.

Since the detector itself is only $25 \mathrm{~mm}$ in diameter, it is imporlant to asrertain the detection efficiency for areas of the filter lying outside its

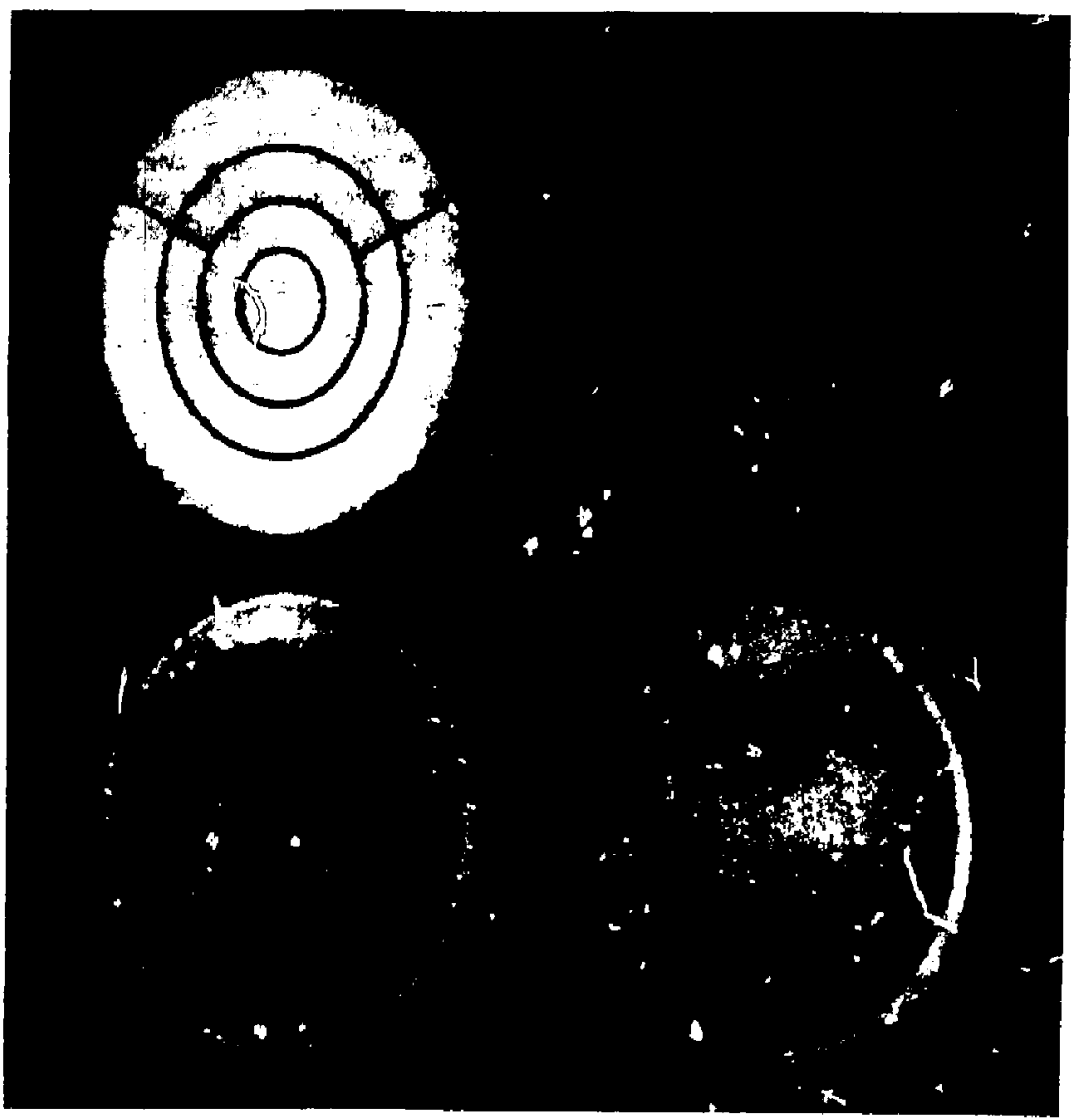

Figure 2. Particle deposition on the collection filter for (a) a clean filter showing subdivided areas, (b) $0.6 \mu \mathrm{m},(\mathrm{c}) 2.7 \mu \mathrm{m}$, and (d) $0.0 \mu \mathrm{m}$ aerosols. The CAM outlet is at the top. 
Table 2. Aerosol deposition on the CAM filter for the three tesl acrosols.

\begin{tabular}{|c|c|c|c|}
\hline & 1 & 2 & 3 \\
\hline Optical diameler ( $\mu \mathrm{m})$ & 6.23 & 2,78 & 0.56 \\
\hline herodynmic diameler ( $\mu \mathrm{m})$ & 5.95 & 2.65 & 0.64 \\
\hline Concentric arex (radius, $\mu \mathrm{m})$ & \multicolumn{3}{|c|}{$\approx$ of lokal tilter deponits } \\
\hline $15-23.5$, top $1 / 3^{2}$ & 17.5 & 18,4 & 16.5 \\
\hline 15-22.5, remainder $2 / 3$ & 25.1 & 31.4 & 33.9 \\
\hline $10-15, \operatorname{top} 1 / 3^{n}$ & 34.0 & 15,7 & 10.5 \\
\hline jo- 15, Jemainder $2 / 3$ & 9.4 & 15.5 & 17.8 \\
\hline $5-10$ & 12.9 & 14.9 & 16.9 \\
\hline $0-5$ & 1.2 & 4.0 & 4,4 \\
\hline
\end{tabular}

- Top 1/3 is the ares of filter directly opposite the CAM inlet.

projected area onto the filter. For this reason, a spatial calibration was performed using a ${ }^{239} \mathrm{Pu}$ source having a 3-mm effective diameter. We can estimate what fraction of particles collected by the filter are actually detected by integrating the product of the spatial calibration and particle collection over the filter area. The percentage of particles acrually delected are 32,34 , and $35 \%$ for the 6.0 2.7-s and 0.6- $\mu \mathrm{m}$ diameter aerosols, respectively.
Thus, many of the nonhomogeneities in particle deposits seen on the filter ure cancelled by the detector integration. Relatir. the percentages to the total deposition throughout the CAM, the fractions detected are 15,32 , and $34 \%$ for the 6.0 . 2.7-, and 0.6- $-\mu \mathrm{m}$ diameter aerosols. The lower value for the larger aerosol test case resulted from the significant particle losses in other areas of the CAM.

\section{Conclusions}

Particle loss in the CAM is extremely sensitive to the aerosol size distribution in the $0.6-$ to 6.0- $\mu \mathrm{m}$ diameter range. Using monodisperse aerosols, losses ranged from $0.3 \%$ for 0.6 - $\mu \mathrm{m}$ diameter to over $50 \%$ for particles as large as $6-\mu \mathrm{m}$ in diam. eter. Particle collection on the $47-\mathrm{mm}$ diameter filter was nonhomogeneous for all particle sizes, but especially so for $2 \mu \mathrm{m}$ and above. For the largest particle size we considered, it was estimated that only $15 \%$ of the aerosol would actually be detected. For smaller aerosols, filter collection approaches $100 \%$ and the amount detected approaches $35 \%$. 


\title{
Mercury Scrubber for the Ostlund Tritium Monitor
}

\author{
Peter M. Swearengen, James S. Johnson, Charles A. Harder, and Lisa M. Caldweel]
}

We describe a mercury srrubber that will be placed in an air stream containing tritjum. The device removes mercury by amalgamation on a gold surface. We observed an inlet-to-outlet removal of mercury ratio of 5000 . The scrubber will be placed in a flow system to protect an Osluund Tritium Monitor.

\section{Introduction}

The Ostiund tritium monitor in Building 331 at LLNL uses a palladium catalyst on molecular sieve material to trap tritiated hydrogen gas. The monitor is in continuous use for stack-effluent observation. Future decontamination operations in the building will release mercury vapor into the effluent. Since mercury poisons the palladium catalyst, a scrubbing system will be necessary to clean mercury vapor from the $250 \mathrm{ml} \cdot \mathrm{min}^{-1}$ gassampling stream passing through the Ostlund device.

\section{Device Description}

The tendency of elemental mercury to combine with certain other metals to form amalgams is well-known. 'Gold readily amalgamates with mercury, and this combination is used as the basis for the scrubber design. To enhance amalgamation, it seemed desirable to provide a large sur$f_{L}$ ce area of gold.

We chose stainless-steel wool material" for its high surface area and electroplated it with gold. Approximately $225 \mathrm{~g}$ of the gold-plated wool material was divided into four sections and compressed into the individual rompartments of the flow device shown in Fig. 1, Each compartment module is individually threaded and the sub-units are screwed together in series for the complete assefnbly. With this construction, disatsembly for cleaning or replacement of the element is simple and rapid.

To further enhance the scrubbing efficiency of this unit, we chose a convoluted flow path. Air enters the cylindrical system through a $0.6350-\mathrm{cm}$ rentral port and must then exit to the next cham-

- Elephant Brand Metallic Wool, 430 stainless steel, medium grade (1), International Steel Wool Corp. Springfteld, Ohio. ber through four $0.3175-\mathrm{cm}$ ports equally spaced near the circumference of a circular baffle disk. Flow from the second chamber then passes through another $0.6350-\mathrm{cm}$ opening centered in a third circular disk. This variation of fow exils is repeated in successive chambers to force a highly dispersed flow of air around the gold plated scrubbing surface of each compartment.

\section{Device Performance}

We tested the scrubber by challenging the assembled unit with a known concentration of mercury vapor in air. Test atmospheres were generated with a system previously discussed by Nelson. ${ }^{2}$ In the Nelson procedure, calculations based on volumetric considerations and the temperature of heated-air flow across a mercury-pool surface are used to determine the flow settings on mercury generator rotameters. We measured mercury-vapor conceritrations with a Bacharach Mercury Snifter (Bacharach lnstruments Co., AMBAC Industries, Model MVZ) and our measurements closely agreed with the mercury concentrations calculated for the Nelson system.

Flow in the Ostlund monitor's sampling line is predetermined at $250 \mathrm{ml} \cdot \mathrm{min}^{-1}$ (air). Our system was assembled to control flot, through the scrubber to this amount. A schematic of the apparatus is shown in Fig. 2. Flow was set by a massflow controller (Control Unit FM360, Tylan, Inc), and the mercury was monitored by passing the exhaust air through an impinger containing a solution of $\mathrm{KMnO}_{4}$ and $\mathrm{H}_{2} \mathrm{SO}_{4}$. Subsequent to each period of testing the permanganate solution was analyzed for mercury content by atomic absorption spectrophotometry (cold-vapor-generation technique). No mercury was detected by this procedure. In addition, valves allowed the upstream or downstream flow to be diverted to the mercury sniffer for periodic instrumental monitoring. Results of the quantitative testing are shown in Table 1. 


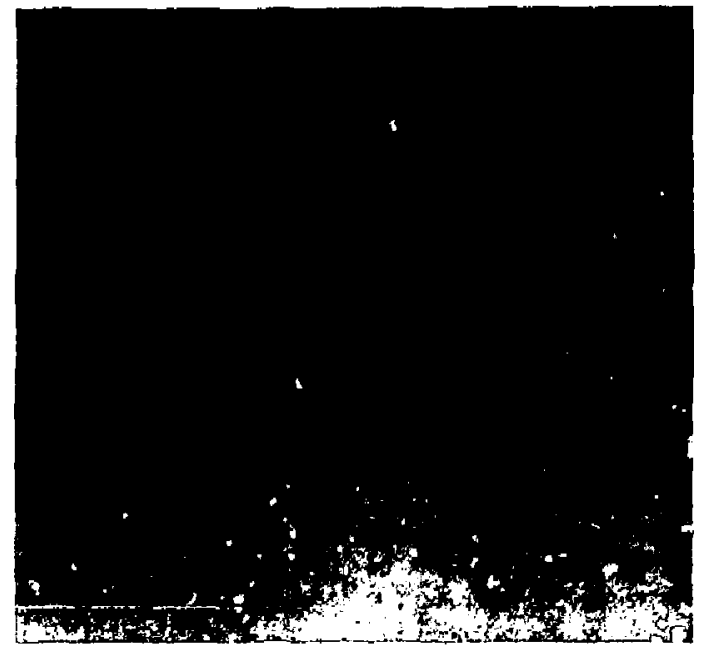

Figure 1. Flow device showing stainless-steelwool inside.

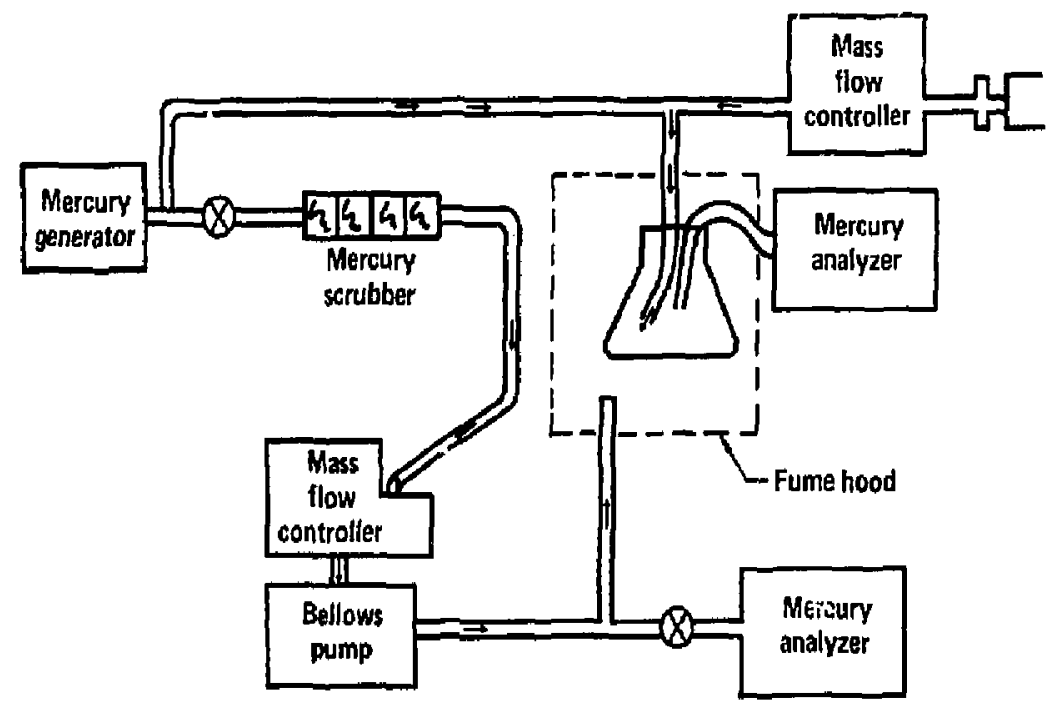

(impinger for Table 1, instrumental for Table 2)

Figure 2 Schematic of experimental apparatus. 
Table 1. Quantilative testing results.

\begin{tabular}{cccc}
\hline Duy & $\begin{array}{c}\text { Time of } \\
\text { flow }\end{array}$ & $\begin{array}{c}\text { Challenge } \\
\text { concentration } \\
\text { (mg } \mathrm{Hg}_{\mathrm{g}} \cdot \mathrm{m}^{-3} \text { ) }\end{array}$ & $\begin{array}{c}\text { Totd } \\
\text { mercury } \\
\text { (mg) }\end{array}$ \\
\hline 1 & $5: 57: 00$ & 0.62 & 0.0553 \\
2 & $5: 59: 00$ & 0.75 & 0.0673 \\
3 & $6: 04: 00$ & 0.78 & 0.0710 \\
4 & $6: 00: 00$ & 0.92 & 0.0646 \\
5 & $5: 50: 00$ & 0.79 & 0.070 \\
6 & $6: 04: 00$ & 0.75 & 0.0663 \\
7 & $5: 12: 00$ & 0.73 & 0.0679
\end{tabular}

Tolsl tetliag time: 12:22:00 Tatal mercary uptake: 0.4851 $\mathrm{mg}$

"Elapaed time of flow through each $\mathrm{KMnO}_{4}$ colution be. fore a freth colution was installed.

A second test of the mercury scrubber was performed at higher mercury concentrations. For this challenge, we used both the Bacharich MV2 anc: : Jerome Model 411 mercury-vapor analyzer (Jerome Instruarent Corp ${ }_{4}$ Jerome, Arizona 86331). The Model 411 can detect mercury concentrations as low as $10^{-3} \mathrm{mg} \cdot \mathrm{m}^{-3}$. We tested for mercuryvapor penetration through the scrubber and found no measurable mercury downstream. Since only a fraction of the mercury-lausi air from the generator was drawn through the scubber, the excess flow was exhausted into a fume hood. The exhaust flow was diluted with clean air from a mass-flow controller, and the diluted mixture was monitored regularly with the Bacharach device. Results from this second test are shown in Table 2.

\section{Conclusions}

The potential source of mercury contamination is from diffusion pumps that have undergone an initial cleaning process. There is no measurable mercury (by volume) in these pumps after this cleaning. The pumps will then be baked in a large oven that exhausts to the stack at a volumetric flow of $180 \mathrm{~cm}$. The stack flow itself is romindlly $13,000 \mathrm{cfm}$. A worst-case mercury ec 7 centration was arbitrarily chosen as the aqdition of $100 \mathrm{~g} \mathrm{hr}^{-1}(7 \mathrm{ml})$ of mercury from the oven to the main stack. This hypothetical endmple assumes seven pumps are heated in the oven at one time, with a total residue of $1 \mathrm{ml}$ of mercury per pump. In this situation, the maximum concentration seen
Table 2. Second test results.

\begin{tabular}{|c|c|c|c|}
\hline Day & $\begin{array}{c}\text { Time of } \\
\text { flow }\end{array}$ & $\begin{array}{c}\text { Challenge } \\
\text { conceniralion } \\
\left(\mathrm{mg} \cdot \mathrm{m}^{-3}\right)\end{array}$ & $\begin{array}{c}\text { Total } \\
\text { mercury } \\
\text { (mig) }\end{array}$ \\
\hline 1 & 6:00100 & 3.89 & 5.45 \\
\hline 2 & $6: 00: 00$ & 3.89 & 5.45 \\
\hline 3 & $5: 00: 00$ & 3.89 & 4.54 \\
\hline 4 & 5:30:00 & 3.89 & 5.00 \\
\hline 5 & $7: 00: 00$ & 3.89 & 6.31 \\
\hline \multicolumn{2}{|c|}{ Tots) lextiog time 29.30:00 } & \multicolumn{2}{|c|}{ Total mereury uptake: $26.75 \mathrm{mg}$} \\
\hline
\end{tabular}

by the scrubber is $5 \mathrm{mg} \cdot \mathrm{m}^{-3}$. Several times during the second phase of testing the challenge concentration rose to this amount before being adjusted back to the indicated average concentration. Each time this cxcursion occurred, the penetrating flow was measured and no mercury was detected by the Jerome Model 411 instrument.

A more complete characterization of this scrubber would require the following questions to be answered:

- What is the fotal mercury capacity of the scrubber before breakthrough?

- What higher concentrations of mercury vapor could the scrubber effectively remove from air?

- Is it possible to regenerate the scrubber to restore its original cleaning capacity?

The answers to these questions would provide a more thorough characterization of the scrubber for an ideal operational use. Since our application of this scrubber is for a specialized case, the data we obtained is adequate for this application. We feel that the gold wool scrubber described here will protect the Ostlund monitor from mercury-vapor poisoning.

\section{References}

1. F. A. Cotton and G. Wilkinson, Advanced Inorganic Chemistry, 2nd Ed. (Wiley, 1962), p. 604 .

2. G. O. Nelson, "Simplified Method for Generating Known Concentrations of Mercury Vapor in Air," Rev. Sci. Int. 41(5), 776 (1970), 


\section{Publication Abstracts}




\section{PUBLICATION ABSTRACTS}

B. Bapliste, The Prevention of Back Injuries and Pain, presented at the 70th Annual National Safety Congress and Exposition, Oxtober 19, 1982, Chicago, Illinois; Lawrence Livermore National Laboratory, Livemore, CA, UCRL-88242 (1982).

1. H. Elliott, The Use of Radiation Damage to Match the Sensitivity of LiF TLD Dosimeters, presented at the Health Physics Annual Meeting, Baltimore, Maryland, 19-23 June, 1983.

Radiation damage has been used to reduce the sersitivity of unmatched LiF TLDs to match that of the working stock in our dosimetry laboratory. Three thousand new TiD ribbon dosimeters, whose mean sensitivity was about $10 \%$ greater than our dosimeter working stock, were grouped by sensitivit;. After some groups were exposed to different doses to determine the rate of sensitivity loss, $S / S_{0}$ vs rads, the semaining groups were exposed to doses obtained from the sensitivity loss plot to obtain a match to the working stack. The shapes of the glow curves obtained before and after irradiation did not change, and the use of our ultraviolet second-read dose-estimation method was still viable. The altered sensitivities fell within the plus or minus $10 \%$ limits of the working stock and remained unchanged after a 20-hour anneal at $400^{\circ} \mathrm{C}$. This method might be useful in producing a large quantity of matched TLDs.

C. L. Grabom and J. H. Elliott, A Scusce of Monornergetic Electrons for Betr Dosimetry, presented at the International Beta Dosimc:ry Symposium, February 15-18, 1983, Washington, D.C.; Lawsence Livermore National Laboratory, Livermore, CA, UCRL-88022 (1983).

$\because$ : have developed an electron spectrometer which can produce a continuous beam of monoenergetsc electrons. The spectrometer uses 20 millicuries of ${ }^{137} \mathrm{Cs}_{5}$ as a source of electrons which can be magnetically focused at the exit port. Various electron energies can be selected by changing the magnetic field. The maximum elec. tron energy and dose rate for the psesent design are approximately $630 \mathrm{keV}$ and $1.5 \mathrm{rad} / \mathrm{hr}$, respectively.

R. V. Griffith, T. A, McMahon, and Guillermo Espinosa, $A$ Commercial Bacterial Colony Cosontey for Semiautomntic Track Coumting, prosented at the 10th International DOE Neutron Dosimetry Workshop, August 30-September 2, 1983, Acapulco, Mexico.

The information one must obtain from a solid-state track detector depends on the specific application. The most common information need is the measurement of track density. The number of tracks per unit area is commonly ed by those performing neutron and alpha dosimetry, for ex. ample, to deteimine radiation dose. In recent years, a class of semi-automatic counting systems has become available for under $\$ 15,000$. These systems, usually developed for bacterial colony counting, are capable of measuring track density. The basic instrument is designed to count relatively large objects $(>100 \mu \mathrm{m}$ ) with low magniffcation using an illuminated stage. However, track counting can be done with an accessory television camera coupled to an optical microscope. Tracks from electrochemical etching can be counted easily with objectives as low as $2 \mathrm{X}$.

R. V. Griffith and T. A. McMahon, A Multicompounent Personnel Nesilron Dosimeter-DOSPEC, presented at the Heaith Physics Sociely Annual Meeting, June 19-23, 1983, Ballimore, Maryland; Lawrence Livermore National Laboratory, Livermore, CA, UCRL-88591 (1983) [Abstract only].

A small, passive multicomponent neutron dosimeter has been developed that overcomes many of the disadvantages of traditional singlecomponent dosimeters-TLD albedo. NTA film, track-etch, etc. The DOSPEC concept combines the sensitivity and ease of processing of TLD with the fast neutron response chararteristics of up to three track-etch materials-CR39, polycarbonate. and cellulose nitrate (LR115). The amount of effort to process multicomponent dosimeters does not have to si ale with the number of deteciors, if the TLD is used to screen out the large proportion of negligib'e exposures. However, when needed, the additional detectors can increase the accuracy of the dosimetry. The DOSPEC detectors provide spectral and body orientation information that is valuable to interpretation of dosimeter response and eventual dose assessment. In addition, the in terpretation of detector res! vises can be easily adapted to a hand-held, programmable calculator. Results from intercomparison and field exposures 
illustrate the advantages and limitations of the DOSPEC concept.

D. E. Hankins, "Beta- and Gamma-Dose Measutements of the Godiva IV Critical Assembly." Hcalth Pinysics; Lawrence Livermore Nationad Laboratory, Livermore, CA, UCRL-88284 (1982).

To aid in the recevaluation of an exposure that occured in 1963, information was required on the response of film badges to the beta- and gamma-ray doses from a critical assembly. Of particular interest was the beta spectra from the assembly. The techniques used and the results obtained in this study are of interest to health physicists at farilities where exposures to belas are occuring.

We ineasured the dose rates from the Los Alamos National Laboratory GodivaIV Critical Assembly at numerous distances from the assembly 4 and 12 days following a burst. We obtained information on the beta-particle spectra using absorption curve studjes. The beta/ganma dose rate ratio as a function of distance from the assembly was determined. We measured the shielding provided by yarious metals, gloves, and clathing. We compared the beta- and gamma-ray doses measured with a film packet used in the past at the Nevada Test Site with two types of current ILD personnel badges. Measurements made with a commercial thin-window ion chamber instrument are compared with the dose rates obtained using other dosimeters.

D. E. Hankins, "Beta Dosimetry Studies at LLNL," Proc. Af she Intemationol Bela Dosimetry Symposium, Washington, D.C., 15-18 February" 1983; Lawrence Livermore National Laboratory. Livermore, CA, UCRL-88041 (1983).

This paper summarizes three beta dosimetry studies made recently at the Lawrence Livennore National Laboratory. The first study was to determine the beta-gamma exposure rates at the Los Alamos Godiva IV Critical Assembly. The beta spectra from the assembly were evaluated using absorption curves, and the beta-gamma dose rates ratios were detemined at various distances from ire assembly. A comparison was made of the doses determined using two types of TLD personnel dosimeters and a film badge. The readings of an Eberline RO-7 instrument and the dose rates determined by TLDs were compared. Shielding provided by various metals, gloves, and clothing were measured. The second study was to deter- mine the beta-entetgy response of the Eberline R0-7 instrument based on measurements made with the PTB beta sources. This study required additional calibration points tor the PTB sources which were made using extrapolation chamber measurements. The third study resulted in two techniques to determine the beta energy $\left(\mathbb{E}_{\max }\right)$ from the readings of thin-window portable survey instruments. Both techniquies are based on the readings obtained using aluminum filters. One technique is for field application, requires one filter, and provides a quick estimate of the beta energy in three energy groups: $<0.5 \mathrm{MeV}$, $0.5-1.5 \mathrm{MeV}$, and $>1.5 \mathrm{MeV}$. The second technique is more complex, requiring measurements with two of three filters, but gives the beta energy and the approximate shape of the beta spectrum.

D. E. Hankins, Beia-Energy-Response Determingtion of the Eberline R0-7 Skroey Insirament, Lawrence Livermore National Laboratory, Livermore, CA, UCID-19484 (August, 1982).

D. E. Hankins, „Evaluation of Beta Energy ( $\left.E_{\text {maxu }}\right)$ and Spectral Type Using Survey Instruments," Heallh Physits; Lawrence Livermore National Laboratory, Livermore, CA, UCRL-88275 (October, 1982).

We describe two techniques for determining the maximum beta energy ( $\left.E_{\text {mul }}\right)$ from a source by using thin-window survey instruments. The first technique is a simple field procedure involving the use of a single absorber. The other technique requires three absorbers. The first lechnique gives beta eneigy in three divisions: $<0.5 \mathrm{MeV}$, $>1.5 \mathrm{MeV}$, and between 0.5 and $1.5 \mathrm{MeV}$. The second technique, which is more accurate, gives $E_{\operatorname{man}}$ and information on the spectrum shape of the source.

D. E. Hankins, Neutron and Gatmma-Ray Measuremetts on the LANL Lillle Boy Comet Assembly, presented at the Little Boy Comet Assembly Mea. surements Meeting Los Alamos, New Mexico, 13-14 September, 1983; Lawrence Livermore National Laboratory, Livemore, CA, UCRL-89797 (1983).

We méasureu neutron and gamma-ray dose rates at various distances from the Litle Boy. Comet Assembly at Los Alamos National Labontory (LANL) in April of 1983. The Little BoyComet Assembly is a replica of the atomic weapon detonated over Hirc:hima. The assembly 
was designed to be operated at various steadystate power levels. The distances selected ranged from 107 to $567 \mathrm{~m}$. The latter point was on the edge of a mesa overlooking the Critical Assembly Facility in Pajarito Canyon, LANL, New Mexico. Gamma-ray measurements were made with a Reuter-Stokes environmental jonization chamber that has a sensitivity of $1.0 \mu \mathrm{R} /$ hour. Neutzon measurements were made with a pulsed-source remmeter, designed and built at Lawrence Livermore National Laboratory (LLNL), that has a sensitivity of $0.1 \mu \mathrm{rem} / \mathrm{hr}$. Our measurements, as well as those made by other experimenters, were intended to verify recent neutron and gamma kerma calculations made with radistion transport contputer codes. Preliminary comparisons with other measurements are in good agreement with our work.

D. E. Hankins, A New Method for Evaluating Albrdo Neutron Dosimeters and a Technique to Determine the Energy of Betas ( $E_{n+a x}$ ) Using Survey Instruments, presented at the Health Physics Annual Meeting, Baltimore, Maryland, 19-23 June, 1983; also in the Proceedings of the Intermational Beta Dosimctry Symposium, published by the U.S. Nuclear Regulatory Commission, Washington, D.C., 15-18 February, 1983.

This report summarizes the results from two studies at the Lawrence Livermore National Laboratory. The first was the development of an improved techrique for the evaluation of our albedo neutron dosimeters. The second was a method to evaluate the beta energy $\left(E_{\max }\right)$ and spectral type using portable survey instruments.

The albedo dosimeter study originated from a review of five years of personnel data. A new evaluation method was developed which is based on the ratio of the readings from the TLD 600 in the albedo neutron dosimeter and the thermal response of the TLD 100 or 600 in the personnel badge. Calibiation factors are obtained which varv depending on this ratio. The variation in these factors is the same within a particular facility, but are not the same at all facilitiej. Limits are set on the calibration factors based un survey instrument results of the thermal nestron dose rate and the 9- to 3-inch sphere rario. Significant improvements in the accuracy of doses determined from albedo neutton dosimetets can be obtained by using this technique.

The second part of this paper describes two techniques for determining the maximum beta energy ( $E_{m s}$ ) from a source by using thin-window survey instru nents. The first technique is a simple field procedure involving the use of a single absorber and gives beta energy in three divisions: $<0.5 \mathrm{MeV}, 0.5$ to $1.5 \mathrm{MeV}$ and $>1.5 \mathrm{MeV}$. The second technique requires three absorbers, but is more accurate, gives $E_{\max }$ and information on the spectrum shape of the source.

\section{E. Hanking, $A$ Wrist Albedo Neutron Dosimeter, presented at the 10th International DOE Neutron Dosimetry Workshop/EURATOM-CENDOS, Acapulco, Mexico, 30 August-2 Seplember, 1983.}

We are developing a wnst dosimeter that can be used to measure the eiposure at the wrist to $x$ rays, gamma rays, beta particles, thermal neutrons, and fast neutrons. It consists of a "Hankinstype" albedo neutron dosimeter that was modified to make it more wearable on the wrist. ABS plastic in the form of an elongated hemisphere provides the beta and low-energy $x$-ray shielding necessary to meet the requirement of depth dose measurements at $1 \mathrm{~cm}$. The dosimeter has a beta window located in the side of the hemisphere oriented toward an object being held in the hand. $A$ TLD 600 is positioned under the $1 . \mathrm{cm}$ thick ABS plastic and is used to measure the thermal neutron. dose. At present, we are using Velcto straps to hold the dosimeter on the inside of the wrist. We are studying the directional response and energy dependence of the albedo dosimeter to fast neutrons; preliminary results indicate no serious problems exist with either.

C. J. Huntzinger, J. L. Cate, Jr, M. Dreicer, and D. E. Hankins, A Sensitive Real-Time Waste Water Moritor, presented at the Health Physics Annual Meeting, Baltimore, Maryland, 19-23 June, 1983.

An automatic, on-line tritium monitoring system for a combined industrial/sanitary waste water stream has been developed. It provides early detection of either chronic or acute tritium spills to the sewer.

Two major tasks were identified: to provide a relatively pure sample, and a reliable sensitive tritium detector. A prototype cross-llow filtration unit is used to clarify the sample stream. Teflon and Dacron filter disks (2" diam) with fore sizes ranging from $10 \mu \mathrm{m}$ down to $0.5 \mu \mathrm{m}$ have been tested. With a sample flow rate of 0.1 milliliter per minule, the $0.5 \mu \mathrm{m}$ and $1.0 \mu \mathrm{m}$ filters were found to be best, lasting over eight days before plugging. Tests were made with a liquid scintillation low 
cell detector. The detector element is a thin-wall Teflon tube coiled flat and sandwiched between two matched photomultiplier tubes operating in the coincidence mode. Pretininary measurements have shown a static minimum detectable activity (MDA) of $50 \mathrm{pCi}(1.85 \mathrm{~Bq}$ ) per milliliter. A combined flow of 0.5 milliiter per minute limits scintillator consumption to 1 gallon ( 3.8 litess) per week.

An improved, second-generation flow-cell detector is under development. It incorporates an extemal source for quench correction and will be connected to an emergency waming system microcomputer that will calculate specific activity, and, if necessary, send an alarm to a central dispatch center.

J. L. Morse, Syslem Safety-A Reality at a National Laboratory, presented at the 6th International System Safety Conference, Houston, Texas, 26-30 September, 1983; Lawrence Livermore National Laboratory, Livermore, CA, UCRL-89089 (1983).

Intensive system safety efforts during the past several years at thet Lawrence Livermore $\mathrm{Na}$ tional Laboratory (LLNL) have brought health and safety considerations into the earliest planning of major new projects. These efforts included organizational changes with fundamental top management philosophical changes, better integration of health and safety disciplines into the design team, antd routine use of system safety analysis techniques. Tangible benefits include more harmony between the Salety Departmeni and project management, eariler and higher quality safety inputs, plus documentation of safety design rationale. Specific system safety techniques used at LLNL are preliminary hazards analysis, failure mode and effects analysis, fault-tree analysis, operational hazards analysis, and various MORT techniques, including occupancy-use readiness trees. The Department of Energy (DOE) has recognized the merit of this approach with the recent DOE Order 5481.1 which requires department-wide application of system safety principles.

J. A. Mosovsky, Laser Dyes: Thrir Hazards and Conirols, presented at the Annual American Industrial Hygiene Conference, Philadelphia, Pennsylvania, 22-27 May, 1983.
Dye lasers utilize a lasting solution which normally contains a complex fluorescent organic dye in solution with an organic solvent. Toxicity information on these laser dyes is scarce, and manufacturers offer littie or no help in describing associated hazar 's on labels or in Material Sajety Data Sheets. Due to the increasing popularity of dye la:ers, dye and solution hazards needs to be definec' in order to protect operating personnel by properly instituting dye solution preparation and dye lastr controls.

Literanure searches were conducted on the most common laser dyes: xanthenes (thodamines and fluoresceins), polymethines (cyanines and carcocyanines), coumarins, and ctibenes. Manufacturers and users were contacted and dyes were subjected to the Ames Mutagesicity Test.

Toxicity of dyes and their solutions were found to vary greatly. Some dyes are reported to be carcinogenic, others relatively harmless, $! D_{; n k} s$ range fron. $2 \mathrm{mg} / \mathrm{kg}$ to greater than $15 \mathrm{~g} / \mathrm{kg}$. Tested routes of exposure are usiikely to be represented in work areas where dye lasers operate or where dye solution preparation takes place. Ames Test results have not been finalizd, but preliminary data show variability in mutagenicity for different dyes.

Engineering, administrative, and personnel protective equipment controls are recommended for handling dyes, prepanng dye solutions, and operating dye lasers. Toxic waste controls are also defined.

B. Odell, OId Explosive Facilities Need Loue (Safety Analyses) Too, presented at the 6th Intemational System Safety Conference, Houston, Texas, 26-30 September, 1983; Lawrence Livermore National Laboratory, Livermore, CA, UCRL-89089 Draft (1983).

The paper gives several teasons why existing explosive test facilities need current safety analyses and how these analyses are performed. Included is a history of the test site, a discussion of a typical explosives experiment, and a summary of the various hazards involved, plus major concerns and findings. This is followed by a discussion on thow the safety analyses reports are written and approved and how the recommendations are incorporated 
P. M. Swearengen, Desorption of Organie Vapors from Activated Cartion Adsorber Beds, presented at the Annual American Industrial Hygiene Conference, Philadel shia, Pennsylvania, 22-27 May, 1983.

The effect of intermittent use on a-tivated carbon adsorber beds is being studied for a variety of solvents under dymamic flow conditions. Adsorption and desorption rate constants are determined and compared to obtain a "retentivity" index for different solvents. The techniques of gas chromatography and infrared analysis are employed for the analysis of vapor streams above and below a carbon bed. Kirntic expressions can be employed to analyse the resulting data. The results obtained can be interpreted in terms of adsorber bed performance in a variety of industrial hygiene situations.

K. C. Young, Charged Parlitle Bearn: A 5ofety Mandate, presented at the 6th Internatione' System Safety Conference, Houston, Texas, $2 t \cdot 30 \mathrm{Sep}$ tember, 1983.

The Advanced Test Accelerator (ATA) is a recent development in the field of charged-particle beam research at Luwrence Livermore National Leboratory (LLNL). With this experimental apparatus, researchers will characterize intense pulses of electron beams propagated through air.

Inherent with the ATA concept was the potential for exposure to hazards, such as high radiation levels and hostile breathing atmogrtheres. The need for a comprehensive safety $\mathrm{p}_{\mathrm{i}}$ jram was mandated; a formal system safety prugram was implemented during the project's conceptual phase.

A project staff position was created for a safety analyst who would act as a liaison between the project staff and the safety department. Additionally, the rafety analyst would be responsible for compiling various haurds analyses reports, which formed the basis of the project's Safety Analysis Report. Recommendations for safety features from the hazards analysis reports were incorporated as necessary at appropriate phases in project deiclopment, rt ther than adding features afterwasos.

The safety program established for the ATA project facilitated in controlling losses and in achieving a low level of acceptable risk. 